\title{
Synthesis and Conformation of Pentopyranoside Nucleoside Phosphonates
}

\author{
Xiaochen Li, Shrinivas Dumbre, Eveline Lescrinier, Elisabetta Groaz, and Piet Herdewijn* \\ Medicinal Chemistry, Rega Institute for Medical Research, KU Leuven, Herestraat 49, Bus 1041, 3000 Leuven, \\ Belgium
}

\section{GRAPHICAL ABSTRACT}

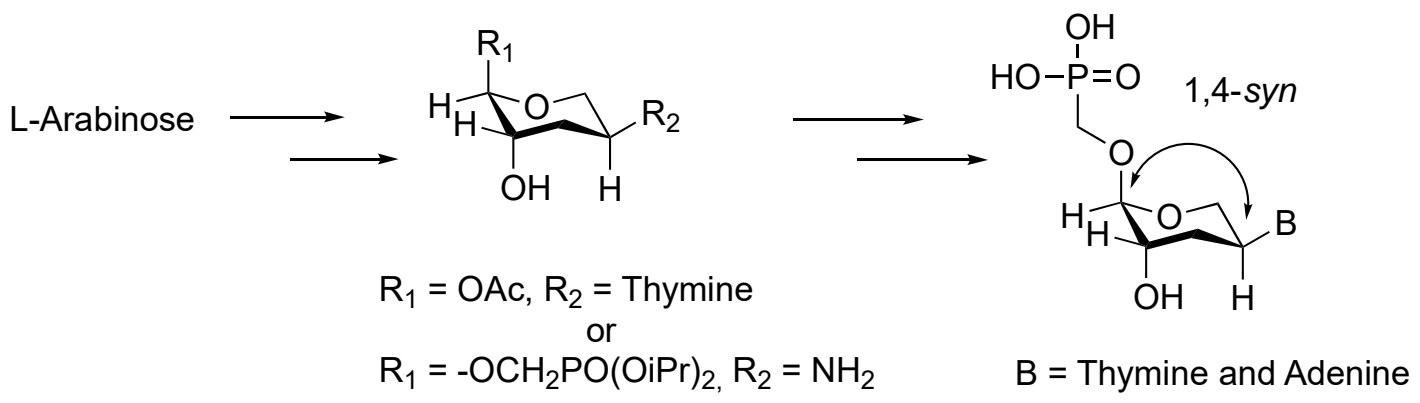

\begin{abstract}
In contrast to natural nucleosides, where the nucleobase is positioned at the anomeric center, we report the synthesis of pentopyranoside nucleosides with a phosphonate functionality at the 1'-anomeric oxygen. Starting from L-arabinose, key functionalized L-glycero- and L-erythro-pentopyranose carbohydrate synthons were prepared and further elaborated into the final six-membered ring nucleosides via nucleobase incorporation and phosphonomethylation reactions. NMR analysis demonstrated that these nucleoside phosphonates exist in solution as conformers predominantly adopting a chair structure in which the base moiety is equatorially positioned. Such conformation prevents unfavorable 1,3-diaxial steric and electronic interactions. Notably, the stereochemical outcome of the Vorbrüggen glycosylation step utilized en route to the thymine analogue clearly suggests the absence of anchimeric assistance, as opposed to what is usually observed during nucleoside synthesis using protected furanose precursors. The finding that the diphosphates of the compounds developed in this study are recognized by DNA polymerases is important in view of the future selection of artificial genetic systems and dedicated polymerases as well as applications in therapy.
\end{abstract}




\section{INTRODUCTION}

Advances in the application of nucleosides and oligonucleotides as antiviral/anticancer therapeutics as well as gene silencing and editing tools largely depend on the systematic exploration of related chemical space through nucleobase and/or backbone modifications. ${ }^{1-4}$ In DNA and RNA, the hydrophobic nitrogenous nucleobases encode information and ensure genetic fidelity through the formation of Watson-Crick pairs, while the furanose sugar and phosphate backbone moieties define the structure and stability of the genetic material. Chemical variations at the sugar moiety have been frequently exploited to modulate the biological and physicochemical properties of these molecules by inducing changes in nucleoside conformation without interfering with the accuracy of base pairing. This strategy has proven highly effective in altering enzyme recognition and activation by kinases and polymerases as well as binding affinity towards RNA or DNA targets.

Our group previously prepared nucleoside analogues comprising a hexopyranose sugar mimic, i.e., 1,5anhydro-2,3-dideoxy- $\beta$-D-arabinohexitol, linked to the nucleobase at $\mathrm{C} 2$ ' rather than the anomeric position. ${ }^{5}$ In contrast to pyranosyl nucleosides, anhydrohexitol derivatives were found to preferentially adopt a slightly distorted chair conformation with an axial orientation of the nucleobase [1a, Figure 1(A)] instead of the usual equatorial position [1a', Figure $1(\mathrm{~A})] .^{5-6}$ This is presumably a consequence of the sterically unfavorable 1,3-diaxial repulsive interactions in the six-membered chair. Such an atypical sugar conformation resulted in both distinguishing biological activities and physicochemical properties at the monomer and oligonucleotide level, respectively. For example, hexitol nucleosides proved to be potent and highly selective inhibitors of herpes simplex virus type 1 and 2 (HSV-1 and HSV-2). With regard to the corresponding oligomers, hexitol nucleic acid (HNA) sequences demonstrated the ability to fold into helical structures $^{7}$ as well as form stable hybrids with natural counterparts, ${ }^{8}$ by reproducing the A-type form of dsRNA. ${ }^{9}$ HNA has been also proven to act as xenobiotic genetic material (XNA) capable of evolution in vitro, ${ }^{10-11}$ while directing DNA synthesis in E. coli. ${ }^{12}$

However, while HNA oligonucleotides are resistant against cellular nucleases, ${ }^{7}$ their phosphorylated nucleoside precursors might be dephosphorylated by phosphatases in a cellular environment. On the other hand, HNA nucleosides are phosphorylated only in herpes virus infected cells by the viral thymidine kinase and not in non-infected cells. One important approach to obtain nucleoside phosphate mimics is to replace the natural P-O-C bond with a phosphonate (P-C-O) linkage. ${ }^{13-14}$ The phosphonate moiety is a bioisostere of the phosphate group with similar polar and electronic properties, which may function just like its natural counterpart within an artificial information system. The improved stability of phosphonate mimics may also lead to prolonged intracellular half-lives. 
(A)

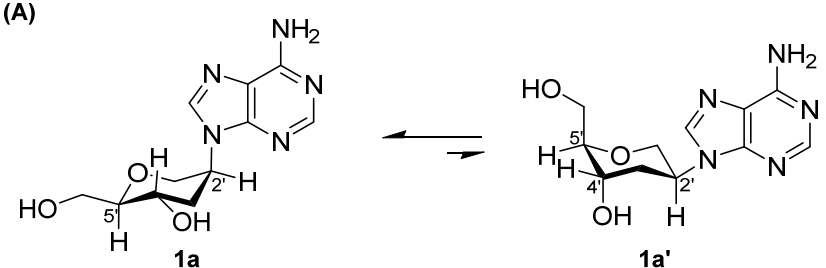

(B)

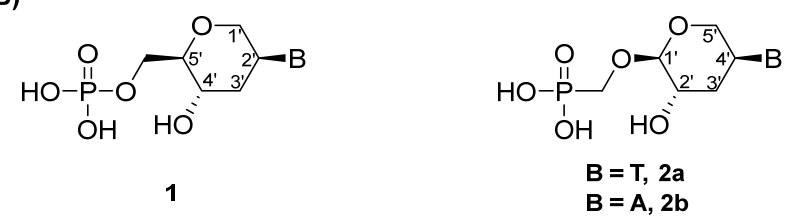

Figure 1. (A) Conformational preference of a hexitol nucleoside; (B) Structural diversity between hexitol nucleoside monophosphates (1) and target D-threo-pentopyranoside nucleoside phosphonates $\mathbf{2 a}$ and $\mathbf{2} \mathbf{b}$.

A number of methods are available in the literature for the preparation of five-membered cyclic as well as acyclic nucleoside phosphonates, ${ }^{13-15}$ however in the case of six-membered ring analogues the synthesis is complicated by the greater conformational diversity arising from the pyranosyl moiety. A general method to generate these derivatives has not yet been described and reported properties of the corresponding monomers/oligomers have therefore been limited. ${ }^{16-20}$ In this context, we set out to investigate plausible synthetic pathways that would enable the construction of a suitably functionalized pentopyranoside scaffold as key intermediate for further nucleobase incorporation and glycosylation reactions.

Herein, we report the results of our synthetic studies that ultimately led to phosphonomethyl D-threo pentopyranoside nucleoside analogues $\mathbf{2 a}$ and $\mathbf{2 b}$ [Figure 1(B)] bearing a 4'-nucleobase, which differ from hexitol nucleoside monophosphates [1, Figure 1(B)] by the presence of an O-C-P bond at the anomeric position, along with their conformational analysis and preliminary biological data.

\section{RESULTS AND DISCUSSION}

Nucleoside phosphonates are usually synthesized either by initial insertion of the nucleobase on the glycone moiety followed by phosphonomethylation ( $\mathrm{S}_{\mathrm{N}} 2$ or glycosylation reaction) or vice versa. The key disconnections in our retrosynthetic analysis of target D-threo-pentopyranoside nucleoside phosphonates 2a,b are shown in Figure 2. For both proposed routes A and B, it was envisaged that the synthesis of a suitably functionalized L-glycero-pentopyranose (II) or L-erythro-pentopyranose (IV) synthon could begin from a five carbon L-sugar; thus, L-arabinose $\mathbf{3}$ was chosen as common starting material. 

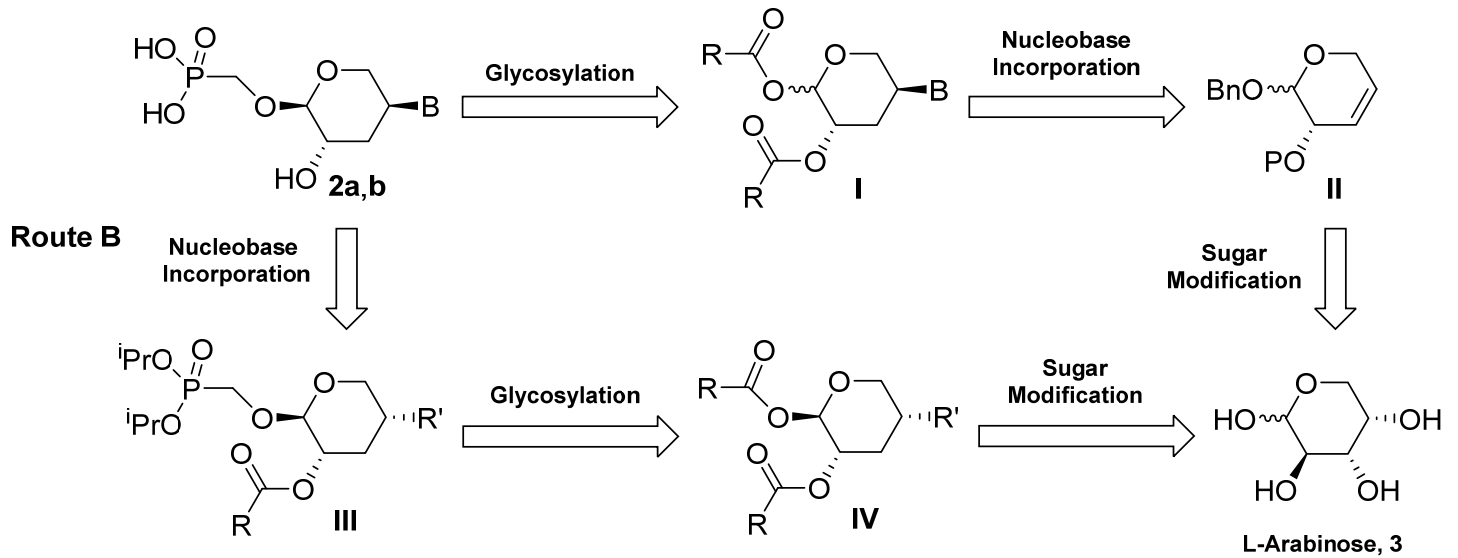

$P=$ protecting group

$\mathrm{R}=\mathrm{Ph}$ or $\mathrm{Me}$

$\mathrm{R}^{\prime}=$ functional group used for nucleobase incorporation

Figure 2. Retrosynthetic analysis of planned D-threo-pentopyranoside nucleoside phosphonates $\mathbf{2 a}$ and $\mathbf{2 b}$.

Since the glycosidic linkage between the anomeric $\mathrm{OH}$ and the phosphonate functionality might be susceptible to epimerization during other synthetic manipulations that need to be performed along the overall synthetic path, route A in Figure 2, which entails the introduction of this group towards the end of the synthetic sequence, was initially pursued in order to minimize this possibility. Thus, benzyl isopropylidene arabinoside $\mathbf{4}$ was readily synthesized from L-arabinose $\mathbf{3}$ in four steps and used without need of chromatographic purification (Scheme 1). ${ }^{21}$ The key step entailed the inversion of configuration of the 2-hydroxyl group via TEMPO-mediated oxidation, followed by reduction of the resultant 2-ketone. Given that the glycosylation step for the introduction of the phosphonomethyl moiety usually requires the anchimeric assistance from a neighboring 2- $O$-acyl group, the 2-hydroxyl of compound 4 was protected as an acetate, affording $\mathbf{5}$ in excellent yield. While initial attempts to hydrolyze the isopropylidene acetal of $\mathbf{5}$ in the presence of $p$-toluenesulfonic acid resulted in the concurrent cleavage of the 2-O-acetyl group, the use of $80 \%$ aq. acetic acid was found to allow for selective cleavage of the acetal functionality to afford diol 6. The next step in the synthesis entailed the regioselective protection of the equatorially oriented 4hydroxy group, however only an inseparable mixture of products was obtained in the presence of TBDMSCl due to concurrent silylation at different positions of the sugar ring. To minimize 3-O-silylation, a bulkier reagent such as TBDPSCl was employed, which successfully led to the highly predominant formation of the desired compound 7. Subsequently, 3-hydroxy glycoside 7 was subjected to BartonMcCombie deoxygenation, however no desired product (8) was formed upon reaction with a variety of sulfur reagents such as $\mathrm{CS}_{2} \mathrm{MeI}, 1,1^{\prime}$-dithiocarbonydiimidazole (TCDI), and $O$-phenyl chlorothionoformate. This result may be attributed to the axial orientation as well as the increased steric hindrance of the bulky 4-OTBDPS moiety, which might prevent the formation of the corresponding $O$-thiocarbonyl intermediate 8. Alternatively, compound 7 was converted to $3-O$-triflate derivative 9 , which underwent successive $\mathrm{S}_{\mathrm{N}} 2$ iodination and radical reduction to furnish fully protected sugar synthon 11. Later, desilylation at the 4- 
position afforded coupling partner 12 required for the construction of 1'-O-phosphonomethyl-D-threopentapyranosides carrying a nucleobase at the 4'-position.

\section{Scheme 1. Initial Routes for the Preparation of Functionalized L-Glycero-pentopyranoside Scaffolds}

\section{2, 14a-c, and 16. ${ }^{a}$}
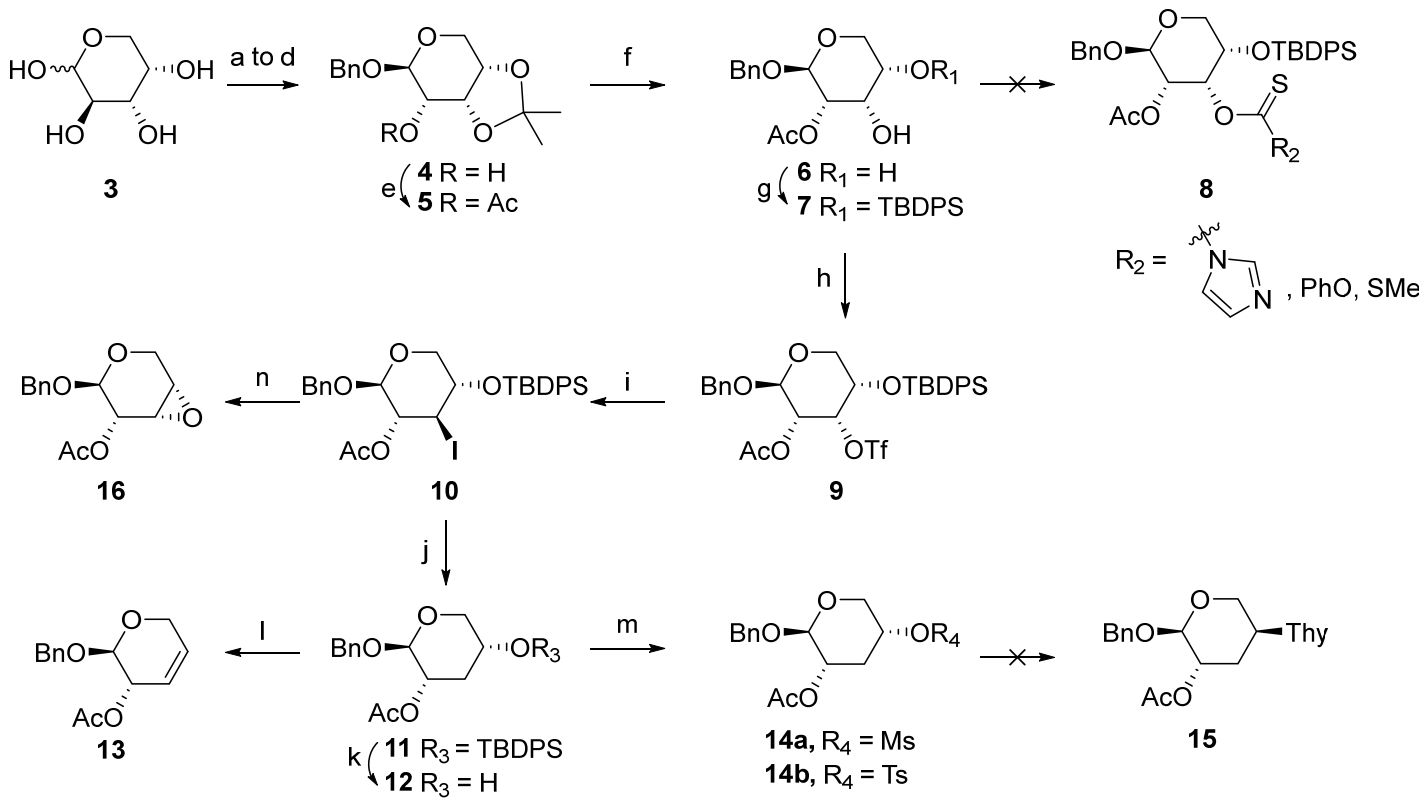

${ }^{a}$ Reagents and conditions: (a) BnOH, $\mathrm{AcCl}, 75 \%$; (b) DMP, CSA, DMF, 96\%; (c) TEMPO, $\mathrm{NaClO}, \mathrm{KBr}, \mathrm{DCM}, \mathrm{H}_{2} \mathrm{O}$, 90\%; (d) $\mathrm{NaBH}_{4}, \mathrm{CH}_{3} \mathrm{OH}, 90 \%$; (e) $\mathrm{Ac}_{2} \mathrm{O}, \mathrm{Et}_{3} \mathrm{~N}$, DMAP, DCM, 93\%; (f) 80\% aq. AcOH, 83\%; (g) TBDPSCl, imidazole, DCM, 71\%; (h) Tf 2 O, pyridine, DCM, 95\%; (i) NaI, DMF, 96\%; (j) Bu 3 SnH, AIBN, toluene, 94\%; (k) TBAF, THF, $87 \%$; (l) thymine or $N^{3}$-benzoylthymine, $\mathrm{PPH}_{3}$, DIAD or DEAD, THF or dioxane, rt; (m) MsCl or TsCl, $\mathrm{Et}_{3} \mathrm{~N} /$ pyridine, DCM; (n) TBAF, THF, 95\%.

However, all attempts to introduce thymine or $N^{3}$-benzoyl protected thymine as nucleobase by reacting $\mathbf{1 2}$ under Mitsunobu conditions ${ }^{5}$ resulted in the formation of E2 elimination product 13 rather than the desired nucleoside, most likely due to the axial orientation of the 4-hydroxyl group (for detailed conditions, see Experimental Section). Further efforts to achieve the nucleophilic substitution of 4-OTs and 4-OMs substituted analogues $\mathbf{1 4 a}, \mathbf{b}$ by thymine in the presence of different bases such as $\mathrm{DBU}, \mathrm{NaH}, \mathrm{Cs}_{2} \mathrm{CO}_{3}$, and $\mathrm{K}_{2} \mathrm{CO}_{3}$ alone or in combination with a variety of crown ethers were also unsuccessful. Moreover, the conversion of the 4-OH of $\mathbf{1 2}$ into a better leaving group using triflic anhydride did not provide the expected activated product, but rather led to a 3,4-elimination reaction (13) and nucleophilic substitution with pyridine at the 4-position. Therefore, another option for the introduction of the nucleobase was investigated focusing on the preparation of a 3,4-epoxy sugar, which could in principle undergo a ring-opening reaction upon nucleophilic attack of a heterocyclic nitrogen. Initially, the envisaged epoxide $\mathbf{1 6}$ was directly obtained in one step from 3-iodo derivative 10 upon removal of the 4-O-silyl protecting group (Scheme 1). It was found that the basic conditions due to the deprotecting reagent TBAF favored efficient epoxide formation once the 4-hydroxyl group was unmasked. However, when epoxide $\mathbf{1 6}$ was reacted with thymine under basic (DBU) and high temperature $\left(110^{\circ} \mathrm{C}\right)$ conditions, conversion to the desired nucleoside occurred 
concomitantly with the migration and hydrolysis of the $2^{\prime}$-acetyl group leading to a complex mixture of products.

This problem was addressed by adopting an alternative synthetic strategy that would allow to generate a differently substituted key sugar intermediate with higher stability under base-sugar coupling conditions (Scheme 2). In particular, a Corey-Winter olefination was employed to install the alkene at the 3,4-position to obtain the L-glycero-pentopyranose ring. Treatment of $\mathbf{6}$ with TCDI afforded cyclic thionocarbonate 17, which subsequently underwent a syn-elimination in the presence of triethyl phosphite to furnish 3,4unsaturated pentose 13 in good yield ( $84 \%$ over two steps). It should be noted that in this case the standard use of trimethyl phosphite was ineffective to promote the desulfurization step. Epoxidation of $\mathbf{1 3}$ using either $m$-CPBA or $\mathrm{H}_{2} \mathrm{O}_{2}$ did not proceed stereoselectively, while resulting in a mixture of diastereomeric epoxides. Hydrolysis of the 2-O-acetyl group of $\mathbf{1 3}$ prior to epoxidation was therefore necessary, in order for the corresponding free hydroxyl moiety to establish a hydrogen bonding interaction with the oxidizing agent that allowed for the reaction to selectively take place from the same side of the 2-hydroxy group. Thus, epoxide 19 was obtained in good yield, and successively subjected to MEM protection, epoxide ring opening with thymine, and Barton deoxygenation to yield 4'-thymidylated sugar 22. The MEM protecting group was then removed under acidic conditions affording a 15:1 mixture of $\alpha$-and $\beta$-anomers 23a and 23b, which were characterized after column chromatography separation, and further benzoylated at the $2^{\prime}$ position to furnish $\mathbf{2 4 a}$ and $\mathbf{2 4 b}$ in an overall $92 \%$ yield. While the $\mathrm{Pd} / \mathrm{C}$-catalyzed hydrogenolysis of the anomeric $\mathrm{OBn}$ functionality proceeded sluggishly in either methanol or acetic acid (3 days), a significant enhancement of the reaction rate was observed when the debenzylation was conducted in THF as solvent $(8 \mathrm{~h})$. Later, we found that treatment of a mixture of $\mathbf{2 4 a}$ and $\mathbf{2 4 \mathbf { b }}$ under transfer hydrogenation conditions (cyclohexene in ethanol) produced the desired glycone $\mathbf{2 5}$ in $88 \%$ yield.

For the final glycosylation step, glycone $\mathbf{2 5}$ was first activated at the anomeric position either as a $N$ phenyltrifluoroacetimidate (PTFAI, 26a), trichloroacetimidate (TCAI, 26b), or acetate (26c), while diisopropyl phosphonomethanol was used as glycosyl acceptor. A variety of standard conditions for the formation of the O-C-P bond were screened and are summarized in Table 1. Glycosylated product $\mathbf{2 7}$ could not be isolated as a pure compound by silica gel column chromatography at this stage due to diisopropylphosphonomethanol contamination, thus it was used as such in the following debenzoylation step, and product characterization was carried out at the level of compound 28. Surprisingly, glycosyl donors 26a and 26b yielded either starting material 25 (entries 1 and 3, Table 1) or a product with undesired stereochemistry at the anomeric center $(\boldsymbol{\beta}-\mathbf{2 8}$, entries 2 and 4, Table 1$)$. The formation of $\boldsymbol{\beta}$-28 suggests the non-participation of the 2'-O-acyl moiety, with the aglycone acceptor approaching the oxocarbenium intermediate from the $\beta$-face to form the 1,4-anti conformer. In contrast, $1^{\prime}$-acetylated nucleoside donor $\mathbf{2 6 c}$ furnished the desired $\boldsymbol{\alpha}-\mathbf{2 8}$ isomer as major compound $(\boldsymbol{\alpha}-\mathbf{2 8}: \boldsymbol{\beta}-\mathbf{2 8}=2: 1)$ in the presence of a strong Lewis acid (TMSOTf) at room temperature. It can be postulated that at low temperature $\left(-78^{\circ} \mathrm{C}\right)$ the presence of aglycone moieties with an increased leaving group ability as those in $\mathbf{2 6} \mathbf{a}$ and $\mathbf{2 6 \mathbf { b }}$ support the formation of product $\boldsymbol{\beta}-\mathbf{2 8}$ as a result of the absence of neighboring group assistance, whereas in the case of $\mathbf{2 6} \mathbf{c}$ bearing a poorer leaving group the reaction favors isomer $\boldsymbol{\alpha}$-28. Final removal of the diisopropyl ester 
functionalities under standard conditions afforded nucleoside phosphonate $\mathbf{2 a}$ in $40 \%$ yield $(0.98 \%$ overall yield).

\section{Scheme 2. Synthesis of Thymine $\alpha$-D-Threo-pentopyranoside Nucleoside Phosphonate 2a. ${ }^{a}$}
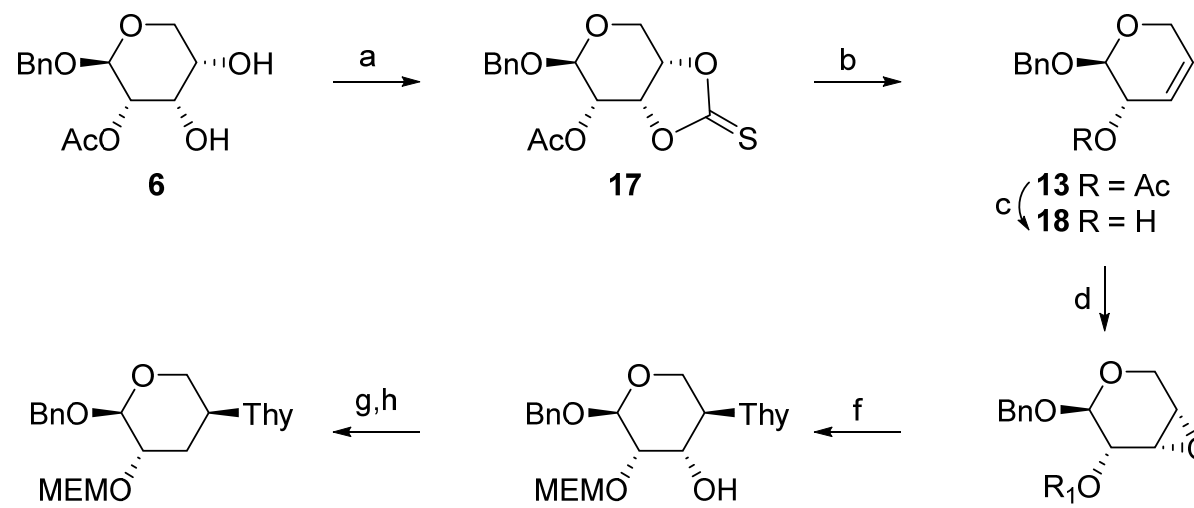

22
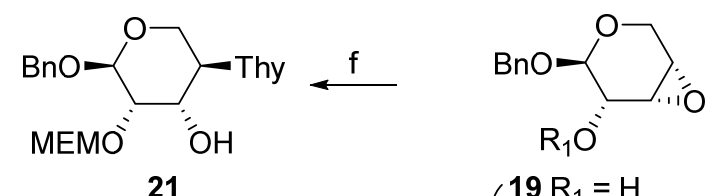

$$
\mathrm{e}\left(\begin{array}{l}
19 \mathrm{R}_{1}=\mathrm{H} \\
20 \mathrm{R}_{1}=\mathrm{MEM}
\end{array}\right.
$$
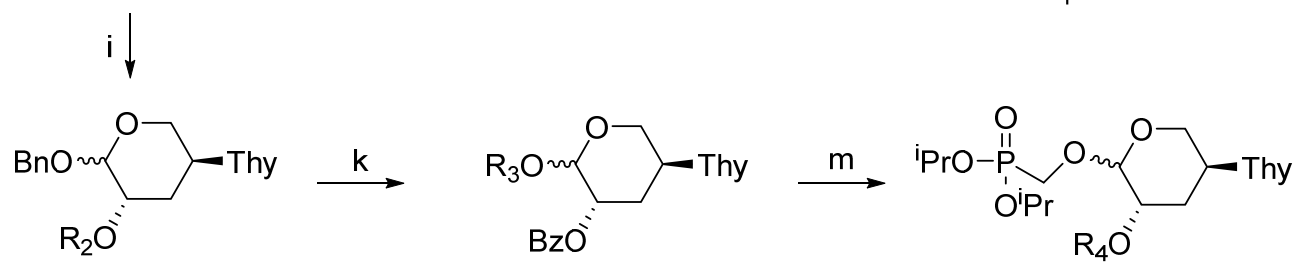

$$
\mathrm{j}\left(\begin{array}{l}
23 \mathrm{R}_{2}=\mathrm{H} \\
24 \mathrm{R}_{2}=\mathrm{Bz}
\end{array}\right.
$$
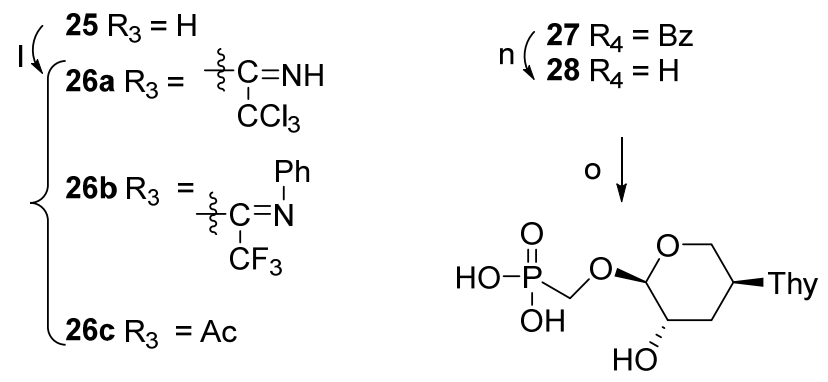

$2 a$

${ }^{a}$ Reagents and conditions: (a) TCDI, DCM, $83 \%$; (b) triethylphosphite, $140{ }^{\circ} \mathrm{C}, 85 \%$; (c) MeONa, methanol, 91\%; (d) m-CPBA, DCM, 89\%; (e) 2-Methoxyethoxymethyl chloride (MEMCl), DCM, 91\%; (f) thymine, DBU, DMF, 85\%; (g) TCDI, DMAP, DCM; (h) $\mathrm{Bu}_{3} \mathrm{SnH}$, AIBN, toluene, $83 \%$ over two steps; (i) $1 \mathrm{M} \mathrm{HCl}$ in dioxane, $75 \%$ for $\boldsymbol{\alpha}-\mathbf{2 5}$ and $5 \%$ for $\boldsymbol{\beta}$-25; (j) $\mathrm{BzCl}$, pyridine, $0{ }^{\circ} \mathrm{C}, 92 \%$; (k) $\mathrm{Pd} / \mathrm{C}$, cyclohexene, ethanol, 88\%; (l) $\mathrm{Ac}_{2} \mathrm{O}$, pyridine, 85\%; (m) TMSOTf, hydroxymethyl phosphonic acid diisopropyl ester, $\mathrm{CH}_{2} \mathrm{Cl}_{2}$; (n) $7 \mathrm{M} \mathrm{NH}_{3}$ in methanol, $20 \%$ over two steps; (o) TMSBr, 2,6-lutidine, acetonitrile, 40\%. 
Table 1. Optimization of the Phosphonylation Step

\begin{tabular}{|c|c|c|c|}
\hline entry & glycosyl donor & Lewis acid and $\mathrm{T}\left({ }^{\circ} \mathrm{C}\right)$ & product (yield\%) \\
\hline 1 & \multirow[t]{2}{*}{$26 a^{b}$} & TMSOTf, $-78^{\circ} \mathrm{C}$ & 25 \\
\hline 2 & & $\mathrm{BF}_{3} \cdot \mathrm{Et}_{2} \mathrm{O},-78^{\circ} \mathrm{C}$ & $\boldsymbol{\beta}-\mathbf{2 8}(30 \%)^{a}$ \\
\hline 3 & \multirow[t]{2}{*}{$26 b^{b}$} & TMSOTf, $-78^{\circ} \mathrm{C}$ & 25 \\
\hline 4 & & $\mathrm{BF}_{3} \cdot \mathrm{Et}_{2} \mathrm{O},-78^{\circ} \mathrm{C}$ & $\boldsymbol{\beta}-\mathbf{2 8}(40 \%)^{a}$ \\
\hline 5 & \multirow[t]{2}{*}{$26 \mathrm{c}$} & TMSOTf, rt & $\alpha-\mathbf{2 8} / \boldsymbol{\beta}-\mathbf{2 8}(20 / 10 \%)^{a}$ \\
\hline 6 & & $\mathrm{BF}_{3} . \mathrm{Et}_{2} \mathrm{O}, \mathrm{rt}$ & $\boldsymbol{\beta}-\mathbf{2 8}(\text { traces })^{a}$ \\
\hline & $\alpha-\mathbf{2 8}$ & $Y$ & \\
\hline
\end{tabular}

${ }^{a}$ Yields refer to the glycosylated product isolated after the following debenzoylation step.

${ }^{b}$ Experimental procedures for the phosphonylation of $\mathbf{2 6 a}$ and $\mathbf{2 6 \mathbf { b }}$ are detailed in the Supporting Information (S192-S193).

By analogy to early work towards thymine D-threo-pentopyranoside phosphonate 2a, we initially investigated the nucleophilic substitution of 4-sulfonate activated sugars 14a-c as well as ring opening reactions of epoxide $\mathbf{2 0}$ with 6-chloropurine and $N^{6}$-benzoyl protected adenine (Scheme S1, in Supporting Information). However, all attempts to directly introduce the purine ring at the 4-position by changing the base or using various additives failed.

Therefore, we opted for the construction of the purine ring via a linear approach. As shown in Scheme 3, radical deoxygenation of previously synthesized thionocarbonate derivative 17 afforded 3-deoxy compound 12 in $60 \%$ yield along with small amounts of the undesired 4-deoxy product (10\%), under high dilution reaction conditions $(0.02 \mathrm{~mol} / \mathrm{L})$. It should be noted that when the reaction was conducted at a concentration of $0.10 \mathrm{~mol} / \mathrm{L}$, the reduction of the $\mathrm{C}=\mathrm{S}$ bond to a methylene moiety $\left(-\mathrm{CH}_{2}\right)$ took place instead of the desired deoxygenation reaction at the 3-position. Mesylation and subsequent azidation of the 4hydroxyl group occurred smoothly to afford 4-azido compound $\mathbf{2 9}$ in good yield. After deacetylation at the 2-position, compound $\mathbf{3 0}$ was reacted under Staudinger conditions to give 4-amino-D-threopentopyranoside 31. Next, a literature procedure was employed for the construction of the purine ring starting from precursor 31 and 4,6-dichloro-5-formamidopyrimidine. ${ }^{22}$ The initially formed pyrimidine nucleoside intermediate underwent in situ cyclization under basic conditions to smoothly provide 6chloropurine pyranoside 32. Subsequent amination at the 6-position of purine in $\mathbf{3 2}$ yielded adenine analogue 33 in excellent yield (95\%), whose further reaction with an excess of benzoyl chloride furnished 
fully protected derivative 34. Following attempts to achieve the removal of the 1'-OBn group along with mono-debenzoylation at the primary amino group of $\mathbf{3 4}$ under different hydrogenation conditions in the presence of a range of $\mathrm{Pd}$ catalysts $\left(10 \% \mathrm{Pd} / \mathrm{C}, 20 \% \mathrm{Pd}(\mathrm{OH})_{2} / \mathrm{C}, \mathrm{Pd}(\mathrm{OAc})_{2}\right.$, and Pd-black $)$ did not deliver chemoselectively glycone $\mathbf{3 5}$, due to the contamination of the desired compound with other fully and partially $N$-debenzoylated by-products. However, the use of a Lewis-acid such as boron trichloride enabled benzyl removal with the exclusive formation of the desired anomeric hydroxyl glycone $\mathbf{3 5}$ in good yield. After acetylation of the anomeric 1'-OH, the resulting glycosyl donor 36 was reacted with diisopropyl phosphonomethanol under conditions similar to those developed earlier for the phosphomethylation of thymine analogue $\mathbf{2 a}$ (Table 1, entry 5). To our dismay, none of these conditions provided the desired target phosphonate glycoside $\mathbf{3 7}$ and similar attempts to prepare a 6-chloropurine containing nucleoside starting from 32 through a similar sequence of steps also met with failure.

\section{Scheme 3. Building of the Purine Ring on 4-Amino-D-Threo-pentopyranoside Sugar 31.}

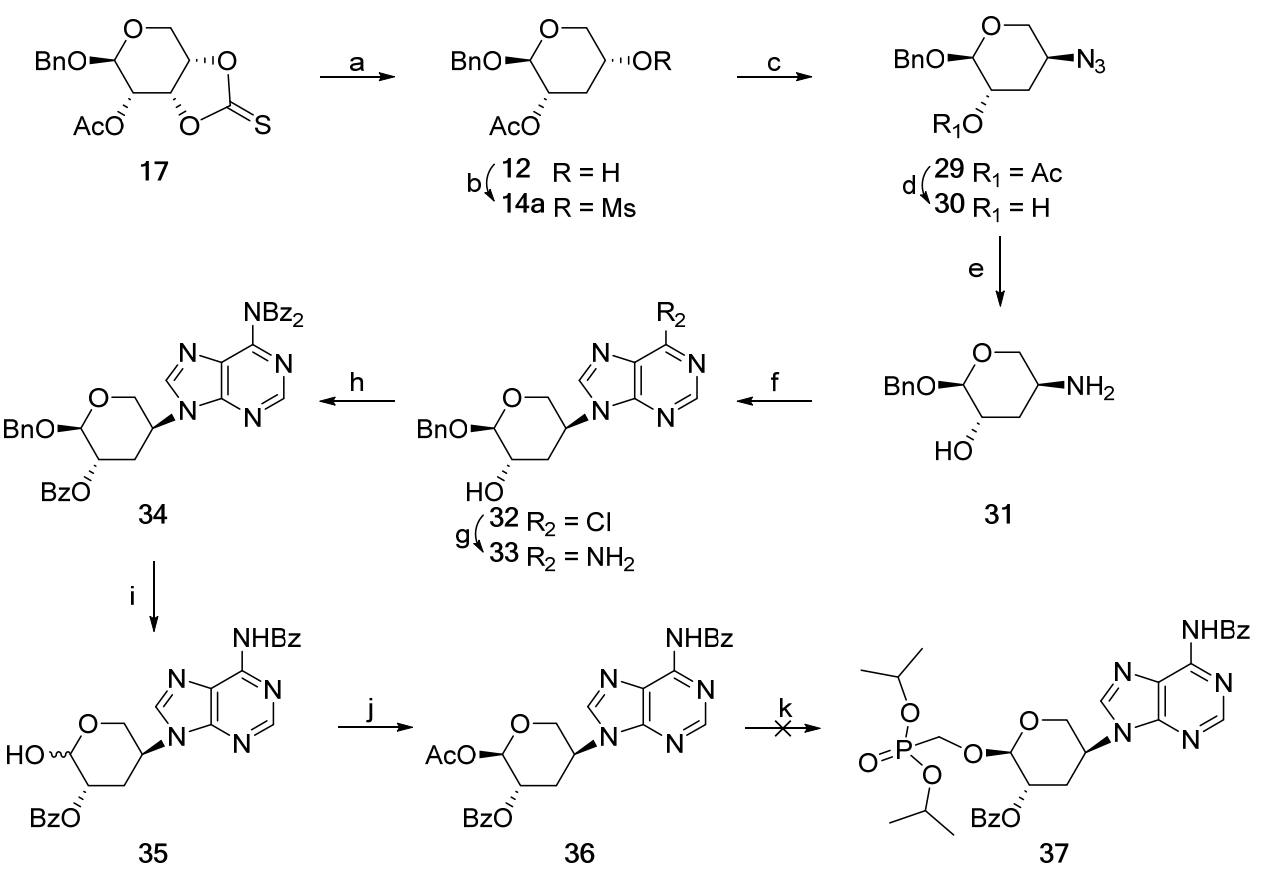

${ }^{a}$ Reagents and conditions: (a) $\mathrm{Bu}_{3} \mathrm{SnH}$, AIBN, toluene; (b) MsCl, TEA, DMAP, DCM, 54\% over two steps; (c) NaN 3 , DMF, 91\%; (d) MeONa, MeOH, 95\%; (e) triphenyl phosphine, THF then water, 92\%; (f) 4,6-dichloro-5formamidopyrimidine, DIPEA, $\mathrm{BuOH}, 75 \%$; (g) $\mathrm{NH}_{3}$ in ethanol, 95\%; (h) BzCl, pyridine, $88 \%$; (i) $1 \mathrm{M} \mathrm{BCl}_{3}, \mathrm{DCM}$, -78 to $0{ }^{\circ} \mathrm{C}, 80 \%$; (j) $\mathrm{Ac}_{2} \mathrm{O}$, pyridine, $78 \%$; (k) TMSOTf, hydroxymethyl phosphonic acid diisopropyl ester, $\mathrm{CH}_{2} \mathrm{Cl}_{2}$.

In view of these results, we therefore decided to turn to route B in our retrosynthetic plan (Figure 2). As illustrated in Scheme 4, the amino moiety of sugar scaffold $\mathbf{3 1}$ was first protected with a trifluoroacetyl group to yield 38, whose benzyl group was later cleaved by $\mathrm{Pd} / \mathrm{C}$ catalytic hydrogenation. Diol 39 was then transformed into 1,2-diacetyl glycosyl donor 40, which underwent smooth glycosylation with diisopropyl 
phosphonomethanol at the 1-position affording $\mathbf{4 1}{ }^{23}$ Subsequent trifluoroacetyl deprotection under basic conditions provided key amino sugar intermediate 42, which served as synthon for the stepwise construction of the purine nucleobase. The final adenine nucleoside phosphonate $\mathbf{2 b}$ was successfully obtained in $40 \%$ yield $(0.78 \%$, overall yield) following the cleavage of the diisopropyl esters with TMSBr in the presence of lutidine. It is worth mentioning that 1-O-diisopropylphosphonomethyl-3,4-dideoxy-4amino- $\alpha$-D-threo-pentopyranoside $\mathbf{4 2}$ might constitute a versatile intermediate for the construction of a variety of purine or pyrimidine nucleobases. ${ }^{22}$

Scheme 4. Synthesis of Adenine $\alpha$-D-threo-pentopyranoside Nucleoside Phosphonate $2 \mathrm{~b}$.

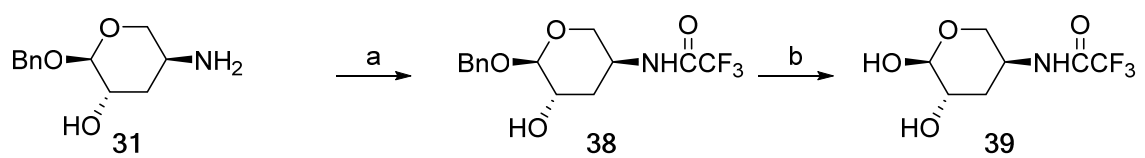

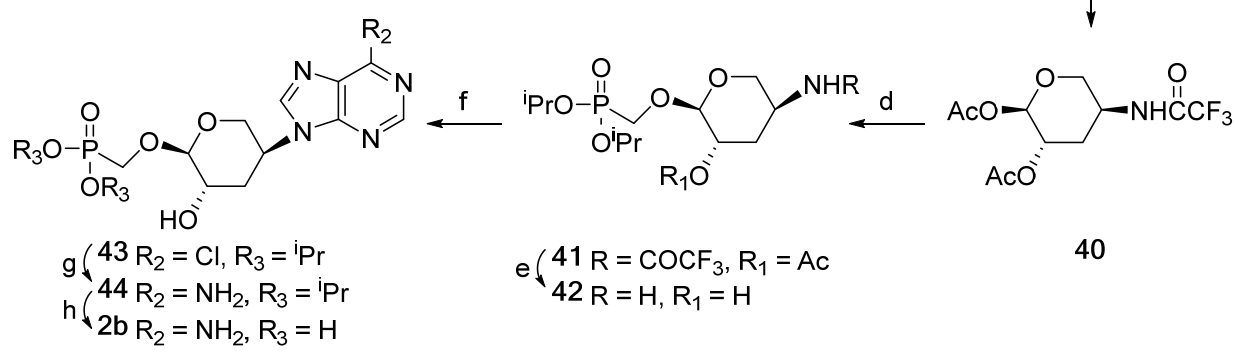

${ }^{a}$ Reagents and conditions: (a) ethyl trifluoroacetate, TEA, methanol, 91\%; (b) $\mathrm{Pd} / \mathrm{C}, \mathrm{H}_{2}$, methanol, 82\%; (c) Ac $2 \mathrm{O}$, pyridine, 80\%; (d) hydroxymethyl phosphonic acid diisopropyl ester, TMSOTf, DCM, rt; (e) 7 M NH 3 in methanol, 40\% over two steps; (f) 4,6-dichloro-5-formamidopyrimidine, DIPEA, $\mathrm{BuOH}, 75 \%$; (g) $\mathrm{NH}_{3}$ in ethanol, 92\%; (h) TMSBr, acetronitrile, $40 \%$.

A detailed solution conformational analysis of the final phosphonate products $\mathbf{2 a}$ and $\mathbf{2} \mathbf{b}$ was carried out using NMR spectroscopy. A preference for a 1,4-syn substitution pattern (Figure 3) was established for both pyrimidine and purine derivatives $\mathbf{2 a}$ and $\mathbf{2 b}$ following complete assignment using 1D and 2D NMR experiments and based on the values of the coupling constants observed in the 1H NMR spectra. Table 2 summarizes the proton NMR spectroscopic data acquired for thymine derivative 2a. The corresponding data obtained for adenine containing nucleoside phosphonate $\mathbf{2} \mathbf{b}$ can be found in the Supporting Information (Table S2) together with all relevant spectra. 


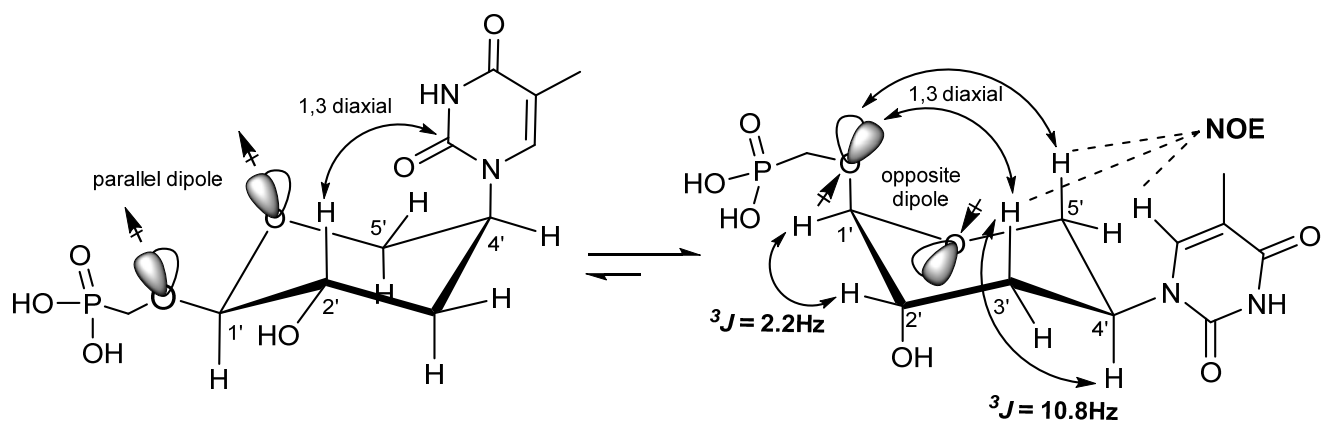

Figure 3. Schematic representation of the solution phase preferential conformation of 1'-phosphonate D-threopentopyranose nucleoside bearing thymine as base (2a) as determined by NMR studies. Dashed lines indicate the observed NOE interaction between the H6 of thymine and the axially positioned H3' and H5'.

As shown in the $1 \mathrm{H}$ NMR spectrum of $2 \mathrm{a}$ (see Supporting Information), H1' ( $\delta 4.68)$ and $H 2^{\prime}(\delta 4.04)$ appear as a doublet and triplet of doublets, respectively, with a small ${ }^{3} J_{1^{\prime}, 2^{\prime}}$ diequatorial coupling constant, which is consistent with a chair conformation with both phosphonomethyl group and 2'-OH occupying an axial orientation. The td pattern of $\mathrm{H} 2$ ' with the largest splitting equal to $3.6 \mathrm{~Hz}$ is characteristic of an equatorial position of this proton. Furthermore, the $\mathrm{H} 4^{\prime}$ signal at $\delta 4.79$ consists of a triplet of triplets arising from the coupling with the protons at $\mathrm{C}^{\prime}$ and $\mathrm{C}^{\prime}$; notably, the observed ${ }^{3} J_{4^{\prime}, 3^{\prime}}$ and ${ }^{3} J_{4^{\prime}, 5^{\prime}}$ values of 12.1 and $10.8 \mathrm{~Hz}$ between $\mathrm{H}^{\prime}$ ' and $\mathrm{H}^{3} \mathrm{\prime}$ a and $\mathrm{H} 5$ 'a, respectively, support an equatorial orientation of the nucleobase at the 4'-position. This chair conformation of the pyranose ring was further confirmed by the presence of a clear NOE correlation between the H6 of thymine and the axially positioned H3' and H5'.

Such 1,4-syn-relationship is similar to that previously reported between the heterocyclic base and either the 5 '-hydroxymethyl to be phosphorylated in 1,5-anhydrohexitol nucleosides ${ }^{5}$ or the 4'-O-phosphonomethyl moiety in $2^{\prime}, 3^{\prime}$-dideoxy-2',3'-didehydro-pentopyranosyl ${ }^{16}$ nucleoside phosphonates. However, nucleoside phosphonates $\mathbf{2 a}, \mathbf{b}$ differ in their conformational behavior from $\mathbf{1}$ by the orientation of the nucleobase, which is equatorial rather than axial, with both the hydroxymethyl and secondary $\mathrm{OH}$ groups at the 1'- and 2 '-positions axially positioned. Thus, it can be assumed that the preferred conformation in $\mathbf{2 a}, \mathbf{b}$ is sterically enforced in order to avoid the 1,3-diaxial steric interactions among bulky substituents and/or between the lone pairs of the ring oxygen and the anomeric oxygen, along with the opposite direction of the dipole moment.

For comparison, the $\beta$-anomer of compound 2a $(\boldsymbol{\beta}$-S2a) was obtained upon deprotection of $\boldsymbol{\beta}-\mathbf{2 8}$ and fully characterized by 1D and 2D NMR experiments (for details, see Table S3 and Figure S3 in the Supporting Information). Accordingly, the analysis of these NMR data indicated that the preferred chair conformation of the pyranose ring in $\boldsymbol{\beta}$-S2a adjusts to a 1,4-trans-diaxial orientation of the bulky substituents.

It is noteworthy that the conformation of such nucleoside analogues is expected to easily adapt to external conditions such as those required by enzyme binding ${ }^{24}$ or insertion within a nucleic acid chain, ${ }^{25}$ thus influencing oligonucleotides properties in a variable way. 
Table 2. 1H NMR Analysis of the Sugar Skeleton of Thymine D-Threo-pentopyranoside Nucleoside Phosphonate $2 \mathrm{a}\left(600 \mathrm{MHz}, \mathrm{D}_{2} \mathrm{O}\right)$.

\begin{tabular}{|c|c|c|c|c|c|}
\hline bond & orientation $^{a}$ & $\delta(\mathrm{ppm})$ & multiplicity & $J(\mathrm{~Hz})\left(\mathrm{D}_{2} \mathrm{O}\right)$ & ${ }^{3} J$ connection \\
\hline $\mathrm{C}-\mathrm{H} 1^{\prime}$ & $\mathrm{e}$ & 4.68 & $\mathrm{~d}$ & 2.2 & $\mathrm{H} 1^{\prime} \mathrm{e}-\mathrm{H} 2^{\prime} \mathrm{e}$ \\
\hline $\mathrm{C}-\mathrm{H} 2^{\prime}$ & $\mathrm{e}$ & 4.04 & $\mathrm{td}$ & $\begin{array}{c}2.2-3.0 \\
3.6\end{array}$ & $\begin{array}{l}\mathrm{H} 2^{\prime} \mathrm{e}-\mathrm{H} 1^{\prime} \mathrm{e} \\
\mathrm{H} 2^{\prime} \mathrm{e}-\mathrm{H} 3^{\prime} \mathrm{e} \\
\mathrm{H} 2^{\prime} \mathrm{e}-\mathrm{H} 3^{\prime} \mathrm{a}\end{array}$ \\
\hline C-H3' & $\mathrm{a}$ & 2.38 & ddd & $\begin{array}{c}3.0 \\
12.1 \\
13.8 \\
\end{array}$ & $\begin{array}{l}\mathrm{H} 3 \text { 'a-H2'e } \\
\text { H3'a-H4'a } \\
\text { H3'a-H3'e }\end{array}$ \\
\hline C-H3" & $\mathrm{e}$ & 1.93 & $\mathrm{dtd}$ & $\begin{array}{c}1.2 \\
3.9 \\
13.1 \\
\end{array}$ & $\begin{array}{l}\mathrm{H} 3{ }^{\prime} \mathrm{e}-\mathrm{H} 2^{\prime} \mathrm{e} \\
\mathrm{H} 3^{\prime} \mathrm{e}-\mathrm{H} 4^{\prime} \mathrm{a} \\
\mathrm{H} 3^{\prime} \mathrm{e}-\mathrm{H} 3 \text { 'a }\end{array}$ \\
\hline C-H4' & $\mathrm{a}$ & 4.79 & $\mathrm{tt}$ & $\begin{array}{l}10.8 \\
4.8\end{array}$ & $\begin{array}{l}\text { H4'a-H3'a } \\
\text { H4'a-H5'a } \\
\text { H4'a-H3'e } \\
\text { H4'a-H5'e }\end{array}$ \\
\hline C-H5' & $\mathrm{a}$ & 3.91 & $\mathrm{t}$ & 10.7 & $\begin{array}{l}\text { H5'a-H5'e } \\
\text { H5'a-H4'a }\end{array}$ \\
\hline C-H5" & $\mathrm{e}$ & 3.73 & ddd & $\begin{array}{c}1.4 \\
4.7 \\
11.2 \\
\end{array}$ & $\begin{array}{l}\mathrm{H}^{\prime} \text { 'e-H3'e } \\
\text { H5'e-H4'a } \\
\text { H5'e-H5'a }\end{array}$ \\
\hline
\end{tabular}

${ }^{a} \mathrm{e}$ stands for equatorial, a for axial. ${ }^{b} \mathrm{~W}$ proton-proton coupling $\left({ }^{4} \mathrm{JHH}\right)$.

In order to define whether D-threo-pentopyranoside nucleoside phosphonates are still recognized by enzymes involved in nucleoside and nucleotide metabolism, compounds $\mathbf{2 a}, \mathbf{b}$ were at first evaluated for their antiviral activity against different herpesviruses (varicella zoster virus (VZV), HSV-1, and HSV-2). Contrary to the results obtained for $\mathbf{1}^{5}$ as well as known furanose nucleoside phosphonates, ${ }^{26}$ these studies revealed that $\mathbf{2 a}, \mathbf{b}$ exerted poor inhibitory activity of DNA viral replication. This could be due to a lack of cell penetration (the negatively charged phosphonate moiety is very polar) as well as inefficient intracellular enzymatic phosphorylation. Specifically, the very high $\mathrm{EC}_{50}$ values determined for $\mathbf{2 a}, \mathbf{b}$ (Table S4, in the Supporting Information) suggest that these issues cannot be overcome by synthesizing the corresponding prodrugs.

Furthermore, aiming to gain knowledge about the potential utility of these synthetic analogues for the selection of artificial information systems, the adenine containing nucleoside phosphonate $\mathbf{2 b}$ was converted to its corresponding diphosphate $\mathbf{4 5}$ using a known phosphorylation procedure (Scheme 5). ${ }^{27}$ Compound 45 was assessed for its ability to be accepted as substrate by DNA polymerases in an enzymatic primer extension assay where a primer-template duplex with a seven 5'-dT overhang was used. Enzymes lacking $3^{\prime}, 5^{\prime}$-proofreading activity such as Klenow fragment (exo-) and Vent (exo-) were tested in the presence or absence of $\mathrm{Mn}^{2+}$ ions and shown to be able to use $\mathbf{4 5}$ as substrate, although only the formation 
of $\mathrm{P}+1$ or $\mathrm{P}+2$ products was detected, as exemplified in Figure 4 (for a complete account of used conditions and results, see Supporting information, Figure S1 and S2).

Scheme 5. Phosphorylation of Adenine $\alpha$-D-Threo-pentopyranoside Phosphonate $2 \mathrm{~b}^{a}$

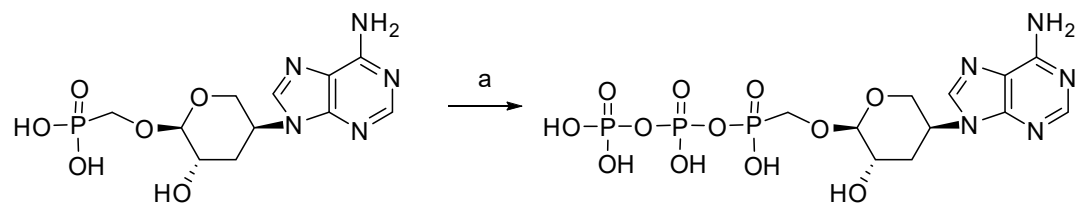

$2 b$

45

${ }^{a}$ Reagents and conditions: (a) (i) $1,1^{\prime}$-carbonyldiimidazole, DMF; (ii) $\left(\mathrm{HNBu}_{3}\right)_{2} \mathrm{H}_{2} \mathrm{P}_{2} \mathrm{O}_{7}$, (ii) TEAB buffer, $30 \%$.

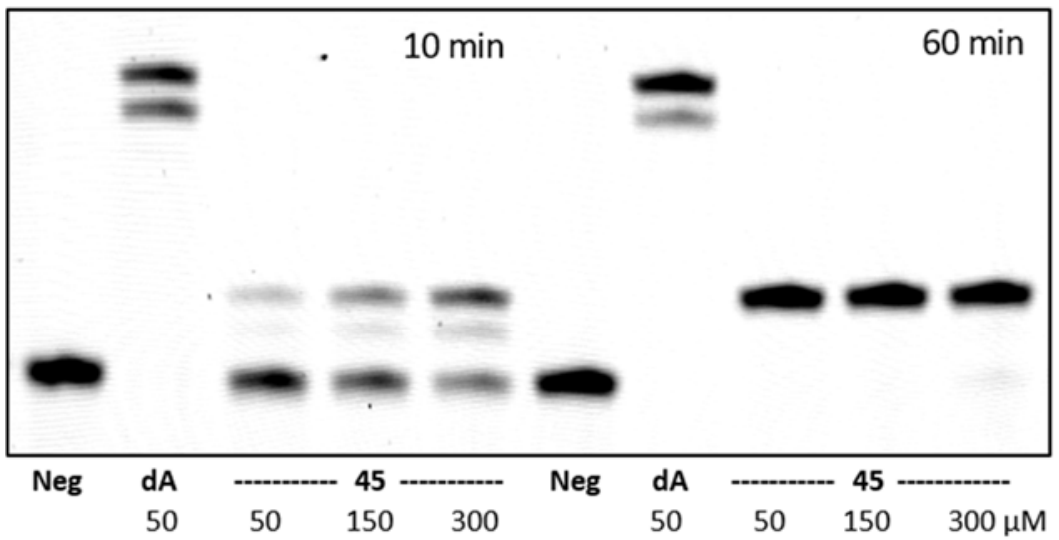

P: 5'- /5Cy3/ CTCGCTATGACACTCGTCTCTT-3':

T: 3 '-GAGCGATACTGTGAGCAGAGAATTTTTTTCAA-5'

Figure 4. Primer extension of compound 45 in the presence of Vent polymerase (exo-) and $\mathrm{Mn}^{2+}$ ions. The positions were $\mathbf{4 5}$ has to be incorporated opposite the template oligonucleotide are in bold. dA stands for 2'-deoxyadenosine triphosphate (positive control), while Neg for negative control.

\section{CONCLUSION}

In summary, D-threo-pentopyranoside nucleoside analogues bearing a phosphonate functionality rather than a nucleobase (i.e., in natural nucleosides) at the anomeric center have been synthetized starting from Larabinose. Specifically, stereocontrolled routes to suitably functionalized key carbohydrate scaffolds have been established and optimized. Such intermediates were further assembled and elaborated into the final six-membered ring nucleosides using two main strategies entailing the initial insertion of the nucleobase on the glycone moiety followed by phosphonomethylation or by inverting this reaction sequence. Notably, when a thymine containing pentopyranose glycosyl donor was subjected to Vorbrüggen glycosylation conditions, the reaction proceeded without neighboring group participation, in contrast to the usual behavior of protected furanose nucleoside precursors. The synthesis of the adenine analogue relied on a linear approach for building the purine base on a phosphonometylated 4-amino pentopyranoside synthon. This method allowed for an improved stereoselectivity and could potentially be extended to the stepwise construction of other purine as well as pyrimidine bases. According to NMR studies, the solution 
conformation of such pentopyranoside nucleoside phosphonates prefers an equatorial orientation of the nucleobase that circumvents unfavorable 1,3-diaxial interactions, in contrast to HNA nucleosides. Preliminary primer incorporation reactions using a mesophilic and thermophilic polymerase revealed that the compounds synthesized by these pathways constitute potentially useful monomers for medicinal and biotechnological applications.

\section{EXPERIMENTAL SECTION}

General Information. All reagents and solvents were purchased from commercial sources and used as obtained. Moisture sensitive reactions were performed using oven-dried glassware under a nitrogen or argon atmosphere. NMR spectra were recorded on a Bruker Advance $300 \mathrm{MHz}\left({ }^{1} \mathrm{H} \mathrm{NMR}, 300 \mathrm{MHz} ;{ }^{13} \mathrm{C}\right.$ NMR, $75 \mathrm{MHz} ;{ }^{31} \mathrm{P}$ NMR, $\left.121 \mathrm{MHz}\right), 500 \mathrm{MHz}\left({ }^{1} \mathrm{H}\right.$ NMR, $500 \mathrm{MHz} ;{ }^{13} \mathrm{C}$ NMR, $125 \mathrm{MHz} ;{ }^{31} \mathrm{P}$ NMR, 202 $\mathrm{MHz})$, or $600 \mathrm{MHz}\left({ }^{1} \mathrm{H} \mathrm{NMR}, 600 \mathrm{MHz} ;{ }^{13} \mathrm{C} \mathrm{NMR}, 150 \mathrm{MHz}\right)$ spectrometer with tetramethylsilane as internal standard or referenced to the residual solvent signal, and $85 \% \mathrm{H}_{3} \mathrm{PO}_{4}$ for ${ }^{31} \mathrm{P} \mathrm{NMR}$. All intermediates and final compounds were characterized by using 2D NMR $\left({ }^{1} \mathrm{H}-\mathrm{COSY}\right.$, HSQC, NOESY, and HMBC) spectroscopic techniques. For NMR assignment of sugar protons and carbons, prime numbering is used. High-resolution mass spectra [HRMS (ESI)] were obtained on a quadruple orthogonal acceleration time-of-flight mass spectrometer (Synapt G2 HDMS, Waters, Milford, MA). Samples were infused at 3 $\mu \mathrm{L} / \mathrm{min}$ and spectra were obtained in positive (or in negative) ionization mode with a resolution of 15000 (fwhm) using leucine enkephalin as lock mass. Precoated aluminum sheets ( $254 \mathrm{~nm}$ ) were used for TLC. Products were purified by column chromatography on silica gel ( $60 \AA, 0.035-0.070 \mathrm{~mm}$, Acros Organics). Preparative RP-HPLC purifications were carried out on a Phenomenex Gemini 110A column (C18, $10 \mu \mathrm{m}$, $21.2 \mathrm{~mm} \times 250 \mathrm{~mm}$ ) using $\mathrm{CH}_{3} \mathrm{CN} / 0.05 \mathrm{M}$ TEAB buffer or $\mathrm{H}_{2} \mathrm{O} / \mathrm{CH}_{3} \mathrm{CN}$ as eluent gradient.

Benzyl 2- $\boldsymbol{O}$-acetyl-3,4- $\boldsymbol{O}$-isopropylidene- $\boldsymbol{\beta}$-L-ribopyranoside (5). Benzyl $3,4-O$-isopropylidene- $\beta$-Lribopyranoside 4 was prepared in 4 steps from L-arabinose 3 following a literature procedure that did not require column chromatography purification. ${ }^{21} \mathrm{Next}$, to a stirred solution of 4 (34.7 g, $\left.123.8 \mathrm{mmol}\right)$, DMAP $(0.76 \mathrm{~g}, 6 \mathrm{mmol})$ and triethylamine $(69.0 \mathrm{~mL}, 495.2 \mathrm{mmol})$ in DCM $(500 \mathrm{~mL})$, acetic anhydride $(23.4 \mathrm{~mL}$, $247.6 \mathrm{mmol}$ ) was added dropwise at $0{ }^{\circ} \mathrm{C}$. The reaction mixture was slowly warmed to room temperature and stirred for $2 \mathrm{~h}$. After completion of the reaction, the mixture was cooled to $0{ }^{\circ} \mathrm{C}$ and quenched with saturated aq. $\mathrm{NaHCO}_{3}$. The organic layer was washed with brine $(200 \mathrm{~mL})$, dried over $\mathrm{Na}_{2} \mathrm{SO}_{4}$, and concentrated in vacuo. The resulting residue was purified by column chromatography on silica gel $(10: 1$, hexane/EtOAc, $\left.R_{f}=0.3\right)$ to afford 5 (37.3 g, $93 \%$ yield) as a white solid. ${ }^{1} \mathrm{H}$ NMR $\left(300 \mathrm{MHz}, \mathrm{CDCl}_{3}\right) \delta$ 7.38-7.26 (m, 5H, Ph), 5.00 (dd, $J=6.1,3.3 \mathrm{~Hz}, 1 \mathrm{H}, \mathrm{H}-2), 4.93$ (d, $J=6.2 \mathrm{~Hz}, 1 \mathrm{H}, \mathrm{H}-1), 4.80$ (d, $J=12.3$ $\left.\mathrm{Hz}, 1 \mathrm{H}, \mathrm{CH}_{2} \mathrm{Ph}\right), 4.80\left(\mathrm{~d}, J=12.3 \mathrm{~Hz}, 1 \mathrm{H}, \mathrm{CH}_{2} \mathrm{Ph}\right), 4.57$ (dd, $\left.J=7.0,3.2 \mathrm{~Hz}, 1 \mathrm{H}, \mathrm{H}-3\right), 4.56$ (d, $J=12.2$ $\mathrm{Hz}, 1 \mathrm{H}, \mathrm{CH}_{2} \mathrm{Ph}$ ), 4.32 (dt, $\left.J=7.0,1.9 \mathrm{~Hz}, 1 \mathrm{H}, \mathrm{H}-4\right), 3.87$ (dd, $\left.J=13.1,2.5 \mathrm{~Hz}, 1 \mathrm{H}, \mathrm{H}-5\right), 3.71$ (dd, $J=13.1$, $\left.1.6 \mathrm{~Hz}, 1 \mathrm{H}, \mathrm{H}-5^{\prime}\right), 2.13$ (s, 3H, $\left.\mathrm{CH}_{3} \mathrm{CO}\right), 1.53\left(\mathrm{~s}, 3 \mathrm{H},\left[\mathrm{C}\left(\mathrm{CH}_{3}\right)_{2}\right]\right), 1.33\left(\mathrm{~s}, 3 \mathrm{H},\left[\mathrm{C}\left(\mathrm{CH}_{3}\right)_{2}\right]\right) ;{ }^{13} \mathrm{C} \mathrm{NMR}(75$ $\left.\mathrm{MHz}, \mathrm{CDCl}_{3}\right) \delta 170.3\left(\mathrm{CH}_{3} \mathrm{CO}\right), 137.6,128.5,127.8,127.7(\mathrm{Ph}), 110.4\left[\mathrm{C}\left(\mathrm{CH}_{3}\right)_{2}\right], 96.9(\mathrm{C}-1), 73.6(\mathrm{C}-2)$, $71.8\left(\mathrm{CH}_{2} \mathrm{Ph}\right), 70.3(\mathrm{C}-3), 69.5(\mathrm{C}-4), 62.5(\mathrm{C}-5), 26.5\left[\mathrm{C}\left(\mathrm{CH}_{3}\right)_{2}\right], 25.3\left[\mathrm{C}\left(\mathrm{CH}_{3}\right)_{2}\right], 21.2\left(\mathrm{CH}_{3} \mathrm{CO}\right)$; HRMS (ESI-TOF) m/z: $[\mathrm{M}+\mathrm{Na}]^{+}$calcd for $\mathrm{C}_{17} \mathrm{H}_{22} \mathrm{O}_{6} \mathrm{Na} 345.1309$; Found 345.1308. 
Benzyl 2-O-acetyl- $\boldsymbol{\beta}$-L-ribopyranoside (6). A solution of 5 (20.0 g, $62.04 \mathrm{mmol})$ in $80 \%$ aq. acetic acid $(400 \mathrm{~mL})$ was stirred at $60^{\circ} \mathrm{C}$ for $2 \mathrm{~h}$. After removal of all the volatiles under reduced pressure, the residue was partitioned between water $(200 \mathrm{~mL})$ and EtOAc $(300 \mathrm{~mL})$. The water layer was extracted with EtOAc $(1 \times 200 \mathrm{~mL})$. The combined organic layers were washed with brine, dried over $\mathrm{Na}_{2} \mathrm{SO}_{4}$ and concentrated in vacuo. The resulting residue was purified by column chromatography on silica gel (100:5 DCM/methanol, $\left.R_{f}=0.25\right)$ to afford $6(14.6 \mathrm{~g}, 83 \%)$ as a white solid. ${ }^{1} \mathrm{H}$ NMR $(500 \mathrm{MHz}$, DMSO-d6) $\delta 7.41-7.18(\mathrm{~m}, 5 \mathrm{H}$, $\mathrm{Ph}$ ), 5.10 (d, $J=4.7 \mathrm{~Hz}, 1 \mathrm{H}, \mathrm{OH}-3), 4.76$ (d, $J=7.0 \mathrm{~Hz}, 1 \mathrm{H}, \mathrm{H}-1), 4.73$ (d, $\left.J=12.4 \mathrm{~Hz}, 1 \mathrm{H}, \mathrm{CH}_{2} \mathrm{Ph}\right), 4.67$ (d, $J=7.0 \mathrm{~Hz}, 1 \mathrm{H}, \mathrm{OH}-4), 4.55$ (dd, $J=6.8,2.9 \mathrm{~Hz}, 1 \mathrm{H}, \mathrm{H}-2), 4.54$ (d, $J=12.3 \mathrm{~Hz}, 1 \mathrm{H}, \mathrm{CH}_{2} \mathrm{Ph}$ ), 3.96 (dt, $J=4.3,2.6 \mathrm{~Hz}, 1 \mathrm{H}, \mathrm{H}-3), 3.69-3.55$ (m, 3H, H-4, H-5 and H-5'), 2.11 (s, 3H, CH$\left.H_{3} \mathrm{CO}\right) ;{ }^{13} \mathrm{C}$ NMR $(125$ MHz, DMSO-d6) $\delta 169.6\left(\mathrm{CH}_{3} \mathrm{CO}\right), 137.8,128.3,127.5,127.4(\mathrm{Ph}), 97.1(\mathrm{C}-1), 72.0(\mathrm{C}-2), 69.5\left(\mathrm{CH}_{2} \mathrm{Ph}\right)$, 67.8 (C-3), 66.7 (C-4), 63.5 (C-5), $20.9\left(\mathrm{CH}_{3} \mathrm{CO}\right)$; HRMS (ESI-TOF) m/z: [M+Na] $]^{+}$calcd for $\mathrm{C}_{14} \mathrm{H}_{18} \mathrm{O}_{6} \mathrm{Na}$ 305.0996; Found 305.0998.

Benzyl 2-O-acetyl-4-O-tert-butyldiphenylsilyl- $\beta$-L-ribopyranoside (7). To a stirred solution of 6 (10.0 g, $35.41 \mathrm{mmol})$ and imidazole $(6.03 \mathrm{~g}, 88.5 \mathrm{mmol})$ in dry acetonitrile $(300 \mathrm{~mL})$ at $0{ }^{\circ} \mathrm{C}$, a solution of tertbutyldiphenylchlorosilane $(10.1 \mathrm{~mL}, 38.9 \mathrm{mmol})$ in anhydrous acetonitrile $(50 \mathrm{~mL})$ was added dropwise. The reaction mixture was stirred at room temperature for $8 \mathrm{~h}$. After removal of all the volatiles under reduced pressure, the resulting residue was partitioned between water $(100 \mathrm{~mL})$ and EtOAc $(200 \mathrm{~mL})$. The water layer was extracted with EtOAc $(1 \times 200 \mathrm{~mL})$. The combined organic layers were washed with brine $(150 \mathrm{~mL})$, dried over $\mathrm{Na}_{2} \mathrm{SO}_{4}$, and concentrated in vacuo. The residue was purified by column chromatography on silica gel (10:1 hexane/EtOAc, $\left.R_{f}=0.3\right)$ to afford $7(13.0 \mathrm{~g}, 71 \%$ yield $)$ as a colorless oil. ${ }^{1} \mathrm{H}$ NMR (300 MHz, $\left.\mathrm{CDCl}_{3}\right) \delta$ 7.75-7.62 (m, 4H, Ph), 7.47-7.36 (m, 6H, Ph), 7.32-7.22 (m, 5H, Ph), 4.92 (d, $J=5.2 \mathrm{~Hz}, 1 \mathrm{H}, \mathrm{H}-1), 4.82$ (dd, $J=5.1,3.6 \mathrm{~Hz}, 1 \mathrm{H}, \mathrm{H}-2), 4.71\left(\mathrm{~d}, J=12.0 \mathrm{~Hz}, 1 \mathrm{H}, \mathrm{CH}_{2} \mathrm{Ph}\right), 4.50$ (d, $J=12.0 \mathrm{~Hz}, 1 \mathrm{H}, \mathrm{CH}_{2} \mathrm{Ph}$ ), 4.10 (t, $J=3.3 \mathrm{~Hz}, 1 \mathrm{H}, \mathrm{H}-3$ ), 3.92 (dt, $\left.J=5.9,3.9 \mathrm{~Hz}, 1 \mathrm{H}, \mathrm{H}-4\right), 3.63-3.49$ (m, 2H, H-5 and H-5'), 2.12 (s, 3H, $\left.\mathrm{CH}_{3} \mathrm{CO}\right), 1.09\left(\mathrm{~s}, 9 \mathrm{H},\left[\mathrm{C}\left(\mathrm{CH}_{3}\right)_{3}\right]\right) ;{ }^{13} \mathrm{C} \mathrm{NMR}\left(75 \mathrm{MHz}, \mathrm{CDCl}_{3}\right) \delta 170.4$ $\left(\mathrm{CH}_{3} \mathrm{CO}\right), 137.3,135.8,135.75,133.2,132.5,130.3,130.2,128.5,128.1,128.0,127.8,127.6(\mathrm{Ph}), 97.3$ (C-1), $71.3(\mathrm{C}-2), 70.1\left(\mathrm{CH}_{2} \mathrm{Ph}\right), 69.1(\mathrm{C}-4), 67.6(\mathrm{C}-3), 63.1(\mathrm{C}-5), 27.0\left[\mathrm{C}\left(\mathrm{CH}_{3}\right)_{3}\right], 21.2\left(\mathrm{CH}_{3} \mathrm{CO}\right), 19.4$ $\left[C\left(\mathrm{CH}_{3}\right)_{3}\right]$; HRMS (ESI-TOF) m/z: $[\mathrm{M}+\mathrm{Na}]^{+}$calcd for $\mathrm{C}_{30} \mathrm{H}_{36} \mathrm{O}_{6} \mathrm{SiNa}$ 543.2174; Found 543.2167.

Benzyl 2-O-acetyl-4-O-tert-butyldiphenylsilyl-3- $O$-trifluoromethanesulfonyl- $\beta$-L-ribopyranoside (9). To a stirred solution of $7(10.0 \mathrm{~g}, 19.22 \mathrm{mmol})$ and pyridine $(4.8 \mathrm{~mL}, 57.7 \mathrm{mmol})$ in dry DCM $(300 \mathrm{~mL})$ at $0{ }^{\circ} \mathrm{C}$, triflic anhydride $(6.5 \mathrm{~mL}, 38.44 \mathrm{mmol})$ was added dropwise. The reaction mixture was stirred at room temperature for $1 \mathrm{~h}$. After completion of the reaction, the mixture was cooled to $0{ }^{\circ} \mathrm{C}$ and quenched with saturated aq. $\mathrm{NaHCO}_{3}$. The reaction mixture was further washed with saturated aq. $\mathrm{NaHCO}_{3}(100 \mathrm{~mL})$ and brine $(100 \mathrm{~mL})$. The organic layer was dried over $\mathrm{Na}_{2} \mathrm{SO}_{4}$ and concentrated in vacuo. The resulting residue was purified by silica gel column chromatography (silica gel was presoaked with $0.5 \%$ of triethylamine in hexane; chromatography was performed using 15:1 hexane/EtOAc, $\left.R_{f}=0.2\right)$ to afford 9 (11.9 g, 95\% yield) as a colorless oil. ${ }^{1} \mathrm{H}$ NMR $\left(300 \mathrm{MHz}, \mathrm{CDCl}_{3}\right) \delta 7.79-7.58(\mathrm{~m}, 4 \mathrm{H}, \mathrm{Ph}), 7.54-7.15(\mathrm{~m}, 11 \mathrm{H}, \mathrm{Ph}), 5.31(\mathrm{dd}$, $J=2.4,2.2 \mathrm{~Hz}, 1 \mathrm{H}, \mathrm{H}-2), 4.82$ (dd, $J=7.3,2.4 \mathrm{~Hz}, 1 \mathrm{H}, \mathrm{H}-3), 4.74$ (d, $\left.J=12.0 \mathrm{~Hz}, 1 \mathrm{H}, \mathrm{CH}_{2} \mathrm{Ph}\right), 4.72$ (d, $J$ $=7.2 \mathrm{~Hz}, 1 \mathrm{H}, \mathrm{H}-1), 4.50\left(\mathrm{~d}, J=12.0 \mathrm{~Hz}, 1 \mathrm{H}, \mathrm{CH}_{2} \mathrm{Ph}\right), 3.94$ (ddd, $\left.J=9.4,5.8,2.3 \mathrm{~Hz}, 1 \mathrm{H}, \mathrm{H}-4\right), 3.56$ (dd, $J$ $=11.6,9.5 \mathrm{~Hz}, 1 \mathrm{H}, \mathrm{H}-5), 3.39\left(\mathrm{dd}, J=11.6,4.8 \mathrm{~Hz}, 1 \mathrm{H}, \mathrm{H}-5\right.$ '), $2.08\left(\mathrm{~s}, 3 \mathrm{H}, \mathrm{CH}_{3} \mathrm{CO}\right), 1.08\left(\mathrm{~s}, 9 \mathrm{H},\left[\mathrm{C}\left(\mathrm{CH}_{3}\right)_{3}\right]\right)$; 
${ }^{13} \mathrm{C}$ NMR $\left(75 \mathrm{MHz}, \mathrm{CDCl}_{3}\right) \delta 169.6\left(\mathrm{CH}_{3} \mathrm{CO}\right), 135.9,135.85,133.0,130.6,130.5,128.6,128.3,128.1$, $127.7(\mathrm{Ph}), 120.8\left(\mathrm{CF}_{3}\right), 97.2(\mathrm{C}-1), 86.0(\mathrm{C}-3), 70.9(\mathrm{C}-2), 68.7\left(\mathrm{CH}_{2} \mathrm{Ph}\right), 67.3(\mathrm{C}-4), 63.7(\mathrm{C}-5), 26.8$ $\left[\mathrm{C}\left(\mathrm{CH}_{3}\right)_{3}\right], 20.7\left(\mathrm{CH}_{3} \mathrm{CO}\right), 19.2\left[C\left(\mathrm{CH}_{3}\right)_{3}\right]$; HRMS (ESI-TOF) m/z: $\left[\mathrm{M}+\mathrm{NH}_{4}\right]^{+}$calcd for $\mathrm{C}_{31} \mathrm{H}_{39} \mathrm{NF}_{3} \mathrm{O}_{8} \mathrm{SSi}$ 670.2118; Found 670.2119.

Benzyl 2-O-acetyl-4-O-tert-butyldiphenylsilyl-3-deoxy-3-iodo- $\beta$-L-xylopyranoside (10). A suspension of $9(4.00 \mathrm{~g}, 6.12 \mathrm{mmol})$ and $\mathrm{NaI}(2.76 \mathrm{~g}, 18.38 \mathrm{mmol})$ in THF $(70 \mathrm{~mL})$ was stirred at room temperature for $12 \mathrm{~h}$. After removal of all the volatiles under reduced pressure, the resulting residue was separated between EtOAc $(100 \mathrm{~mL})$ and saturated aq. $\mathrm{NaHCO}_{3}(50 \mathrm{~mL})$. The water layer was extracted with EtOAc $(50 \mathrm{~mL})$ once. The combined organic layers were washed with brine $(50 \mathrm{~mL})$, dried over $\mathrm{Na}_{2} \mathrm{SO}_{4}$, and concentrated in vacuo. The residue was purified by column chromatography on silica gel (15:1 hexane/EtOAc) to afford 10 (3.71 g, 96\% yield) as a colorless oil. ${ }^{1} \mathrm{H}$ NMR (300 MHz, $\left.\mathrm{CDCl}_{3}\right) \delta 7.94-7.62$ (m, 4H, Ph), 7.56-7.10 (m, 11H, Ph), 5.06 (dd, $J=10.5,7.2 \mathrm{~Hz}, 1 \mathrm{H}, \mathrm{H}-2), 4.76$ (d, $J=12.4 \mathrm{~Hz}, 1 \mathrm{H}, \mathrm{CH}_{2} \mathrm{Ph}$ ), 4.49 (d, $J=12.4 \mathrm{~Hz}, 1 \mathrm{H}, \mathrm{CH}_{2} \mathrm{Ph}$ ), 4.29 (d, $\left.J=7.2 \mathrm{~Hz}, 1 \mathrm{H}, \mathrm{H}-1\right), 4.14-3.87$ (m, 2H, H-3 and H-4), 3.64 (dd, $J=11.6,4.4 \mathrm{~Hz}, 1 \mathrm{H}, \mathrm{H}-5), 3.28-3.03\left(\mathrm{~m}, 1 \mathrm{H}, \mathrm{H}-5^{\prime}\right), 2.07$ (s, 3H, $\left.\mathrm{CH}_{3} \mathrm{CO}\right), 1.09$ (s, 9H, [C(CH3) 3$) ;{ }^{13} \mathrm{C}$ $\operatorname{NMR}\left(75 \mathrm{MHz}, \mathrm{CDCl}_{3}\right) \delta 169.0\left(\mathrm{CH}_{3} \mathrm{CO}\right), 136.3,135.9,130.3,130.1,128.5,128.0,127.9,127.8,127.7$ $(\mathrm{Ph}), 100.4$ (C-1), 73.7 (C-2), 73.1 (C-4), $70.4\left(\mathrm{CH}_{2} \mathrm{Ph}\right), 68.2(\mathrm{C}-5), 33.5(\mathrm{C}-3), 27.2\left[\mathrm{C}^{\left.\left(\mathrm{CH}_{3}\right)_{3}\right],} 21.0\right.$ $\left(\mathrm{CH}_{3} \mathrm{CO}\right), 19.7\left[\mathrm{C}\left(\mathrm{CH}_{3}\right)_{3}\right]$; HRMS (ESI-TOF) m/z: $[\mathrm{M}+\mathrm{Na}]^{+}$calcd for $\mathrm{C}_{30} \mathrm{H}_{35} \mathrm{IO}_{5} \mathrm{SiNa}$ 653.1193; Found 653.1196.

Benzyl 2-O-acetyl-4-O-tert-butyldiphenylsilyl-3-deoxy- $\beta$-L-erythro-pentopyranoside (11). To a stirred solution of $10(2.00 \mathrm{~g}, 3.17 \mathrm{mmol})$ and $\operatorname{AIBN}(0.26 \mathrm{~g}, 1.59 \mathrm{mmol})$ in toluene $(100 \mathrm{~mL})$, tributyltin hydride $(1.7 \mathrm{~mL}, 6.34 \mathrm{mmol})$ was added dropwise. The reaction mixture was heated at $110^{\circ} \mathrm{C}$ for $1 \mathrm{~h}$. After removal of all the volatiles under reduced pressure, the resulting crude residue was purified by column chromatography on silica gel (15:1 hexane/EtOAc, $\left.R_{f}=0.2\right)$ to afford $\mathbf{1 1}(1.5 \mathrm{~g}, 94 \%$ yield $)$ as a colorless oil. ${ }^{1} \mathrm{H}$ NMR (300 MHz, $\mathrm{CDCl}_{3}$ ) $\delta$ 7.70-7.60 (m, 4H, Ph), 7.45-7.34 (m, 6H, Ph), 7.33-7.25 (m, 5H, Ph), $4.75\left(\mathrm{~d}, J=12.2 \mathrm{~Hz}, 1 \mathrm{H}, \mathrm{CH}{ }_{2} \mathrm{Ph}\right), 4.72-4.65$ (m, 1H, H-2), 4.56 (d, $\left.J=5.3 \mathrm{~Hz}, 1 \mathrm{H}, \mathrm{H}-1\right), 4.52$ (d, $J=12.2$ $\mathrm{Hz}, 1 \mathrm{H}, \mathrm{CH}_{2} \mathrm{Ph}$ ), 3.88-3.78 (m, 1H, H-4), 3.74 (ddd, $\left.J=11.4,3.7,1.2 \mathrm{~Hz}, 1 \mathrm{H}, \mathrm{H}-5 \mathrm{a}\right), 3.32$ (dd, $J=11.4$, $6.3 \mathrm{~Hz}, 1 \mathrm{H}, \mathrm{H}-5 \mathrm{e}$ ), 2.21 (dtd, $J=13.2,4.6,1.2 \mathrm{~Hz}, 1 \mathrm{H}, \mathrm{H}-3 \mathrm{e}$ ), 2.04 (s, 3H, $\mathrm{CH}_{3} \mathrm{CO}$ ), 1.77 (dt, $J=13.2,7.6$ $\mathrm{Hz}, 1 \mathrm{H}, \mathrm{H}-3 \mathrm{a}), 1.06$ (s, 9H, [C(CH3 $\left.\left.)_{3}\right]\right) ;{ }^{13} \mathrm{C} \mathrm{NMR}\left(75 \mathrm{MHz} \mathrm{CDCl}_{3}\right) \delta 170.2\left(\mathrm{CH}_{3} \mathrm{CO}\right), 137.6,135.8,133.9$, 133.6, 123.0, 128.5, 127.9, $127.8(\mathrm{Ph}), 99.2$ (C-1), $69.7\left(\mathrm{CH}_{2} \mathrm{Ph}\right), 68.6(\mathrm{C}-2), 67.4$ (C-5), 65.5 (C-4), 34.3

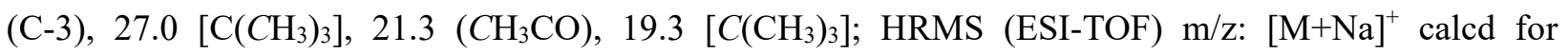
$\mathrm{C}_{30} \mathrm{H}_{36} \mathrm{O}_{5} \mathrm{SiNa}$ 527.2224; Found 527.2216.

Benzyl 2- $\boldsymbol{O}$-acetyl-3-deoxy- $\boldsymbol{\beta}$-L-erythro-pentopyranoside (12). To a stirred solution of $\mathbf{1 1}(1.00 \mathrm{~g}, 1.98$ $\mathrm{mmol})$ in THF $(40 \mathrm{~mL})$ at $0{ }^{\circ} \mathrm{C}$, TBAF $(1 \mathrm{M}$ in THF, $3.96 \mathrm{~mL}, 3.96 \mathrm{mmol})$ was added dropwise. The reaction mixture was slowly warmed to room temperature and stirred for $5 \mathrm{~h}$. After completion of the reaction, all volatiles were removed in vacuo. The resulting residue was separated between EtOAc $(40 \mathrm{~mL})$ and saturated aq. $\mathrm{NaHCO}_{3}(20 \mathrm{~mL})$. The water layer was extracted with EtOAc $(30 \mathrm{~mL})$ once. The combined organic layers were washed with brine $(20 \mathrm{~mL})$, dried over $\mathrm{Na}_{2} \mathrm{SO}_{4}$, and concentrated in vacuo. The residue was purified by column chromatography on silica gel (gradient hexane/EtOAc, 5:1, v/v; 1:1, v/v) affording $12(0.46 \mathrm{~g}, 87 \%)$ as a colorless oil. ${ }^{1} \mathrm{H}$ NMR $\left(600 \mathrm{MHz}, \mathrm{CDCl}_{3}\right) \delta 7.41-7.30(\mathrm{~m}, 5 \mathrm{H}, \mathrm{Ph}), 4.90(\mathrm{dt}, J=3.2$, 
$2.3 \mathrm{~Hz}, 1 \mathrm{H}, \mathrm{H}-2), 4.78$ (bs, $1 \mathrm{H}, \mathrm{H}-1 \mathrm{e}$ ), 4.77 ( d, $J=11.6 \mathrm{~Hz}, 1 \mathrm{H}, \mathrm{CH}_{2} \mathrm{Ph}$ ), 4.56 (d, $J=11.6 \mathrm{~Hz}, 1 \mathrm{H}, \mathrm{CH}_{2} \mathrm{Ph}$ ), $4.01(\mathrm{dd}, J=12.0,1.8 \mathrm{~Hz}, 1 \mathrm{H}, \mathrm{H}-5 \mathrm{a}), 3.75$ (dq, $J=2.7,2.4 \mathrm{~Hz}, 1 \mathrm{H}, \mathrm{H}-4 \mathrm{e}), 3.67$ (dt, $J=11.9,2.3 \mathrm{~Hz}, 1 \mathrm{H}$, H-5e), 2.22 (td, $J=15.0,3.7 \mathrm{~Hz}, 1 \mathrm{H}, \mathrm{H}-3 \mathrm{a}$ ), 2.1 (s, 3H, $\mathrm{CH}_{3} \mathrm{CO}$ ), 1.96 (ddtd, $J=15.0,3.2,2.4,0.93 \mathrm{~Hz}$, $1 \mathrm{H}, \mathrm{H}-3 \mathrm{e}) ;{ }^{13} \mathrm{C}$ NMR $\left(151 \mathrm{MHz}, \mathrm{CDCl}_{3}\right) \delta 169.5\left(\mathrm{CH}_{3} \mathrm{CO}\right), 137.0,128.5,127.9,127.8(\mathrm{Ph}), 95.8(\mathrm{C}-1)$, $69.3\left(\mathrm{CH}_{2} \mathrm{Ph}\right), 68.5(\mathrm{C}-2), 64.5(\mathrm{C}-5), 64.2(\mathrm{C}-4), 29.3(\mathrm{C}-3), 21.2\left(\mathrm{CH}_{3} \mathrm{CO}\right)$; HRMS (ESI-TOF) m/z: $[\mathrm{M}+\mathrm{Na}]^{+}$calcd for $\mathrm{C}_{14} \mathrm{H}_{19} \mathrm{O}_{5} \mathrm{Na} 289.1046$; Found 289.1045.

Benzyl 2-O-acetyl- $\beta$-L-glycero-pent-3-enopyranoside (13). This compound was first obtained as a side product during the Mitsunobu reaction (see Scheme 1), and it was later synthesized by using the triethyl phosphite method.

Mitsunobu conditions: To a stirred suspension of $\mathbf{1 2}$ (1 eq), thymine or Bz-thymine (2 eq), and triphenylphosphine (2.2 eq) in anhydrous dioxane or THF, a solution of DEAD or DIAD in $2 \mathrm{~mL}$ of THF or dioxane was slowly added. The mixture was stirred until disappearance of starting material $\mathbf{1 2}$. After removal of all the volatiles under reduced pressure, the resulting residue was separated between EtOAc and saturated aq. $\mathrm{NaHCO}_{3}$. The water layer was extracted with EtOAc. The combined organic layers were washed with brine, dried over $\mathrm{Na}_{2} \mathrm{SO}_{4}$, filtered, and concentrated in vacuo. The residue was purified by flash column chromatography on silica gel using 15:1(v/v) hexane/ EtOAc. The reaction was conducted at different temperatures $\left(-78,-20,0{ }^{\circ} \mathrm{C}\right.$, and $\left.\mathrm{rt}\right)$, however only the elimination product $\mathbf{1 3}$ was formed instead of the desired nucleoside.

Triethyl phosphite conditions: A stirring solution of $\mathbf{1 7}(8.00 \mathrm{~g}, 24.7 \mathrm{mmol})$ in triethylphosphite $(250 \mathrm{~mL})$ was maintained at $140{ }^{\circ} \mathrm{C}$ for $14 \mathrm{~h}$ and the reaction was monitored by TLC for completion. After removal of all the volatiles under reduced pressure, the crude residue was subjected to column chromatography on silica gel (15:1 hexane/EtOAc) to give $\mathbf{1 3}$ (5.20 g, 85\% yield) as a colorless oil. ${ }^{1} \mathrm{H} \mathrm{NMR}\left(300 \mathrm{MHz}, \mathrm{CDCl}_{3}\right)$

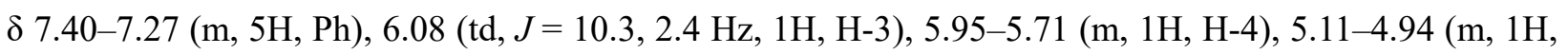
$\mathrm{H}-2$ ), 4.90 (bs, 1H, H-1), 4.81 (d, $J=12.0 \mathrm{~Hz}, 1 \mathrm{H}, \mathrm{CH}_{2} \mathrm{Ph}$ ), 4.62 (d, $J=12.0 \mathrm{~Hz}, 1 \mathrm{H}, \mathrm{CH}_{2} \mathrm{Ph}$ ), 4.37-4.09 (m, 2H, H-5 and $\mathrm{H}-5$ '), 2.07 (s, 3H, $\left.\mathrm{CH}_{3} \mathrm{CO}\right) ;{ }^{13} \mathrm{C}$ NMR (75 MHz, $\left.\mathrm{CDCl}_{3}\right) \delta 170.4\left(\mathrm{CH}_{3} \mathrm{CO}\right), 137.4,131.3$, 128.6, $128.0(\mathrm{Ph}), 127.9(\mathrm{C}-3), 120.4(\mathrm{C}-4), 96.8(\mathrm{C}-1), 69.9(\mathrm{C}-2), 66.1\left(\mathrm{CH}_{2} \mathrm{Ph}\right), 59.7(\mathrm{C}-5), 21.2\left(\mathrm{CH}_{3} \mathrm{CO}\right)$; HRMS (ESI-TOF) m/z: $[\mathrm{M}+\mathrm{H}]^{+}$calcd for $\mathrm{C}_{14} \mathrm{H}_{17} \mathrm{O}_{4} 249.1121$; Found 249.1123.

General procedure for the synthesis of benzyl 2-O-acetyl-3-deoxy-4-sulfonate- $\beta$-L-erythropentopyranosides 14a-c. To a stirred solution of $12(0.2 \mathrm{~g}, 0.75 \mathrm{mmol})$ and pyridine $(0.18 \mathrm{~mL}, 2.25 \mathrm{mmol})$ in DCM $(10 \mathrm{~mL})$ at $0{ }^{\circ} \mathrm{C}$, a solution of a sulfonyl chloride in DCM $(2 \mathrm{~mL})$ was added dropwise. The progress of the reaction was monitored by TLC, and $0.5 \mathrm{~mL}$ of saturated aq. $\mathrm{NaHCO}_{3}$ was added to quench the reaction at $0{ }^{\circ} \mathrm{C}$. The reaction mixture was washed with saturated aq. $\mathrm{NaHCO}_{3}(5 \mathrm{~mL})$ and brine $(5 \mathrm{~mL})$. The organic layer was dried over $\mathrm{Na}_{2} \mathrm{SO}_{4}$ and concentrated in vacuo. The crude mesylate or tosylate was purified by column chromatography on silica gel to afford the desired sulfonate, after prewashing the column with $0.1 \%$ of triethylamine in hexane.

Mesylate (14a). Following the general procedure in the presence of mesyl chloride ( $0.12 \mathrm{~mL}, 1.5 \mathrm{mmol})$, a crude product was obtained, which was purified by column chromatography using 5:1 hexane/EtOAc as eluent to afford 14a ( $0.23 \mathrm{~g}, 87 \%$ yield) as a colorless oil. ${ }^{1} \mathrm{H} \mathrm{NMR}\left(300 \mathrm{MHz}, \mathrm{CDCl}_{3}\right) \delta 7.39-7.27(\mathrm{~m}, 5 \mathrm{H}$, $\mathrm{Ph}), 4.84-4.70$ (m, H-1, H-2, H-4 and $\left.\mathrm{CH}_{2} \mathrm{Ph}\right), 4.54$ (d, $\left.J=12.1 \mathrm{~Hz}, 1 \mathrm{H}, \mathrm{CH}_{2} \mathrm{Ph}\right), 4.03$ (dd, $J=13.0,1.8$ 
$\mathrm{Hz}, 1 \mathrm{H}, \mathrm{H}-5$ ), 3.82 (d, $\left.J=13.0 \mathrm{~Hz}, 1 \mathrm{H}, \mathrm{H}-5^{\prime}\right), 3.01$ (s, 3H, $\mathrm{CH}_{3} \mathrm{SO}_{2}$ ), 2.29-2.21 (bs, 2H, H-3 and H-3'), $2.07\left(\mathrm{~s}, 3 \mathrm{H}, \mathrm{CH}_{3} \mathrm{CO}\right) ;{ }^{13} \mathrm{C} \mathrm{NMR}\left(75 \mathrm{MHz}, \mathrm{CDCl}_{3}\right) \delta 179.9\left(\mathrm{CH}_{3} \mathrm{CO}\right), 136.7,128.3,127.8,127.7(\mathrm{Ph}), 95.9$ (C-1), 72.5 (C-2), $69.2\left(\mathrm{CH}_{2} \mathrm{Ph}\right), 66.2(\mathrm{C}-4), 61.5(\mathrm{C}-5), 38.4\left(\mathrm{CH}_{3} \mathrm{Ms}\right), 27.8(\mathrm{C}-3), 20.8\left(\mathrm{CH}_{3} \mathrm{CO}\right)$; HRMS (ESI-TOF) $\mathrm{m} / \mathrm{z}$ : $[\mathrm{M}+\mathrm{Na}]^{+}$calcd for $\mathrm{C}_{15} \mathrm{H}_{20} \mathrm{O}_{7} \mathrm{~S}_{1} \mathrm{Na}$ 367.0822; Found 367.0816.

Tosylate (14b). Following the general procedure in the presence of tosyl chloride $(0.29 \mathrm{~g}, 1.5 \mathrm{mmol})$, a crude product was obtained, which was purified by column chromatography using 10:1 hexane/EtOAc to afford $14 \mathbf{b}(0.267 \mathrm{~g}, 85 \%$ yield $)$ as a colorless oil. ${ }^{1} \mathrm{H} \mathrm{NMR}\left(300 \mathrm{MHz}, \mathrm{CDCl}_{3}\right) \delta 7.79(\mathrm{~d}, J=8.1 \mathrm{~Hz}, 2 \mathrm{H}$, $\mathrm{Ph}$ ), 7.45-7.18 (m, 7H, Ph), 4.84-4.66 (m, 3H, H-1, H-2 and $\mathrm{CH}_{2} \mathrm{Ph}$ ), 4.61- 4.56 (m, 2H, H-4 and $\mathrm{CH}_{2} \mathrm{Ph}$ ), $3.95(\mathrm{~d}, J=12.8 \mathrm{~Hz}, 1 \mathrm{H}, \mathrm{H}-5), 3.68$ (d, $\left.J=12.8 \mathrm{~Hz}, 1 \mathrm{H}, \mathrm{H}-5{ }^{\prime}\right), 2.45$ (s, 3H, CH3 Ts), 2.24-2.06 (m, 2H, H3 and $\left.\mathrm{H}-3^{\prime}\right), 2.04$ (s, $\left.3 \mathrm{H}, \mathrm{CH}_{3} \mathrm{CO}\right) ;{ }^{13} \mathrm{C}$ NMR $\left(75 \mathrm{MHz}, \mathrm{CDCl}_{3}\right) \delta 170.3\left(\mathrm{CH}_{3} \mathrm{CO}\right), 145.0,137.0,134.2$, 130.0, 128.6, 128.1, 128.0, 127.8 (Ph), $96.3(\mathrm{C}-1), 73.0(\mathrm{C}-2), 69.6\left(\mathrm{CH}_{2} \mathrm{Ph}\right), 66.6(\mathrm{C}-4), 61.9(\mathrm{C}-5), 28.0$ (C-3), $21.7\left(\mathrm{CH}_{3} \mathrm{Ts}\right), 21.2\left(\mathrm{CH}_{3} \mathrm{CO}\right)$; HRMS (ESI-TOF) m/z: [M+Na] $]^{+}$calcd for $\mathrm{C}_{21} \mathrm{H}_{24} \mathrm{O}_{7} \mathrm{~S}_{1} \mathrm{Na} 443.1135$; Found 443.1135.

Benzyl 2- $\boldsymbol{O}$-acetyl-3,4-anhydro- $\boldsymbol{\beta}$-L-ribopyranoside (16). Following a similar procedure as that used for the synthesis of 12, epoxide 16 was obtained starting from 10 ( $0.57 \mathrm{~g}, 0.32 \mathrm{mmol})$, TBAF $(0.63 \mathrm{~mL}, 0.63$ mmol, $1 \mathrm{M}$ in THF) in THF $(10 \mathrm{~mL})$. The crude residue was purified by column chromatography using hexane/EtOAc $(8: 1, \mathrm{v} / \mathrm{v} ; 3: 1 \mathrm{v} / \mathrm{v})$ to give $\mathbf{1 6}$ as a white solid $(0.2 \mathrm{~g}, 95 \%) .{ }^{1} \mathrm{H}$ NMR $\left(300 \mathrm{MHz}, \mathrm{CDCl}_{3}\right) \delta$ 7.51-7.24 (m, 5H, Ph), 4.95 (dd, $J=4.7,3.2 \mathrm{~Hz}, 1 \mathrm{H}, \mathrm{H}-2), 4.74$ (d, $\left.J=12.0 \mathrm{~Hz}, 1 \mathrm{H}, \mathrm{C} H_{2} \mathrm{Ph}\right), 4.65$ (d, $J=$ $3.0 \mathrm{~Hz}, 1 \mathrm{H}, \mathrm{H}-1), 4.52$ (d, $\left.J=12.0 \mathrm{~Hz}, 1 \mathrm{H}, \mathrm{CH}_{2} \mathrm{Ph}\right), 4.08$ (dd, $\left.J=13.3,1.6 \mathrm{~Hz}, 1 \mathrm{H}, \mathrm{H}-5\right), 3.98$ (d, $J=13.3$ Hz, 1H, H-5'), 3.59 (appt, $J=4.0 \mathrm{~Hz}, 1 \mathrm{H}, \mathrm{H}-3$ ), 3.34 (dd, $J=3.9,1.2 \mathrm{~Hz}, 1 \mathrm{H}, \mathrm{H}-4), 2.14$ (s, 3H, CH $3 \mathrm{CO}$ ); ${ }^{13} \mathrm{C} \mathrm{NMR}\left(75 \mathrm{MHz}, \mathrm{CDCl}_{3}\right) \delta 170.3\left(\mathrm{CH}_{3} \mathrm{CO}\right), 137.0,128.6,128.1,127.9(\mathrm{Ph}), 95.8(\mathrm{C}-1), 69.9(\mathrm{C}-2), 68.3$ $\left(\mathrm{CH}_{2} \mathrm{Ph}\right), 58.7$ (C-5), $51.2(\mathrm{C}-3), 49.8(\mathrm{C}-4), 20.9\left(\mathrm{CH}_{3} \mathrm{CO}\right)$; HRMS (ESI-TOF) m/z: [M+Na] ${ }^{+}$calcd for $\mathrm{C}_{14} \mathrm{H}_{16} \mathrm{O}_{5} \mathrm{Na} 287.0890$; Found 287.0894.

Benzyl 2-O-acetyl-3,4-O-thiocarbonyl- $\beta$-L-ribopyranoside (17). A solution of 6 (10.0 g, $35.42 \mathrm{mmol})$ and TCDI (12.6 g, $70.9 \mathrm{mmol})$ in anhydrous DCM $(500 \mathrm{~mL})$ was stirred at room temperature for $10 \mathrm{~h}$. The reaction mixture was washed with saturated aq. $\mathrm{NaHCO}_{3}(200 \mathrm{~mL})$. The organic layer was separated, and the aqueous layer was extracted with DCM. The combined organic layers were washed with brine and dried over $\mathrm{Na}_{2} \mathrm{SO}_{4}$. After removal of all the volatiles under reduced pressure, the crude residue was purified by column chromatography (3:1 DCM/hexane) to afford 17 (9.60 g, 83\% yield) as a white solid. ${ }^{1} \mathrm{H}$ NMR (300 $\mathrm{MHz}, \mathrm{CDCl}_{3}$ ) $\delta 7.43-7.30$ (m, 5H, Ph), 5.22 (dd, $\left.J=7.7,4.0 \mathrm{~Hz}, 1 \mathrm{H}, \mathrm{H}-4\right), 5.11$ (appt, $J=4.2 \mathrm{~Hz}, 1 \mathrm{H}, \mathrm{H}-$ 2), 5.00 (d, $J=4.6 \mathrm{~Hz}, 1 \mathrm{H}, \mathrm{H}-1), 4.98$ (dd, $J=7.8,1.2 \mathrm{~Hz}, 1 \mathrm{H}, \mathrm{H}-3), 4.78$ (d, $J=11.9 \mathrm{~Hz}, 1 \mathrm{H}, \mathrm{CH}{ }_{2} \mathrm{Ph}$ ), $4.60\left(\mathrm{~d}, J=11.9 \mathrm{~Hz}, 1 \mathrm{H}, \mathrm{CH}{ }_{2} \mathrm{Ph}\right), 4.10(\mathrm{dd}, J=14.1,0.7 \mathrm{~Hz}, 1 \mathrm{H}, \mathrm{H}-5), 4.01(\mathrm{dd}, J=14.1,2.0 \mathrm{~Hz}, 1 \mathrm{H}, \mathrm{H}-$ $\left.5^{\prime}\right), 2.15\left(\mathrm{~s}, 3 \mathrm{H}, \mathrm{CH} \mathrm{CO}_{3}\right) ;{ }^{13} \mathrm{C} \mathrm{NMR}\left(75 \mathrm{MHz}, \mathrm{CDCl}_{3}\right) \delta 191.2(\mathrm{CS}), 169.9\left(\mathrm{CH}_{3} \mathrm{CO}\right), 136.5,128.7,128.4$, $128.1(\mathrm{Ph}), 96.1(\mathrm{C}-1), 78.4(\mathrm{C}-4), 75.6(\mathrm{C}-3), 70.1\left(\mathrm{CH}_{2} \mathrm{Ph}\right), 66.7$ (C-2), $58.6(\mathrm{C}-5), 20.8\left(\mathrm{CH}_{3} \mathrm{CO}\right)$; HRMS (ESI-TOF) $\mathrm{m} / \mathrm{z}:[\mathrm{M}+\mathrm{H}]^{+}$calcd for $\mathrm{C}_{15} \mathrm{H}_{17} \mathrm{O}_{6} \mathrm{~S}_{1} 325.0740$; Found 325.0740 .

Benzyl $\beta$-L-glycero-pent-3-enopyranoside (18). To a stirred solution of 13 (3.75 g, $15.1 \mathrm{mmol})$ in methanol $(150 \mathrm{~mL})$ at $0{ }^{\circ} \mathrm{C}$, a $30 \% \mathrm{NaOMe}$ solution in $\mathrm{MeOH}(5.59 \mathrm{~mL}, 30.2 \mathrm{mmol})$ was added dropwise. The reaction mixture was stirred at room temperature for $2 \mathrm{~h}$. After completion of the reaction, all the volatiles were removed in vacuo. The remaining residue was partitioned between EtOAc $(100 \mathrm{~mL})$ and 
saturated aq. $\mathrm{NaHCO}_{3}(100 \mathrm{~mL})$. The water layer was extracted with EtOAc $(1 \times 50 \mathrm{~mL})$. The combined organic layers were washed with brine $(50 \mathrm{~mL})$, dried over $\mathrm{Na}_{2} \mathrm{SO}_{4}$, and concentrated in vacuo. The crude residue was purified by column chromatography on silica gel (4:1 hexane/EtOAc) to give $\mathbf{1 8}$ ( $2.86 \mathrm{~g}, 91 \%$ yield) as a colorless oil. ${ }^{1} \mathrm{H}$ NMR $\left(300 \mathrm{MHz}, \mathrm{CDCl}_{3}\right) \delta$ 7.56-7.24 (m, 5H, Ph), 6.08-5.78 (m, 2H, H-3 and H-4), 4.80 (d, $J=11.8 \mathrm{~Hz}, 1 \mathrm{H}, \mathrm{CH}_{2} \mathrm{Ph}$ ), 4.77 (d, $\left.J=2.6 \mathrm{~Hz}, 1 \mathrm{H}, \mathrm{H}-1\right), 4.58$ (d, $J=11.8 \mathrm{~Hz}, 1 \mathrm{H}, \mathrm{CH}_{2} \mathrm{Ph}$ ), 4.27-4.03 (m, 2H, H-5 and H-5'), 3.89 (bs, $1 \mathrm{H}, \mathrm{H}-2), 2.61$ (s, $1 \mathrm{H}, \mathrm{OH}) ;{ }^{13} \mathrm{C} \mathrm{NMR}\left(75 \mathrm{MHz}, \mathrm{CDCl}_{3}\right) \delta 137.4$, 128.7, 128.5, $128.0(\mathrm{Ph}), 127.9(\mathrm{C}-3), 124.6(\mathrm{C}-4), 99.9(\mathrm{C}-1), 70.0\left(\mathrm{CH}_{2} \mathrm{Ph}\right), 64.8(\mathrm{C}-2), 60.8$ (C-5); HRMS (ESI-TOF) m/z: $[\mathrm{M}+\mathrm{H}]^{+}$calcd for $\mathrm{C}_{12} \mathrm{H}_{15} \mathrm{O}_{3} 229.08353$; Found 229.0842.

Benzyl 3,4-anhydro- $\boldsymbol{\beta}$-L-ribopyranoside (19). A solution of $m$-chloroperbenzoic acid ( $m$ CPBA, 77\%, 4.12 $\mathrm{g}, 9.46 \mathrm{mmol})$ in DCM (5 mL) was added dropwise to a stirring solution of $\mathbf{1 8}$ (2.60 g, $12.6 \mathrm{mmol})$ in dry $\operatorname{DCM}(120 \mathrm{~mL})$ at $0{ }^{\circ} \mathrm{C}$. After the addition was completed, the reaction mixture was stirred at $8-9{ }^{\circ} \mathrm{C}$ for 24 h. It was then cooled to $0{ }^{\circ} \mathrm{C}$ and $20 \%$ aq. $\mathrm{Na}_{2} \mathrm{~S}_{2} \mathrm{O}_{3}(25 \mathrm{~mL})$ was added, and the stirring was continued for $2 \mathrm{~h}$. The organic layer was separated and successively washed with saturated aq. $\mathrm{NaHCO}_{3}$ and brine, dried over $\mathrm{Na}_{2} \mathrm{SO}_{4}$, and concentrated in vacuo. The residue was purified by silica gel column chromatography (3:1 hexane/EtOAc) to afford 19 (2.50 g, 89\% yield) as a white solid. ${ }^{1} \mathrm{H}$ NMR $\left(300 \mathrm{MHz}, \mathrm{CDCl}_{3}\right) \delta 7.46-$ $7.22(\mathrm{~m}, 5 \mathrm{H}, \mathrm{Ph}), 4.72$ (d, $\left.J=11.8 \mathrm{~Hz}, 1 \mathrm{H}, \mathrm{CH}_{2} \mathrm{Ph}\right), 4.58$ (d, $\left.J=2.3 \mathrm{~Hz}, 1 \mathrm{H}, \mathrm{H}-1\right), 4.49$ (d, $J=11.8 \mathrm{~Hz}, 1 \mathrm{H}$, $\mathrm{CH}_{2} \mathrm{Ph}$ ), 4.01 (dd, $\left.J=13.4,1.5 \mathrm{~Hz}, 1 \mathrm{H}, \mathrm{H}-5\right), 3.93$ (d, $\left.J=13.4 \mathrm{~Hz}, 1 \mathrm{H}, \mathrm{H}-5^{\prime}\right), 3.82$ (dd, $J=4.5,2.4 \mathrm{~Hz}, 1 \mathrm{H}$, $\mathrm{H}-2$ ), 3.50 (appt, $J=4.5 \mathrm{~Hz}, 1 \mathrm{H}, \mathrm{H}-3), 3.33$ (ddd, $J=4.2,1.5,0.6 \mathrm{~Hz}, 1 \mathrm{H}, \mathrm{H}-4) ;{ }^{13} \mathrm{C} \mathrm{NMR}\left(75 \mathrm{MHz}, \mathrm{CDCl}_{3}\right)$

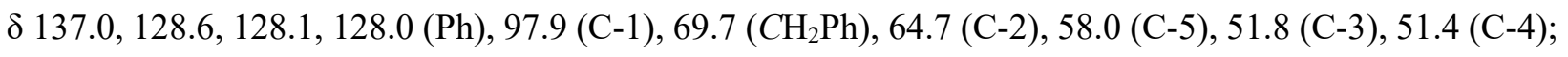
HRMS (ESI-TOF) m/z: [M+Na] $]^{+}$calcd for $\mathrm{C}_{12} \mathrm{H}_{14} \mathrm{O}_{4} \mathrm{Na} 245.0785$; Found 245.0791.

Benzyl 3,4-anhydro-2-O-methoxyethoxymethyl- $\beta$-L-ribopyranoside (20). To a stirred solution of 19 $(2.10 \mathrm{~g}, 9.45 \mathrm{mmol})$ and DIPEA $(4.90 \mathrm{~mL}, 28.4 \mathrm{mmol})$ in dry DCM $(50 \mathrm{~mL})$ at $0{ }^{\circ} \mathrm{C}$ was added MEMCl $(2.16 \mathrm{~mL}, 18.9 \mathrm{mmol})$. After the addition was completed, the reaction mixture was stirred at room tempearture for $1 \mathrm{~h}$, and later at $40^{\circ} \mathrm{C}$ for $8 \mathrm{~h}$. The reaction mixture was washed with saturated aq. $\mathrm{NaHCO}_{3}$ and brine. The organic layer was dried over $\mathrm{Na}_{2} \mathrm{SO}_{4}$ and concentrated in vacuo. The remaining residue was purified by column chromatography on silica gel (15:1 hexane/EtOAc) to afford $\mathbf{2 0}$ (2.68 g, 91\% yield) as a colorless oil. ${ }^{1} \mathrm{H}$ NMR $\left(300 \mathrm{MHz}, \mathrm{CDCl}_{3}\right) \delta 7.39-7.20(\mathrm{~m}, 5 \mathrm{H}, \mathrm{Ph}), 4.89\left(\mathrm{~s}, 2 \mathrm{H}, \mathrm{OCH} \mathrm{H}_{2} \mathrm{O}\right), 4.75(\mathrm{~d}, J=$ $\left.11.9 \mathrm{~Hz}, 1 \mathrm{H}, \mathrm{CH}_{2} \mathrm{Ph}\right), 4.61$ (d, $\left.J=4.0 \mathrm{~Hz}, 1 \mathrm{H}, \mathrm{H}-1\right), 4.50$ (d, $J=11.8 \mathrm{~Hz}, 1 \mathrm{H}, \mathrm{CH}_{2} \mathrm{Ph}$ ), 4.07 (dd, $J=13.4$, $2.3 \mathrm{~Hz}, 1 \mathrm{H}, \mathrm{H}-5), 3.92\left(\mathrm{~d}, J=13.4 \mathrm{~Hz}, 1 \mathrm{H}, \mathrm{H}-5^{\prime}\right), 3.92-3.79\left(\mathrm{~m}, 2 \mathrm{H}, \mathrm{H}-2\right.$ and $\left.\mathrm{OCH}_{2} \mathrm{CH}_{2} \mathrm{O}\right), 3.76-3.63(\mathrm{~m}$, $1 \mathrm{H}, \mathrm{OCH}_{2} \mathrm{CH}_{2} \mathrm{O}$ ), 3.56-3.47 (m, 3H, H-3 and $\mathrm{OCH}_{2} \mathrm{CH}_{2} \mathrm{O}$ ), 3.39-3.31 (m, $\left.1 \mathrm{H}, \mathrm{H}-4\right), 3.35$ (s, 3H, OCH $\mathrm{H}_{3}$; ${ }^{13} \mathrm{C}$ NMR $\left(75 \mathrm{MHz}, \mathrm{CDCl}_{3}\right) \delta 137.1,128.3,127.7,127.7(\mathrm{Ph}), 97.6\left(\mathrm{OCH}_{2} \mathrm{O}\right), 95.1(\mathrm{C}-1), 71.7(\mathrm{C}-2), 71.6$ $\left(\mathrm{OCH}_{2} \mathrm{CH}_{2} \mathrm{O}\right), 69.9\left(\mathrm{CH}_{2} \mathrm{Ph}\right), 67.1\left(\mathrm{OCH}_{2} \mathrm{CH}_{2} \mathrm{O}\right), 59.9(\mathrm{C}-5), 58.8\left(\mathrm{OCH}_{3}\right), 51.9(\mathrm{C}-3), 51.7(\mathrm{C}-4)$; $[\mathrm{M}+\mathrm{Na}]^{+}$ calcd for $\mathrm{C}_{16} \mathrm{H}_{22} \mathrm{O}_{6} \mathrm{Na} 333.1309$; Found 333.1317.

Benzyl 4-deoxy-2-O-(2-methoxyethoxymethyl)-4-(thymid-1-yl)- $\alpha$-D-lyxopyranoside (21). To a stirred suspension of $20(1.90 \mathrm{~g}, 6.12 \mathrm{mmol})$ and thymine $(2.32 \mathrm{~g}, 18.4 \mathrm{mmol})$ in dry DMF $(50 \mathrm{~mL})$ at $0{ }^{\circ} \mathrm{C}$ was slowly added DBU ( $3 \mathrm{~mL}, 18.87 \mathrm{mmol})$. The suspension was stirred at room temperature for $30 \mathrm{~min}$ until all the solid dissolved and then heated at $80{ }^{\circ} \mathrm{C}$ for $8 \mathrm{~h}$. After removal of all the volatiles under reduced pressure, the remaining syrup was dissolved in EtOAc and washed with saturated aq. $\mathrm{NaHCO}_{3}$. The organic phase was collected, dried over $\mathrm{Na}_{2} \mathrm{SO}_{4}$ and concentrated in vacuo. The product was purified by silica gel 
column chromatography (100:2 DCM/Methanol) to afford 21 (2.27 g, 85\% yield) as a colorless oil. ${ }^{1} \mathrm{H}$ NMR (500 MHz, $\left.\mathrm{CDCl}_{3}\right) \delta 9.74(\mathrm{~s}, 1 \mathrm{H}, \mathrm{NH}), 7.35(\mathrm{~m}, 5 \mathrm{H}, \mathrm{Ph}), 7.03(\mathrm{~s}, 1 \mathrm{H}, \mathrm{H}-6), 5.02(\mathrm{~d}, J=1.5 \mathrm{~Hz}, 1 \mathrm{H}$, H-1'), $4.87\left(\mathrm{~d}, J=7.2 \mathrm{~Hz}, 1 \mathrm{H}, \mathrm{OCH}_{2} \mathrm{O}\right), 4.80\left(\mathrm{~d}, J=7.2 \mathrm{~Hz}, 1 \mathrm{H}, \mathrm{OCH}_{2} \mathrm{O}\right), 4.76\left(\mathrm{~d}, J=11.7 \mathrm{~Hz}, 1 \mathrm{H}, \mathrm{CH}_{2} \mathrm{Ph}\right)$, 4.54 (d, $J=11.7 \mathrm{~Hz}, 1 \mathrm{H}, \mathrm{CH}_{2} \mathrm{Ph}$ ), 4.28 (appt, $J=7.9 \mathrm{~Hz}, 1 \mathrm{H}, \mathrm{H}-3^{\prime}$ ), 3.98 (appt, $J=2.4 \mathrm{~Hz}, 1 \mathrm{H}, \mathrm{H}-2^{\prime}$ ), 3.89 $3.66\left(\mathrm{~m}, 4 \mathrm{H}, \mathrm{H}-5^{\prime}, \mathrm{H}-5^{\prime}\right.$ and $\left.\mathrm{OCH}_{2} \mathrm{CH}_{2} \mathrm{O}\right), 3.51$ (s, $\left.2 \mathrm{H}, \mathrm{OCH}_{2} \mathrm{CH}_{2} \mathrm{O}\right), 3.34\left(\mathrm{~s}, 3 \mathrm{H}, \mathrm{OCH}_{3}\right), 1.88(\mathrm{~s}, 3 \mathrm{H}, \mathrm{T}$ $\left.\mathrm{CH}_{3}\right) ;{ }^{13} \mathrm{C}$ NMR $\left(126 \mathrm{MHz}, \mathrm{CDCl}_{3}\right) \delta 163.9$ (C-4), 151.8 (C-2), 137.1 (C-6), 137.0, 128.6, 128.1, 127.9 $(\mathrm{Ph}), 111.0(\mathrm{C}-5), 98.3\left(\mathrm{C}-1^{\prime}\right), 96.7\left(\mathrm{OCH}_{2} \mathrm{O}\right), 78.9\left(\mathrm{C}-2^{\prime}\right), 71.5\left(\mathrm{OCH}_{2} \mathrm{CH}_{2} \mathrm{O}\right), 69.4\left(\mathrm{CH}_{2} \mathrm{Ph}\right), 67.8$ $\left(\mathrm{OCH}_{2} \mathrm{CH}_{2} \mathrm{O}\right), 65.9\left(\mathrm{C}-3^{\prime}\right), 60.2\left(\mathrm{C}-5^{\prime}\right), 58.9\left(\mathrm{OCH}_{3}\right), 54.7\left(\mathrm{C}-4^{\prime}\right), 12.5\left(\mathrm{~T} \mathrm{CH}_{3}\right)$; HRMS (ESI-TOF) m/z: $[\mathrm{M}+\mathrm{Na}]^{+}$calcd for $\mathrm{C}_{21} \mathrm{H}_{28} \mathrm{~N}_{2} \mathrm{O}_{8} \mathrm{Na} 459.1738$; Found 459.1731 .

Benzyl 3,4-dideoxy-2-O-(2-methoxyethoxymethyl)-4-(thymid-1-yl)- $\alpha$-D-threo-pentopyranoside (22). To a solution of $21(1.40 \mathrm{~g}, 2.6 \mathrm{mmol})$ and DMAP $(100 \mathrm{mg}, 0.8 \mathrm{mmol})$ in anhydrous DCM $(30 \mathrm{~mL})$ was added TCDI ( $940 \mathrm{mg}, 5.20 \mathrm{mmol})$ at room temperature. The reaction mixture was stirred at $40{ }^{\circ} \mathrm{C}$ overnight. It was then washed with brine, dried over $\mathrm{Na}_{2} \mathrm{SO}_{4}$, and concentrated under reduced pressure. The resulting residue was dissolved in toluene $(50 \mathrm{~mL})$, and AIBN $(170 \mathrm{mg}, 1.10 \mathrm{mmol})$ was added followed by tributyltin hydride $(1.70 \mathrm{~mL}, 4.20 \mathrm{mmol})$. The reaction mixture was refluxed for $1 \mathrm{~h}$. After removal of all the volatiles under reduced pressure, the crude residue was purified by column chromatography on silica gel (gradient $\mathrm{CH}_{2} \mathrm{Cl}_{2} / \mathrm{MeOH}, 100: 0$, v/v; 100:2, v/v; 30:1, v/v) to afford 22 (1.10 g, 83\% yield over two steps) as a colorless oil. ${ }^{1} \mathrm{H}$ NMR $\left(300 \mathrm{MHz}, \mathrm{CDCl}_{3}\right) \delta 9.95(\mathrm{~s}, 1 \mathrm{H}, \mathrm{NH}), 7.47-7.19(\mathrm{~m}, 5 \mathrm{H}, \mathrm{Ph}), 7.06(\mathrm{~s}$, $1 \mathrm{H}, \mathrm{H}-6), 5.10-4.89$ (m, 1H, H-4'), 4.80 (m, 4H, OCH $\mathrm{O}_{2} \mathrm{O}, \mathrm{CH}_{2} \mathrm{Ph}$ and $\left.\mathrm{H}-1^{\prime}\right), 4.59$ (d, $J=11.1 \mathrm{~Hz}, 1 \mathrm{H}$, $\mathrm{CH}_{2} \mathrm{Ph}$ ), 3.93 (bs, 1H, H-2'), 3.85-3.64 (m, 4H, H-5', H-5', $\mathrm{OCH}_{2} \mathrm{CH}_{2} \mathrm{O}$ ), 3.51 (dd, $J=5.4,3.6 \mathrm{~Hz}, 2 \mathrm{H}$, $\left.\mathrm{OCH}_{2} \mathrm{CH}_{2} \mathrm{O}\right), 3.34\left(\mathrm{~s}, 3 \mathrm{H}, \mathrm{OCH}_{3}\right), 2.30\left(\mathrm{td}, J=12.7,2.8 \mathrm{~Hz}, 1 \mathrm{H}, \mathrm{H}-3^{\prime}\right), 2.03(\mathrm{dt}, J=12.6,3.1 \mathrm{~Hz}, 1 \mathrm{H}, \mathrm{H}-$ 3"), 1.90 (s, 3H, T CH$) ;{ }^{13} \mathrm{C} \mathrm{NMR}\left(75 \mathrm{MHz}, \mathrm{CDCl}_{3}\right) \delta 164.3$ (C-4), $151.4(\mathrm{C}-2), 137.5(\mathrm{C}-6), 137.0,128.8$, 128.20, $128.25(\mathrm{Ph}), 111.2(\mathrm{C}-5), 96.7\left(\mathrm{OCH}_{2} \mathrm{O}\right), 95.2\left(\mathrm{C}-1^{\prime}\right), 73.0\left(\mathrm{C}-2^{\prime}\right), 71.9\left(\mathrm{OCH}_{2} \mathrm{CH}_{2} \mathrm{O}\right), 69.5\left(\mathrm{CH}_{2} \mathrm{Ph}\right)$, $67.5\left(\mathrm{OCH}_{2} \mathrm{CH}_{2} \mathrm{O}\right), 61.3\left(\mathrm{C}-5^{\prime}\right), 59.2\left(\mathrm{OCH}_{3}\right), 47.6\left(\mathrm{C}-4^{\prime}\right), 29.2\left(\mathrm{C}-3^{\prime}\right), 12.8\left(\mathrm{~T} \mathrm{CH}_{3}\right)$; HRMS (ESI-TOF) $\mathrm{m} / \mathrm{z}:[\mathrm{M}+\mathrm{H}]^{+}$calcd for $\mathrm{C}_{21} \mathrm{H}_{29} \mathrm{~N}_{2} \mathrm{O}_{7} 421.1969$; Found 421.1964 .

Benzyl 3,4-dideoxy-4-(thymid-1-yl)- $\alpha / \beta$-D-threo-pentopyranoside (23). Hydrochloric acid in 1,4dioxane (4 M, $8 \mathrm{~mL}$ ) was added dropwise to a solution of $22(1.20 \mathrm{~g}, 2.86 \mathrm{mmol})$ in 1,4-dioxane $(24 \mathrm{~mL})$, and the reaction mixture was stirred at room temperature for $8 \mathrm{~h}$. After removal of all the volatiles under reduced pressure, the remaining syrup was co-evaporated with triethylamine $(5 \mathrm{~mL})$ once and then subjected to column chromatography on silica gel to give $\alpha / \beta$-23. Data for the $\alpha-23$ : $(0.72 \mathrm{~g}, 75 \%$ yield); ${ }^{1} \mathrm{H}$ NMR (600 MHz, $\mathrm{CDCl}_{3}$ ) $\delta 9.96$ (s, 1H, NH), 7.46-7.29 (m, 5H, Ph), 7.12 (d, J=1.1 Hz, 1H, H-6), 5.13-4.97 (m, 1H, H-4'), 4.80 (d, $\left.J=11.9 \mathrm{~Hz}, 1 \mathrm{H}, \mathrm{CH}_{2} \mathrm{Ph}\right), 4.71$ (d, $\left.J=2.4 \mathrm{~Hz}, 1 \mathrm{H}, \mathrm{H}-1^{\prime}\right), 4.57$ (d, $J=11.9$ $\mathrm{Hz}, 1 \mathrm{H}, \mathrm{CH}_{2} \mathrm{Ph}$ ), 3.96 (bs, 1H, H-2'), 3.82 (m, 2H, H-5' and H-5"), 3.67 (d, $\left.J=6.1 \mathrm{~Hz}, 1 \mathrm{H}, \mathrm{OH}\right), 2.27$ (appt d, $\left.J=13.0,3.3 \mathrm{~Hz}, 1 \mathrm{H}, \mathrm{H}-3^{\prime}\right), 2.01$ (d appt, $\left.J=13.3,4.3 \mathrm{~Hz}, 1 \mathrm{H}, \mathrm{H}-3^{\prime}\right), 1.88$ (d, $J=1.1 \mathrm{~Hz}, 3 \mathrm{H}, \mathrm{T} \mathrm{CH}$ ); ${ }^{13} \mathrm{C}$ NMR $\left(151 \mathrm{MHz}, \mathrm{CDCl}_{3}\right) \delta 163.8(\mathrm{C}-4), 151.3$ (C-2), $137.0(\mathrm{C}-6), 136.6,128.5,128.0,128.0(\mathrm{Ph}), 111.0$ (C-5), $98.3\left(\mathrm{C}-1^{\prime}\right), 69.5\left(\mathrm{CH}_{2} \mathrm{Ph}\right), 67.0\left(\mathrm{C}-2^{\prime}\right), 61.4\left(\mathrm{C}-5^{\prime}\right), 46.8$ (C-4'), $30.8\left(\mathrm{C}-3^{\prime}\right), 12.5\left(\mathrm{~T} \mathrm{CH}_{3}\right)$; HRMS (ESI-TOF) $\mathrm{m} / \mathrm{z}$ : $[\mathrm{M}+\mathrm{H}]^{+}$calcd for $\mathrm{C}_{17} \mathrm{H}_{21} \mathrm{~N}_{2} \mathrm{O}_{5} 333.1445$; Found 333.1443 .

Data for the $\beta-23$ : (48 mg, $5 \%$ yield); ${ }^{1} \mathrm{H}$ NMR $\left(500 \mathrm{MHz}, \mathrm{CDCl}_{3}\right) \delta 9.52(\mathrm{~s}, 1 \mathrm{H}, \mathrm{NH}), 7.61(\mathrm{~d}, J=1.2 \mathrm{~Hz}$, 1H, H-6), 7.42-7.29 (m, 5H, Ph), 4.92 (d, $\left.J=2.9 \mathrm{~Hz}, 1 \mathrm{H}, \mathrm{H}-1^{\prime}\right), 4.84$ (d, $\left.J=11.9 \mathrm{~Hz}, 1 \mathrm{H}, \mathrm{CH}_{2} \mathrm{Ph}\right), 4.76-$ 
4.52 (m, 2H, CH$\left.H_{2} \mathrm{Ph}, \mathrm{H}-4^{\prime}\right), 4.13$ (dd, $\left.J=13.0,3.9 \mathrm{~Hz}, 1 \mathrm{H}, \mathrm{H}-5^{\prime}\right), 3.94-3.73$ (m, 2H, H-5', H-2'), 2.48 (d, $J$ $=8.3 \mathrm{~Hz}, 1 \mathrm{H}, \mathrm{OH}), 2.21-2.17\left(\mathrm{dT}, J=12.9,3.8 \mathrm{~Hz}, 1 \mathrm{H}, \mathrm{H}-3^{\prime}\right), 2.15-2.09\left(\mathrm{~m}, 1 \mathrm{H}, \mathrm{H}-3^{\prime \prime}\right), 1.95-1.86(\mathrm{~d}, J$ $=1.2 \mathrm{~Hz}, 3 \mathrm{H}, \mathrm{T} \mathrm{CH}) ;{ }^{13} \mathrm{C}$ NMR $\left(126 \mathrm{MHz}, \mathrm{CDCl}_{3}\right) \delta 164.0(\mathrm{C}-4), 150.9(\mathrm{C}-2), 138.2,136.4(\mathrm{C}-6), 128.5$, 128.1, $128.0(\mathrm{Ph}), 110.6(\mathrm{C}-5), 97.3\left(\mathrm{C}-1^{\prime}\right), 69.9\left(\mathrm{CH}_{2} \mathrm{Ph}\right), 64.4\left(\mathrm{C}-2^{\prime}\right), 61.1\left(\mathrm{C}-5^{\prime}\right), 51.2\left(\mathrm{C}-4^{\prime}\right), 31.1\left(\mathrm{C}-3^{\prime}\right)$, $12.5\left(\mathrm{~T} \mathrm{CH}_{3}\right)$.

Benzyl 2-O-benzoyl-3,4-dideoxy-4-(thymid-1-yl)- $\alpha / \beta$-D-threo-pentopyranoside (24). To a solution of $\alpha / \beta$-23 (400 mg, $1.20 \mathrm{mmol})$ in pyridine $(15 \mathrm{~mL})$ at $0{ }^{\circ} \mathrm{C}$, benzoyl chloride $(0.24 \mathrm{~mL}, 1.81 \mathrm{mmol})$ was added dropwise. The reaction mixture was stirred at $0{ }^{\circ} \mathrm{C}$ for $2 \mathrm{~h}$. After removal of all the volatiles under reduced pressure, the remaining residue was partitioned between $\mathrm{DCM}(30 \mathrm{~mL})$ and saturated aq. $\mathrm{NaHCO}_{3}(20 \mathrm{~mL})$. The aqueous layer was extracted again with DCM $(20 \mathrm{~mL})$. The combined organic layers were washed with saturated aq. $\mathrm{NaHCO}_{3}$ and brine, dried over $\mathrm{Na}_{2} \mathrm{SO}_{4}$, and concentrated in vacuo. The residue was purified by silica gel column chromatography (3:1 hexane/EtOAc) to afford $\alpha / \beta-24(483 \mathrm{mg}, 92 \%$ yield) as a colorless oil.

Data for $\alpha$-24: ${ }^{1} \mathrm{H}$ NMR (600 MHz, $\left.\mathrm{CDCl}_{3}\right) \delta 9.17(\mathrm{~s}, 1 \mathrm{H}, \mathrm{NH}), 8.09$ (m, 2H, Ph), 7.64-7.30 (m, 8H, Ph), $7.04(\mathrm{~d}, J=1.2 \mathrm{~Hz}, 1 \mathrm{H}, \mathrm{H}-6), 5.31$ (td, $\left.J=3.5,3.2 \mathrm{~Hz}, 1 \mathrm{H}, \mathrm{H}-2^{\prime}\right), 5.09$ (tt, $\left.J=11.7,5.01 \mathrm{H}, \mathrm{H}-4^{\prime}\right), 4.92$ (d, $\left.J=1.6 \mathrm{~Hz}, 1 \mathrm{H}, \mathrm{H}-1^{\prime}\right), 4.82\left(\mathrm{~d}, J=11.9 \mathrm{~Hz}, 1 \mathrm{H}, \mathrm{CH}_{2} \mathrm{Ph}\right), 4.62\left(\mathrm{~d}, J=11.9 \mathrm{~Hz}, 1 \mathrm{H}, \mathrm{CH} \mathrm{H}_{2} \mathrm{Ph}\right), 3.87$ (appt, $J=$ $\left.10.8 \mathrm{~Hz}, 1 \mathrm{H}, \mathrm{H}-5^{\prime}\right), 3.81$ (ddd, $\left.J=10.7,5.0,1.9 \mathrm{~Hz}, 1 \mathrm{H}, \mathrm{H}-5^{\prime}\right), 2.49$ (td, $\left.J=13.2,3.2 \mathrm{~Hz}, 1 \mathrm{H}, \mathrm{H}-3^{\prime}\right), 2.26-$ $2.04\left(\mathrm{dt}, J=13.8,3.6 \mathrm{~Hz}, 1 \mathrm{H}, \mathrm{H}-3^{\prime \prime}\right), 1.92\left(\mathrm{~d}, J=1.2 \mathrm{~Hz}, 3 \mathrm{H}, \mathrm{T} \mathrm{CH}{ }_{3}\right) ;{ }^{13} \mathrm{C} \mathrm{NMR}\left(151 \mathrm{MHz}, \mathrm{CDCl}_{3}\right) \delta 165.5$ (PhCO), 163.5 (C-4), 150.8 (C-2), 136.8, 136.1 (C-6), 133.4, 129.8, 129.4(Ar-C), 128.6, 128.5, 128.3, 128.1, $127.9(\mathrm{Ph}), 111.3(\mathrm{C}-5), 95.0\left(\mathrm{C}-1^{\prime}\right), 69.5\left(\mathrm{CH}_{2} \mathrm{Ph}\right), 69.1\left(\mathrm{C}-2^{\prime}\right), 60.7\left(\mathrm{C}-5^{\prime}\right), 47.0\left(\mathrm{C}-4^{\prime}\right), 28.2\left(\mathrm{C}-3^{\prime}\right), 12.5$ ( $\mathrm{T} \mathrm{CH}_{3}$ ); HRMS (ESI-TOF) m/z: [M+H] $]^{+}$calcd for $\mathrm{C}_{24} \mathrm{H}_{25} \mathrm{~N}_{2} \mathrm{O}_{6} 437.1707$; Found 437.1700.

Data for $\beta$-24: ${ }^{1} \mathrm{H}$ NMR $\left(300 \mathrm{MHz}, \mathrm{CDCl}_{3}\right) \delta 9.36(\mathrm{~s}, 1 \mathrm{H}, \mathrm{NH}), 8.18-7.72(\mathrm{~m}, 2 \mathrm{H}, \mathrm{Ph}), 7.46(\mathrm{~m}, 3 \mathrm{H}, \mathrm{Ph})$, $7.19(\mathrm{~m}, 5 \mathrm{H}, \mathrm{Ph}), 5.29$ (dd, $\left.J=6.9,9.9 \mathrm{~Hz}, 1 \mathrm{H}, \mathrm{H}-2^{\prime}\right), 5.01$ (td, $\left.J=5.9,10.9 \mathrm{~Hz}, 1 \mathrm{H}, \mathrm{H}-4^{\prime}\right), 4.85$ (d, $J=$ $\left.12.4 \mathrm{~Hz}, 1 \mathrm{H}, \mathrm{CH}_{2} \mathrm{Ph}\right), 4.63$ (d, $\left.J=12.4 \mathrm{~Hz}, 1 \mathrm{H}, \mathrm{CH}_{2} \mathrm{Ph}\right), 4.58$ (d, $\left.J=7.4 \mathrm{~Hz}, 1 \mathrm{H}, \mathrm{H}-1^{\prime}\right), 4.11$ (dd, $J=3.7$, $\left.11.1 \mathrm{~Hz}, 1 \mathrm{H}, \mathrm{H}-5^{\prime}\right), 3.60$ (appt, $\left.J=11.0 \mathrm{~Hz}, 1 \mathrm{H}, \mathrm{H}-5^{\prime \prime}\right), 2.18-1.74$ (m, 5H, , H-3', , H-3" and $\mathrm{T} \mathrm{CH}$ ); ${ }^{13} \mathrm{C}$ NMR (75 MHz, $\left.\mathrm{CDCl}_{3}\right) \delta 165.4$ (PhCO), 163.6 (C-4), 151.4 (C-2), 136.8 , 136.0 (C-6), 133.5, 130.0, 129.0, 128.5, 128.4, 127.9, $127.9(\mathrm{Ph}), 111.7(\mathrm{C}-5), 100.6\left(\mathrm{C}-1^{\prime}\right), 71.1\left(\mathrm{C}-2^{\prime}\right), 70.3\left(\mathrm{CH}_{2} \mathrm{Ph}\right), 62.6\left(\mathrm{C}-5^{\prime}\right), 54.0(\mathrm{C}-$ $\left.4^{\prime}\right), 30.8\left(\mathrm{C}-3^{\prime}\right), 12.7\left(\mathrm{~T} \mathrm{CH}_{3}\right)$.

2-O-Benzoyl-3,4-dideoxy-4-(thymid-1-yl)- $\alpha$-D-threo-pentopyranose (25). To a solution of $\alpha / \beta$-24 (300 $\mathrm{mg}, 0.69 \mathrm{mmol})$ in ethanol $(10 \mathrm{~mL}), \mathrm{Pd} / \mathrm{C}(366 \mathrm{mg}, 0.34 \mathrm{mmol})$ and cyclohexene $(1.39 \mathrm{~mL}, 13.8 \mathrm{mmol})$ were added. The reaction mixture was stirred at $80^{\circ} \mathrm{C}$ for $6 \mathrm{~h}$. It was then cooled and filtered through a pad of Celite to give 25 (209 mg, 88\%) as a white solid. ${ }^{1} \mathrm{H}$ NMR (600 MHz, DMSO-d6) $\delta 11.3$ (s, 1H, NH), 8.01 (m, 2H, Ph), 7.72-7.68 (m, 1H, Ph), 7.65 (d, $J=1.2 \mathrm{~Hz}, 1 \mathrm{H}, \mathrm{H}-6), 7.59-7.56$ (m, 2H, Ph), 7.00 (d, $J$ $=4.7 \mathrm{~Hz}, 1 \mathrm{H}, \mathrm{OH}), 5.04\left(\mathrm{td}, J=4.7,3.6 \mathrm{~Hz}, 1 \mathrm{H}, \mathrm{H}-2^{\prime}\right), 5.01\left(\mathrm{dd}, J=4.7,1.4 \mathrm{~Hz}, 1 \mathrm{H}, \mathrm{H}-1^{\prime}\right), 4.79$ (tt, $J=$ 10.7, $4.3 \mathrm{~Hz}, 1 \mathrm{H}, \mathrm{H}-4^{\prime}$ ), 4.03 (appt, $J=10.8 \mathrm{~Hz}, 1 \mathrm{H}, \mathrm{H}-5^{\prime}$ ), 3.59 (ddd, $J=10.5,4.4,1.7 \mathrm{~Hz}, 1 \mathrm{H}, \mathrm{H}-5^{\prime \prime}$ ), 2.59 $\left(\mathrm{td}, J=13.4,3.1 \mathrm{~Hz}, 1 \mathrm{H}, \mathrm{H}-3^{\prime}\right), 2.01$ (dt, $\left.J=13.4,4.5 \mathrm{~Hz}, 1 \mathrm{H}, \mathrm{H}-3^{\prime}\right), 1.79$ (d, $\left.J=0.9 \mathrm{~Hz}, 3 \mathrm{H}, \mathrm{T} \mathrm{CH}\right) ;{ }^{13} \mathrm{C}$ NMR (151 MHz, DMSO-d6) $\delta 165.0$ (PhCO), 163.8 (C-4), 151.0 (C-2), 138.0, 133.7 (C-6), 129.7, 129.4, 129.3, 128.9, $128.8(\mathrm{Ph}), 109.2(\mathrm{C}-5), 89.7\left(\mathrm{C}-1^{\prime}\right), 70.9\left(\mathrm{C}-2^{\prime}\right), 59.8\left(\mathrm{C}-5^{\prime}\right), 47.3\left(\mathrm{C}-4^{\prime}\right), 27.3\left(\mathrm{C}-3^{\prime}\right), 12.1$ ( $\mathrm{CH}_{3}$ ); HRMS (ESI-TOF) m/z: $[\mathrm{M}+\mathrm{H}]^{+}$calcd for $\mathrm{C}_{17} \mathrm{H}_{19} \mathrm{~N}_{2} \mathrm{O}_{6}$ 347.1238; Found 347.1241. 
General procedure for the synthesis of trichloroacetimidate and $\mathrm{N}$-phenyltrifluoroacetimidate glycosylation donors 26a and 26b. To a stirred solution of 25 (100 mg, $0.29 \mathrm{mmol})$ and $\mathrm{K}_{2} \mathrm{CO}_{3}(44 \mathrm{mg}$, $0.32 \mathrm{mmol})$ in acetone $(3 \mathrm{~mL})$ at $0{ }^{\circ} \mathrm{C}, N$-aryltrifluoroacetimidoyl chloride $(120 \mathrm{mg}, 0.58 \mathrm{mmol})$ or trichloroacetonitrile $(0.06 \mathrm{~mL}, 0.58 \mathrm{mmol})$ was added dropwise. The reaction was monitored by TLC for completion. The reaction mixture was then filtered through a pad of Celite and concentrated under reduce pressure to afford the corresponding crude donor.

Data for 26a: ${ }^{1} \mathrm{H}$ NMR $\left(300 \mathrm{MHz},\left(\mathrm{CD}_{3}\right)_{2} \mathrm{CO}\right) \delta 9.27(\mathrm{~s}, 1 \mathrm{H}, \mathrm{NH}), 8.00-7.97(\mathrm{~m}, 2 \mathrm{H}, \mathrm{Ph}), 7.59-7.50(\mathrm{~m}$, 1H, Ph), 7.42 (m, 2H, Ph), 7.31 (s, 1H, H-6), 6.21 (bs, 1H, H-1' ), 5.31 (bs, 1H, H-2'), 4.89 (m, 1H, H-4'), $4.14\left(\mathrm{t}, J=10.8 \mathrm{~Hz}, 1 \mathrm{H}, \mathrm{H}-5^{\prime}\right), 3.88\left(\mathrm{~m}, 1 \mathrm{H}, \mathrm{H}-5^{\prime \prime}\right), 2.76$ (t, $\left.J=13.3 \mathrm{~Hz}, 1 \mathrm{H}, \mathrm{H}-3^{\prime}\right), 2.29$ (d, $J=13.6 \mathrm{~Hz}$, $\left.1 \mathrm{H}, \mathrm{H}-3^{\prime}\right), 1.68\left(\mathrm{~s}, 3 \mathrm{H}, \mathrm{T} \mathrm{CH} \mathrm{H}_{3}\right),{ }^{13} \mathrm{C}$ NMR $\left(75 \mathrm{MHz},\left(\mathrm{CD}_{3}\right)_{2} \mathrm{CO}\right) \delta 165.8(\mathrm{C}-4), 151.8(\mathrm{C}-2), 138.6,134.4$ (C-6), 130.5, 129.5 (Ph), 110.9 (C-5), $93.9\left(\mathrm{C}-1^{\prime}\right), 69.4\left(\mathrm{C}-2^{\prime}\right), 63.1\left(\mathrm{C}-5^{\prime}\right), 49.2\left(\mathrm{C}-4^{\prime}\right), 28.5\left(\mathrm{C}-3^{\prime}\right), 12.4$ ( $\left.\mathrm{CH}_{3}\right)$.

Data for 26b: ${ }^{1} \mathrm{H}$ NMR $\left(300 \mathrm{MHz}, \mathrm{CDCl}_{3}\right) \delta 8.18-8.00(\mathrm{~m}, 2 \mathrm{H}, \mathrm{Ph}), 7.61(\mathrm{~m}, 1 \mathrm{H}, \mathrm{Ph}), 7.48(\mathrm{~m}, \mathrm{Ph}), 7.32$ (m, 2H, Ph), 7.13 (m, 1H, Ph), 6.96 (bs, 1H, H-6), 6.88 (d, J=7.7 Hz, 2H, Ph), 6.27 (bs, 1H, H-1'), 5.46 (bs, 1H, H-2'), 5.12 (m, 1H, H-4'), 3.95 (bs, 2H, H-5', H-5'), 2.54 (m, 1H, H-3'), 2.31 (m, 1H, H-3'), 1.96 $(\mathrm{d}, J=1.0 \mathrm{~Hz}, 3 \mathrm{H}, \mathrm{T} \mathrm{CH}) ;{ }^{13} \mathrm{C}$ NMR $\left(75 \mathrm{MHz}, \mathrm{CDCl}_{3}\right) \delta 165.4,163.1$ (C-4), 150.7(C-2), 143.2, 135.9, 133.9 (C-3), 130.1, 129.2, 129.0, 128.8, $124.9(\mathrm{Ph}), 119.7\left(\mathrm{CF}_{3}\right), 111.9$ (C-5), $92.4\left(\mathrm{C}-1^{\prime}\right), 67.9$ (C-2'), 62.4 (C-5'), $47.0\left(\mathrm{C}-4^{\prime}\right), 28.3\left(\mathrm{C}-3^{\prime}\right), 12.7\left(\mathrm{~T} \mathrm{CH}_{3}\right) ;[\mathrm{M}+\mathrm{Na}]^{+}$calcd for $\mathrm{C}_{25} \mathrm{H}_{22} \mathrm{~F}_{3} \mathrm{~N}_{3} \mathrm{O}_{6} \mathrm{Na}$ 540.1353; Found 540.1362 .

Acetyl 2-O-benzoyl-3,4-dideoxy-4-(thymid-1-yl)- $\alpha$-D-threo-pentopyranoside (26c). To a solution of 25 $(150 \mathrm{mg}, 0.43 \mathrm{mmol})$ in pyridine $(5 \mathrm{~mL})$ at $0{ }^{\circ} \mathrm{C}$, acetic anhydride $(0.082 \mathrm{~mL}, 0.87 \mathrm{mmol})$ was added dropwise. The reaction mixture was slowly warmed to room temperature and left stirring for $2 \mathrm{~h}$. After removal of all the volatiles under reduced pressure, the remaining residue was taken up with DCM $(10 \mathrm{~mL})$, and $10 \mathrm{~mL}$ of saturated aq. $\mathrm{NaHCO}_{3}$ was added. The aqueous layer was then extracted with $\mathrm{DCM}(2 \times 10$ $\mathrm{mL})$. The combined organic layers were washed with saturated aq. $\mathrm{NaHCO}_{3}(5 \mathrm{~mL})$ and brine $(5 \mathrm{~mL})$, dried over $\mathrm{Na}_{2} \mathrm{SO}_{4}$, and concentrated in vacuo. The residue was purified by silica gel column chromatography (2:1 hexane/EtOAc) to give 26c (142.8 $\mathrm{mg}, 85 \%)$ as a colorless oil. ${ }^{1} \mathrm{H} \mathrm{NMR}\left(600 \mathrm{MHz}, \mathrm{CDCl}_{3}\right) \delta 9.26(\mathrm{~s}$, $1 \mathrm{H}, \mathrm{NH}), 8.17-8.01$ (m, 2H, Ph), 7.63-7.54 (m, 1H, Ph), 7.53-7.40 (m, 2H, Ph), $7.08(\mathrm{~d}, J=1.2 \mathrm{~Hz}, 1 \mathrm{H}$, H-6), 6.10 (d, $\left.J=1.9 \mathrm{~Hz}, 1 \mathrm{H}, \mathrm{H}-1^{\prime}\right), 5.28$ (td, $\left.J=3.4,1.9 \mathrm{~Hz}, 1 \mathrm{H}, \mathrm{H}-2^{\prime}\right), 4.93$ (tt, $J=10.4,4.3 \mathrm{~Hz}, 1 \mathrm{H}, \mathrm{H}-$ 4'), 4.02 (appt, $J=10.8 \mathrm{~Hz}, 1 \mathrm{H}, \mathrm{H}-5^{\prime}$ ), 3.92 (ddd, $\left.J=11.0,4.7,1.8 \mathrm{~Hz}, 1 \mathrm{H}, \mathrm{H}-5^{\prime \prime}\right), 2.61$ (ddd, $J=13.6,12.3$, $\left.3.3 \mathrm{~Hz}, 1 \mathrm{H}, \mathrm{H}-3^{\prime}\right), 2.27$ (dt, $\left.J=13.6,3.7 \mathrm{~Hz}, 1 \mathrm{H}, \mathrm{H}-3^{\prime \prime}\right), 2.21$ (s, 3H, $\mathrm{CH}_{3} \mathrm{CO}$ ), 1.95 (d, $J=1.1 \mathrm{~Hz}, 3 \mathrm{H}, \mathrm{T}$ $\left.\mathrm{CH}_{3}\right) ;{ }^{13} \mathrm{C}$ NMR $\left(151 \mathrm{MHz}, \mathrm{CDCl}_{3}\right) \delta 168.8\left(\mathrm{CH}_{3} \mathrm{CO}\right), 165.4(\mathrm{PhCO}), 163.7(\mathrm{C}-4), 150.9(\mathrm{C}-2), 136.9(\mathrm{C}-$ 6), 133.8, 130.0, 129.2, $128.7(\mathrm{Ph}), 111.6(\mathrm{C}-5), 89.6\left(\mathrm{C}-1^{\prime}\right), 68.3\left(\mathrm{C}-2^{\prime}\right), 62.5\left(\mathrm{C}-5^{\prime}\right), 48.7\left(\mathrm{C}-4^{\prime}\right), 28.5(\mathrm{C}-$ $\left.3^{\prime}\right), 21.1\left(\mathrm{CH}_{3} \mathrm{CO}\right)$ ), $12.7\left(\mathrm{~T} \mathrm{CH}_{3}\right)$; HRMS (ESI-TOF) m/z: $[\mathrm{M}+\mathrm{Na}]^{+}$calcd for $\mathrm{C}_{19} \mathrm{H}_{20} \mathrm{~N}_{2} \mathrm{O}_{7} \mathrm{Na} 411.1163$; Found 411.1157.

\section{Diisopopylphosphonomethyl 2-O-benzoyl-3,4-dideoxy-4-(thymid-1-yl)- $\alpha$-D-threo-pentopyranoside} (27). To a stirred solution of 26c (120 mg, $0.31 \mathrm{mmol})$ and diisopropylphosphonomethanol $(121 \mathrm{mg}, 0.62$ $\mathrm{mmol})$ in dry DCM $(3 \mathrm{~mL})$ was added $4 \AA$ molecular sieves, and the mixture was stirred for $30 \mathrm{~min}$ at room temperature. The reaction mixture was cooled to $0^{\circ} \mathrm{C}$ and TMSOTf $(0.073 \mathrm{~mL}, 0.40 \mathrm{mmol})$ was added. The 
mixture was warmed to room temperature and stirred for $10 \mathrm{~h}$. The reaction was quenched by addition of saturated aq. $\mathrm{NaHCO}_{3}$ at $0{ }^{\circ} \mathrm{C}$. It was then diluted with $\mathrm{DCM}(10 \mathrm{~mL})$ and saturated aq. $\mathrm{NaHCO}_{3}(10 \mathrm{~mL})$. The aqueous layer was extracted with DCM $(2 \times 10 \mathrm{~mL})$. The combined organic layers were washed with saturated aq. $\mathrm{NaHCO}_{3}$ and brine, dried over $\mathrm{Na}_{2} \mathrm{SO}_{4}$, and concentrated in vacuo. The residue was purified by silica gel column chromatography to afford 27 as a mixture of a and $\beta$ isomers, along with residual diisopropylphosphonomethanol. This material was used in the next step without further purification. HRMS (ESI-TOF) m/z: [M+Na] $]^{+}$calcd for $\mathrm{C}_{24} \mathrm{H}_{33} \mathrm{~N}_{2} \mathrm{O}_{9} \mathrm{P}_{1} \mathrm{Na}$ 547.1816; Found 547.1801.

Diisopopylphosphonomethyl $\quad 3,4-d i d e o x y-4-(t h y m i d-1-y l)-\alpha / \beta$-D-threo-pentopyranoside $\quad(28)$ A solution of crude 27 in $7 \mathrm{~N} \mathrm{NH}_{3}$ in $\mathrm{MeOH}(5 \mathrm{~mL})$ was stirred at room temperature for $2 \mathrm{~h}$. The mixture was concentrated under reduced pressure and the resultant residue was purified by silica gel column chromatography $\left(20: 1 \mathrm{CH}_{2} \mathrm{Cl}_{2} / \mathrm{MeOH}\right)$ to give $\alpha / \beta$-28 as a white foam.

Data for $\alpha$-28: $25 \mathrm{mg}, 20 \%$ over two steps; ${ }^{1} \mathrm{H}$ NMR (500 MHz, $\left.\mathrm{CDCl}_{3}\right) \delta 9.69(\mathrm{~s}, 1 \mathrm{H}, \mathrm{NH}), 7.24(\mathrm{~s}, 1 \mathrm{H}$, H-6), 5.01 (tt, $\left.J=10.3,4.0 \mathrm{~Hz}, 1 \mathrm{H}, \mathrm{H}-4^{\prime}\right), 4.84-4.73\left(\mathrm{~m}, 2 \mathrm{H},\left[\mathrm{CH}\left(\mathrm{CH}_{3}\right)_{2}\right]\right), 4.68\left(\mathrm{~d}, J=2.6 \mathrm{~Hz}, 1 \mathrm{H}, \mathrm{H}-1^{\prime}\right)$, 4.05-3.93 (m, 2H, $\mathrm{PCH}_{2}$ and $\left.\mathrm{H}-2^{\prime}\right), 3.86\left(\mathrm{td}, J=10.8,4.2 \mathrm{~Hz}, 1 \mathrm{H}, \mathrm{H}-5^{\prime}\right), 3.80-3.70$ (m, 2H, H-5" and $\mathrm{PC} H_{2}$ ), 2.27 (ddd, $\left.J=12.8,3.7,1.2 \mathrm{~Hz}, 1 \mathrm{H}, \mathrm{H}-3^{\prime}\right), 2.05-1.97$ (dt, $\left.J=13.2,4.3 \mathrm{~Hz}, 1 \mathrm{H}, \mathrm{H}-3^{\prime \prime}\right), 1.91$ (d, $J=1.1 \mathrm{~Hz}$, $3 \mathrm{H}, \mathrm{T} \mathrm{CH}), 1.41-1.29\left(\mathrm{~m}, 12 \mathrm{H},\left[\mathrm{CH}\left(\mathrm{CH}_{3}\right)_{2}\right]\right) ;{ }^{13} \mathrm{C} \mathrm{NMR}\left(126 \mathrm{MHz}, \mathrm{CDCl}_{3}\right) \delta 163.9(\mathrm{C}-4), 151.3(\mathrm{C}-2)$, 137.0 (C-6), $111.2(\mathrm{C}-5), 100.4\left(\mathrm{~d},{ }^{3} J_{\mathrm{P}, \mathrm{C}}=11.1 \mathrm{~Hz}, \mathrm{C}-1^{\prime}\right), 71.6\left[\mathrm{CH}\left(\mathrm{CH}_{3}\right)_{2}\right], 66.5\left(\mathrm{C}-2^{\prime}\right), 61.9\left(\mathrm{C}-5^{\prime}\right), 61.8$ $\left(\mathrm{d},{ }^{1} J_{\mathrm{P}, \mathrm{C}}=171.8 \mathrm{~Hz}, \mathrm{PCH}_{2}\right), 47.0\left(\mathrm{C}-4^{\prime}\right), 31.0\left(\mathrm{C}-3^{\prime}\right), 24.2\left[\mathrm{CH}\left(\mathrm{CH}_{3}\right)_{2}\right], 12.6\left(\mathrm{~T} \mathrm{CH}_{3}\right) ;{ }^{31} \mathrm{P} \mathrm{NMR}(121 \mathrm{MHz}$, $\mathrm{CDCl}_{3}$ ) $\delta$ 20.0; HRMS (ESI-TOF) m/z: [M+H] $]^{+}$calcd for $\mathrm{C}_{17} \mathrm{H}_{30} \mathrm{~N}_{2} \mathrm{O}_{8} \mathrm{P}_{1} 421.1734$; Found 421.1735 .

Data for $\beta$-28: $13 \mathrm{mg}, 10 \%$ over two steps; ${ }^{1} \mathrm{H}$ NMR $\left(500 \mathrm{MHz}, \mathrm{CDCl}_{3}\right) \delta 9.24(\mathrm{~s}, 1 \mathrm{H}, \mathrm{NH}), 7.64(\mathrm{~d}, J=$

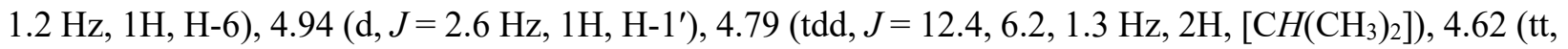
$\left.J=4.4,3.7 \mathrm{~Hz}, 1 \mathrm{H}, \mathrm{H}-4^{\prime}\right), 4.17$ (dd, $\left.J=13.2,3.9 \mathrm{~Hz}, 1 \mathrm{H}, \mathrm{H}-5^{\prime}\right), 4.03$ (dd, $J=13.8,9.4 \mathrm{~Hz}, 1 \mathrm{H}, \mathrm{PC} H_{2}$ ), 3.90-3.67 (m, 3H, H-5", PCH ${ }_{2}$ and H-2' ), 2.19-2.16 (dt, $J=13.8,4.9 \mathrm{~Hz}, 1 \mathrm{H}, \mathrm{H}-3^{\prime}$ ), 2.19-2.06 (ddd, $J=$ 13.8, 9.8, 3.9 Hz, 1H, H-3"), 1.93 (d, $J=1.1 \mathrm{~Hz}, 3 \mathrm{H}, \mathrm{T} \mathrm{CH}), 1.34\left(\mathrm{~m}, 12 \mathrm{H},\left[\mathrm{CH}\left(\mathrm{CH}_{3}\right)_{2}\right]\right) ;{ }^{13} \mathrm{C} \mathrm{NMR}(126$ $\left.\mathrm{MHz}, \mathrm{CDCl}_{3}\right) \delta 163.9(\mathrm{C}-4), 151.0(\mathrm{C}-2), 138.2(\mathrm{C}-6), 110.8(\mathrm{C}-5), 99.8\left(\mathrm{~d},{ }^{3} J_{\mathrm{P}, \mathrm{C}}=9.9 \mathrm{~Hz}, \mathrm{C}-1^{\prime}\right), 71.8,71.7$ $\left(\mathrm{d},{ }^{2} J_{\mathrm{P}, \mathrm{C}}=6.6 \mathrm{~Hz},\left[\mathrm{CH}\left(\mathrm{CH}_{3}\right)_{2}\right]\right), 64.3\left(\mathrm{C}-2^{\prime}\right), 62.6\left(\mathrm{~d},{ }^{1} J_{\mathrm{P}, \mathrm{C}}=171.0 \mathrm{~Hz}, \mathrm{PCH}_{2}\right), 61.2\left(\mathrm{C}-5^{\prime}\right), 51.2\left(\mathrm{C}-4^{\prime}\right), 30.9$ $\left(\mathrm{C}-3^{\prime}\right), 24.2\left[\mathrm{CH}\left(\mathrm{CH}_{3}\right)_{2}\right], 12.8\left(\mathrm{~T} \mathrm{CH}_{3}\right) ;{ }^{31} \mathrm{P} \mathrm{NMR}\left(121 \mathrm{MHz}, \mathrm{CDCl}_{3}\right) \delta 20.0$.

Phosphonomethyl 3,4-dideoxy-4-(thymid-1-yl)- $\alpha$-D-threo-pentopyranoside (2a). To a solution of $\alpha-28$ $(20 \mathrm{mg}, 0.048 \mathrm{mmol})$ and 2,6-lutidine $(0.04 \mathrm{~mL}, 0.38 \mathrm{mmol})$ in dry $\mathrm{CH}_{3} \mathrm{CN}(2 \mathrm{~mL})$ was added bromotrimethylsilane $(0.05 \mathrm{~mL}, 0.38 \mathrm{mmol})$ at $0{ }^{\circ} \mathrm{C}$. The reaction mixture was stirred at room tempearture overnight and quenched with $1.0 \mathrm{M}$ aq. TEAB solution $(1 \mathrm{~mL})$. After removal of all the volatiles under reduced pressure, the remaining residue was partitioned between water and EtOAc/ether (1:1) and the water layer was lyophilized. The crude residue was first purified by silica gel column chromatography (10:1:0 to 10:5:1, $\mathrm{CH}_{2} \mathrm{Cl}_{2} / \mathrm{MeOH} / 1 \mathrm{M}$ aq. TEAB) and then by preparative reverse phase HPLC with a gradient of $\mathrm{CH}_{3} \mathrm{CN}$ in $0.05 \mathrm{M}$ aq. TEAB ranging from 2 to $30 \%$ to give $\mathbf{2 a}\left(\mathbf{2 a} \cdot 0.67 \mathrm{Et}_{3} \mathrm{~N}\right.$ salt, $\left.8.3 \mathrm{mg}, 40 \%\right)$ as a white foam. $\varepsilon_{267}=9.7 \times 10^{3}\left(\mathrm{M}^{-1} \mathrm{~cm}^{-1}\right)$ in water; ${ }^{1} \mathrm{H} \mathrm{NMR}\left(600 \mathrm{MHz}, \mathrm{D}_{2} \mathrm{O}\right) \delta 7.66(\mathrm{~s}, 1 \mathrm{H}, \mathrm{H}-6), 4.79$ (tt, $J=10.8$, $\left.4.8 \mathrm{~Hz}, 1 \mathrm{H}, \mathrm{H}-4^{\prime}\right), 4.68$ (d, $\left.J=2.2 \mathrm{~Hz}, 1 \mathrm{H}, \mathrm{H}-1^{\prime}\right), 4.04$ (td, $\left.J=3.0,3.6 \mathrm{~Hz}, 1 \mathrm{H}, \mathrm{H}-2^{\prime}\right), 3.91$ (appt t, $J=10.7$ $\mathrm{Hz}, 1 \mathrm{H}, \mathrm{H}-5^{\prime}$ ), 3.87 (dd, $J=13.1,9.3 \mathrm{~Hz}, 1 \mathrm{H}, \mathrm{PCH}_{2}$ ), 3.73 (ddd, $\left.J=11.2,4.7,1.4 \mathrm{~Hz}, 1 \mathrm{H}, \mathrm{H}-5^{\prime \prime}\right), 3.63$ (dd, $\left.J=13.2,9.3 \mathrm{~Hz}, 1 \mathrm{H}, \mathrm{PCH})_{2}\right), 3.18$ (q, $\left.J=7.4 \mathrm{~Hz}, 4 \mathrm{H}, \mathrm{CH}_{2} \mathrm{CH}_{3}\right), 2.38$ (ddd, $J=13.8,12.1,3.0 \mathrm{~Hz}, 1 \mathrm{H}, \mathrm{H}-$ 
$\left.3^{\prime}\right), 1.93\left(\mathrm{dtd}, J=13.1,3.9,1.2 \mathrm{~Hz}, 1 \mathrm{H}, \mathrm{H}-3\right.$ ') $1.88\left(\mathrm{~s}, 3 \mathrm{H}, \mathrm{T} \mathrm{CH} \mathrm{CH}_{3}\right), 1.26\left(\mathrm{t}, J=7.3 \mathrm{~Hz}, 6 \mathrm{H}, \mathrm{CH}_{2} \mathrm{CH}_{3}\right) ;{ }^{13} \mathrm{C}$ NMR (151 MHz, D $2 \mathrm{O}) \delta 166.1$ (C-4), 151.9 (C-2), 139.1 (C-6), 110.7 (C-5), 99.3 (d, $\left.{ }^{3} J_{\mathrm{P}, \mathrm{C}}=12.0 \mathrm{~Hz}, \mathrm{C}-1^{\prime}\right)$, $99.3\left(\mathrm{C}-1^{\prime}\right), 65.7\left(\mathrm{C}-2^{\prime}\right), 62.9\left(\mathrm{~d},{ }^{1} J_{\mathrm{P}, \mathrm{C}}=156.6 \mathrm{~Hz}, \mathrm{PCH}\right), 60.4\left(\mathrm{C}-5^{\prime}\right), 46.7\left(\mathrm{C}-4^{\prime}\right), 29.2\left(\mathrm{C}-3^{\prime}\right), 11.0\left(\mathrm{~T} \mathrm{CH}_{3}\right)$; ${ }^{31} \mathrm{P}$ NMR (121 MHz, $\left.\mathrm{D}_{2} \mathrm{O}\right) \delta$ 15.7; HRMS (ESI-): [M-H] $]^{-}$calcd for $\mathrm{C}_{11} \mathrm{H}_{16} \mathrm{~N}_{2} \mathrm{O}_{8} \mathrm{P}_{1}$ 335.0650; Found 335.0654 .

Benzyl 2-O-acetyl-3-deoxy- $\boldsymbol{\beta}$-L-erythro-pentopyranoside (12). A solution of $\mathbf{1 7}$ (2.00 g, $6.20 \mathrm{mmol})$ and AIBN (306 mg, $1.86 \mathrm{mmol})$ in toluene $(310 \mathrm{~mL})$ was heated at $100{ }^{\circ} \mathrm{C}$ until complete dissolution of the reagents. To this solution, $\mathrm{Bu}_{3} \mathrm{SnH}(3.34 \mathrm{~mL}, 12.4 \mathrm{mmol})$ was added and the mixture was stirred for $30 \mathrm{~min}$ at $100{ }^{\circ} \mathrm{C}$ under an argon atmosphere. After removal of all the volatiles under reduced pressure, the remaining residue was directly subjected to silica gel column chromatography to afford a mixture of 3 'deoxy $(60 \%)$ and $4{ }^{\prime}$-deoxy $(10 \%)$ products, which were separated after the next mesylation step.

Benzyl 2-O-acetyl-4-azido-3,4-dideoxy- $\alpha$-D-threo-pentopyranoside (29). A suspension of 14a (5.60 g, $16.3 \mathrm{mmol})$ and sodium azide $(2.11 \mathrm{~g}, 32.52 \mathrm{mmol})$ in DMF $(150 \mathrm{~mL})$ was stirred at $90{ }^{\circ} \mathrm{C}$ for $8 \mathrm{~h}$. After removal of all the volatiles under reduced pressure, the resulting residue was taken up with DCM $(150 \mathrm{~mL})$, and $100 \mathrm{~mL}$ of saturated aq. $\mathrm{NaHCO}_{3}$ was added. The aqueous layer was extracted with $\mathrm{DCM}(2 \times 75 \mathrm{~mL})$. The combined organic layers were washed with brine, dried over $\mathrm{Na}_{2} \mathrm{SO}_{4}$ and concentrated in vacuo. The crude residue was purified by silica gel column chromatography (15:1 hexane/EtOAc) to give 29 (4.30 g, 91\%) as a colorless oil. ${ }^{1} \mathrm{H} \mathrm{NMR}\left(500 \mathrm{MHz}, \mathrm{CDCl}_{3}\right) \delta 7.44-7.21(\mathrm{~m}, 5 \mathrm{H}, \mathrm{Ph}), 4.94(\mathrm{dt}, J=3.3,2.9 \mathrm{~Hz}, 1 \mathrm{H}$, H-2), 4.72 (d, $\left.J=11.9 \mathrm{~Hz}, 1 \mathrm{H}, \mathrm{CH}_{2} \mathrm{Ph}\right), 4.69$ (d, $\left.J=1.6 \mathrm{~Hz}, 1 \mathrm{H}, \mathrm{H}-1\right), 4.49$ (d, $J=11.9 \mathrm{~Hz}, 1 \mathrm{H}, \mathrm{CH}_{2} \mathrm{Ph}$ ), 3.77 (tt, $J=11.1,5.5 \mathrm{~Hz}, 1 \mathrm{H}, \mathrm{H}-4), 3.70$ (ddd, $J=10.7,4.9,1.9 \mathrm{~Hz}, 1 \mathrm{H}, \mathrm{H}-5$ ), 3.60 (appt, $J=10.8 \mathrm{~Hz}, 1 \mathrm{H}$, $\left.\mathrm{H}-5^{\prime}\right), 2.21-1.90$ (m, 5H, H-3, H-3', $\left.\mathrm{CH}_{3} \mathrm{CO}\right) ;{ }^{13} \mathrm{C} \mathrm{NMR}\left(126 \mathrm{MHz}, \mathrm{CDCl}_{3}\right) \delta 169.7\left(\mathrm{CH}_{3} \mathrm{CO}\right), 136.9,128.4$, 127.8, 127.7 (Ph), $94.8(\mathrm{C}-1), 69.0\left(\mathrm{CH}_{2} \mathrm{Ph}\right), 68.6$ (C-2), 61.4 (C-5), 52.1 (C-4), $29.1(\mathrm{C}-3), 20.9\left(\mathrm{CH}_{3} \mathrm{CO}\right)$; HRMS (ESI-TOF) m/z: [M+Na] calcd for $\mathrm{C}_{14} \mathrm{H}_{17} \mathrm{~N}_{3} \mathrm{O}_{4} \mathrm{Na}$ 314.1111; Found 314.1113.

Note: Concentrating azide-containing reaction mixtures and products through rotary evaporation have caused documented explosions. NaN3 is known to decopose violently causing explosing at $275^{\circ} \mathrm{C}$

Benzyl 4-azido-3,4-dideoxy- $\boldsymbol{\alpha}$-D-threo-pentopyranoside (30). A methanolic solution of $\mathrm{NaOMe}(5.4 \mathrm{M}$, $5.09 \mathrm{~mL}, 27.5 \mathrm{mmol})$ was added dropwise to a solution of $29(4.00 \mathrm{~g}, 13.73 \mathrm{mmol})$ in methanol $(150 \mathrm{~mL})$. The reaction was stirred at room temperature for $3 \mathrm{~h}$. After removal of all the volatiles under reduced pressure, the resulting residue was taken up with $\mathrm{DCM}(100 \mathrm{~mL})$, and $50 \mathrm{~mL}$ of saturated aq. $\mathrm{NaHCO}_{3}$ was added. The aqueous layer was extracted again with DCM $(50 \mathrm{~mL})$. The combined organic layers were washed with saturated aq. $\mathrm{NaHCO}_{3}$ and brine, dried over $\mathrm{Na}_{2} \mathrm{SO}_{4}$, and concentrated in vacuo. The residue was purified by silica gel column chromatography (10:1 hexane/EtOAc) give $\mathbf{3 0}$ ( $3.25 \mathrm{~g}, 95 \%)$ as a colorless oil. ${ }^{1} \mathrm{H}$ NMR (500 MHz, $\left.\mathrm{CDCl}_{3}\right) \delta 7.41-7.25$ (m, 5H, Ph), 4.79 (d, $\left.J=11.8 \mathrm{~Hz}, 1 \mathrm{H}, \mathrm{CH}_{2} \mathrm{Ph}\right), 4.50(\mathrm{~d}, J=$ $\left.11.9 \mathrm{~Hz}, 1 \mathrm{H}, \mathrm{CH}_{2} \mathrm{Ph}\right), 4.47$ (d, $\left.J=4.2 \mathrm{~Hz}, 1 \mathrm{H}, \mathrm{H}-1\right), 3.80$ (td, $\left.J=5.3,2.0 \mathrm{~Hz}, 1 \mathrm{H}, \mathrm{H}-2\right), 3.76$ (m, 1H, H-4), 3.74-3.69 (dd, $J=7.3,11.2 \mathrm{~Hz}, 1 \mathrm{H}, \mathrm{H}-5), 3.63$ (ddd, $\left.J=11.0,3.8,1.2 \mathrm{~Hz}, 1 \mathrm{H}, \mathrm{H}-5{ }^{\prime}\right), 2.68$ (d, $J=3.0 \mathrm{~Hz}$, 1H, OH), 2.06-1.97 (dddd, $J=13.5,8.9,3.7,1.0 \mathrm{~Hz}, 1 \mathrm{H}, \mathrm{H}-3$ ), 1.90 (dddd, $J=13.5,6.3,4.2,1.1 \mathrm{~Hz}, 1 \mathrm{H}$, $\left.\mathrm{H}-3{ }^{\prime}\right) ;{ }^{13} \mathrm{C}$ NMR (126 MHz, $\left.\mathrm{CDCl}_{3}\right) \delta 137.0,128.4,128.3,127.9(\mathrm{Ph}), 99.6(\mathrm{C}-1), 69.5\left(\mathrm{CH}_{2} \mathrm{Ph}\right), 66.5(\mathrm{C}-$ 2), 63.4 (C-5), 53.4 (C-4), 32.1 (C-3); HRMS (ESI-TOF) m/z: [M+Na $]^{+}$calcd for $\mathrm{C}_{12} \mathrm{H}_{15} \mathrm{~N}_{3} \mathrm{O}_{3} \mathrm{Na} 272.1006$; Found 272.1003. 
Benzyl 4-amino-3,4-dideoxy- $\boldsymbol{\alpha}$-D-threo-pentopyranoside (31). To a solution of $\mathbf{3 0}$ ( $2.00 \mathrm{~g}, 8.02 \mathrm{mmol})$ in dry THF $(80 \mathrm{~mL})$ was added $\mathrm{Ph}_{3} \mathrm{P}(0.46 \mathrm{~g}, 1.75 \mathrm{mmol})$. The mixture was stirred at room temperature for 1 h. Water $(2 \mathrm{~mL})$ was added and the mixture was stirred at $50{ }^{\circ} \mathrm{C}$ for $6 \mathrm{~h}$. It was then evaporated, and the resulting residue was purified by silica gel column chromatography (100/15 DCM/MeOH) to give 31 (1.65 g, $92 \%)$ as a colorless oil. ${ }^{1} \mathrm{H}$ NMR $\left(500 \mathrm{MHz}, \mathrm{CDCl}_{3}\right) \delta 7.46-7.28(\mathrm{~m}, 5 \mathrm{H}, \mathrm{Ph}), 4.80(\mathrm{~d}, J=11.8 \mathrm{~Hz}, 1 \mathrm{H}$, $\mathrm{CH}_{2} \mathrm{Ph}$ ), 4.52 (d, $\left.J=11.8 \mathrm{~Hz}, 1 \mathrm{H}, \mathrm{CH}_{2} \mathrm{Ph}\right), 4.50$ (d, $\left.J=3.3 \mathrm{~Hz}, 1 \mathrm{H}, \mathrm{H}-1\right), 3.80$ (dt, $J=5.9,3.5 \mathrm{~Hz}, 1 \mathrm{H}, \mathrm{H}-$ 2), 3.60 (ddd, $J=11.0,4.1,1.3 \mathrm{~Hz}, 1 \mathrm{H}, \mathrm{H}-5), 3.50$ (dd, $J=11.0,8.0 \mathrm{~Hz}, 1 \mathrm{H}, \mathrm{H}-5), 3.15$ (tt, $J=12.7,4.2$ $\mathrm{Hz}, 1 \mathrm{H}, \mathrm{H}-4), 2.05-1.53$ (m, 5H, H-3, H-3, OH, NH ); ${ }^{13} \mathrm{C} \mathrm{NMR}\left(126 \mathrm{MHz}, \mathrm{CDCl}_{3}\right) \delta 137.3,128.4,127.9$, $127.8(\mathrm{Ph}), 99.7$ (C-1), $69.4\left(\mathrm{CH}_{2} \mathrm{Ph}\right), 67.6$ (C-5), 66.9 (C-2), 43.6 (C-4), 36.4 (C-3); HRMS (ESI-TOF) $\mathrm{m} / \mathrm{z}:[\mathrm{M}+\mathrm{H}]^{+}$calcd for $\mathrm{C}_{12} \mathrm{H}_{18} \mathrm{~N}_{1} \mathrm{O}_{3} 224.1281$; Found 224.1283.

Benzyl 4-(6-chloropurine-9-yl)-3,4-dideoxy- $\boldsymbol{\alpha}$-D-threo-pentopyranoside (32). 4,6-Dichloro-5formamidopyrimidine ( $860 \mathrm{mg}, 4.48 \mathrm{mmol})$ and DIPEA $(1.17 \mathrm{~mL}, 6.72 \mathrm{mmol})$ were added to a solution of pentopyranoside 31 (500 mg, $2.24 \mathrm{mmol})$ in $n$-butanol $(25 \mathrm{~mL})$. The reaction mixture was stirred for $2 \mathrm{~h}$ at $100^{\circ} \mathrm{C}$, the temperature was then raised to $140{ }^{\circ} \mathrm{C}$ and maintained at this temperature for $10 \mathrm{~h}$. After removal of all the volatiles under reduced pressure, the remaining residue was purified by silica gel column chromatography (gradient $\mathrm{CH}_{2} \mathrm{Cl}_{2} / \mathrm{MeOH}, 100: 0$, v/v; 99:1, v/v; 20:1, v/v) to give $32(605 \mathrm{mg}, 75 \%$ ) as a colorless oil. ${ }^{1} \mathrm{H}$ NMR (600 MHz, DMSO-d6) $\delta 8.25$ (s, 1H, H-8), 8.16 (s, 1H, H-2), 7.45-7.25 (m, 5H, Ph), $5.34(\mathrm{~d}, J=3.9 \mathrm{~Hz}, 1 \mathrm{H}, \mathrm{OH}), 4.92$ (tt, $\left.J=11.1,4.2 \mathrm{~Hz}, 1 \mathrm{H}, \mathrm{H}-4^{\prime}\right), 4.76$ (d, $\left.J=12.2 \mathrm{~Hz}, 1 \mathrm{H}, \mathrm{CH}_{2} \mathrm{Ph}\right), 4.66$ (d, $\left.J=1.8 \mathrm{~Hz}, 1 \mathrm{H}, \mathrm{H}-1^{\prime}\right), 4.54$ (d, $J=12.2 \mathrm{~Hz}, 1 \mathrm{H}, \mathrm{CH}_{2} \mathrm{Ph}$ ), 4.10 (appt, $\left.J=10.6 \mathrm{~Hz}, 1 \mathrm{H}, \mathrm{H}-5^{\prime}\right), 3.82$ (dt, $J$ $\left.=6.0,3.3 \mathrm{~Hz}, 1 \mathrm{H}, \mathrm{H}-2^{\prime}\right), 3.76\left(\mathrm{ddd}, J=10.6,4.4,1.6 \mathrm{~Hz}, 1 \mathrm{H}, \mathrm{H}-5^{\prime}\right), 2.71\left(\mathrm{td}, J=12.6,3.0 \mathrm{~Hz}, 1 \mathrm{H}, \mathrm{H}-3^{\prime}\right)$, $1.99\left(\mathrm{dt}, J=12.8,3.8 \mathrm{~Hz}, 1 \mathrm{H}, \mathrm{H}-3^{\prime}\right) ;{ }^{13} \mathrm{C}$ NMR (150 MHz, DMSO-d6) $\delta 156.2$ (C-6), 152.4 (C-2), 149.6 (C-4), 139.6 (C-8), 137.9, 128.4, 127.9, $127.7(\mathrm{Ph}), 119.1$ (C-5), $98.1\left(\mathrm{C}-1^{\prime}\right), 68.2\left(\mathrm{CH}_{2} \mathrm{Ph}\right), 65.7\left(\mathrm{C}-2^{\prime}\right)$, $61.7\left(\mathrm{C}-5^{\prime}\right), 46.7$ (C-4'), $31.6\left(\mathrm{C}-3^{\prime}\right)$; HRMS (ESI-TOF) m/z: [M+H] ${ }^{+}$calcd for $\mathrm{C}_{17} \mathrm{H}_{18} \mathrm{Cl}_{1} \mathrm{~N}_{4} \mathrm{O}_{3} 361.1061$; Found 361.1056 .

Benzyl 4-(adenine-9-yl)-3,4-dideoxy- $\boldsymbol{\alpha}$-D-threo-pentopyranoside (33). A solution of 32 (300 mg, 0.83 $\mathrm{mmol})$ in saturated ammonia in ethanol $(10 \mathrm{~mL})$ was stirred in a sealed flask at $60{ }^{\circ} \mathrm{C}$ for $8 \mathrm{~h}$. After removal of all the volatiles under reduced pressure, the resulting residue was purified by silica gel column chromatography $\left(\mathrm{CH}_{2} \mathrm{Cl}_{2} / \mathrm{MeOH}, 15: 1\right)$ to give 33 (269 mg, 95\%) as a colorless oil. ${ }^{1} \mathrm{H}$ NMR (500 MHz, DMSO-d6) $\delta 8.82$ (s, 1H, H-8), 8.79 (s, 1H, H-2), 7.46-7.29 (m, 5H, Ph), 5.38 (d, J=4.0 Hz, 1H, OH), $5.07\left(\mathrm{tt}, J=11.5,4.3 \mathrm{~Hz}, 1 \mathrm{H}, \mathrm{H}-4^{\prime}\right), 4.76\left(\mathrm{~d}, J=12.2 \mathrm{~Hz}, 1 \mathrm{H}, \mathrm{CH}_{2} \mathrm{Ph}\right), 4.67$ (d, $\left.J=1.8 \mathrm{~Hz}, 1 \mathrm{H}, \mathrm{H}-1^{\prime}\right), 4.55$ (d, $J=12.2 \mathrm{~Hz}, 1 \mathrm{H}, \mathrm{CH}_{2} \mathrm{Ph}$ ), 4.16 (appt, $J=10.6 \mathrm{~Hz}, 1 \mathrm{H}, \mathrm{H}-5^{\prime}$ ), 3.99-3.74 (m, 2H, H-5' and H-2'), 2.76 (td, $\left.J=12.5,3.0 \mathrm{~Hz}, 1 \mathrm{H}, \mathrm{H}-3^{\prime}\right), 2.06$ (ddd, $\left.J=12.7,5.2,2.8 \mathrm{~Hz}, 1 \mathrm{H}, \mathrm{H}-3^{\prime \prime}\right) ;{ }^{13} \mathrm{C}$ NMR (126 MHz, DMSOd6) $\delta 152.0$ (C-4), 151.4 (C-2), 149.2 (C-6), 146.4 (C-8), 137.8, 131.2 (C-5), 128.4, 127.8, 127.6 (Ph), 98.0 $\left(\mathrm{C}-1^{\prime}\right), 68.3\left(\mathrm{CH}_{2} \mathrm{Ph}\right), 65.6\left(\mathrm{C}-2^{\prime}\right), 61.2\left(\mathrm{C}^{\prime} 5^{\prime}\right), 47.9$ (C-4'), 31.4 (C-3'); HRMS (ESI-TOF) m/z: [M+H] calcd for $\mathrm{C}_{17} \mathrm{H}_{20} \mathrm{~N}_{5} \mathrm{O}_{3} 342.1561$; Found 342.1566.

\section{Benzyl 2-O-benzoyl-4-( $N^{6}, N^{6}$-dibenzoyladenine-9-yl)-3,4-dideoxy- $\alpha$-D-threo-pentopyranoside (34). To} a solution of $\mathbf{3 3}(200 \mathrm{mg}, 0.59 \mathrm{mmol})$ in dry pyridine $(6 \mathrm{~mL})$ at $0{ }^{\circ} \mathrm{C}$ was added benzoyl chloride $(0.46 \mathrm{~mL}$, $3.52 \mathrm{mmol}$ ), and the reaction mixture was warmed to room temperature and stirred for $3 \mathrm{~h}$. After removal of all the volatiles under reduced pressure, the resulting residue was partitioned between saturated aq. 
$\mathrm{NaHCO}_{3}(10 \mathrm{~mL})$ and DCM $(20 \mathrm{~mL})$. The water layer was further extracted with DCM $(1 \times 10 \mathrm{~mL})$. The combined organic layers were washed with brine $(10 \mathrm{~mL})$, dried over $\mathrm{Na}_{2} \mathrm{SO}_{4}$, and concentrated in vacuo. The crude residue was purified by silica gel column chromatography (gradient hexane/EtOAc, 10:1, v/v; $3: 1)$ to give 34 (282 mg, $88 \%)$ as a white solid. ${ }^{1} \mathrm{H}$ NMR (500 MHz, $\left.\mathrm{CDCl}_{3}\right) \delta 8.67(\mathrm{~s}, 1 \mathrm{H}, \mathrm{H}-2), 8.21-8.04$ (m, 3H, H-8, Ph), 8.00-7.74 (m, 4H, Ph), 7.65-7.53 (m, 1H, Ph), 7.51-7.27 (m, 14H, Ph), 5.36 (td, J=4.2, $\left.1.5 \mathrm{~Hz}, 1 \mathrm{H}, \mathrm{H}-2^{\prime}\right), 5.15$ (tt, $\left.J=11.7,4.3 \mathrm{~Hz}, 1 \mathrm{H}, \mathrm{H}-4^{\prime}\right), 5.01$ (d, $\left.J=1.3 \mathrm{~Hz}, 1 \mathrm{H}, \mathrm{H}-1^{\prime}\right), 4.86$ (d, $J=11.9 \mathrm{~Hz}$, $1 \mathrm{H}, \mathrm{CH}_{2} \mathrm{Ph}$ ), 4.64 (d, $J=11.9 \mathrm{~Hz}, 1 \mathrm{H}, \mathrm{CH}_{2} \mathrm{Ph}$ ), 4.24 (appt, $J=10.9 \mathrm{~Hz}, 1 \mathrm{H}, \mathrm{H}-5$ ') 4.03 (ddd, $J=10.4,5.1$, $\left.1.8 \mathrm{~Hz} 1 \mathrm{H}, \mathrm{H}-5^{\prime}\right), 3.01$ (td, $\left.J=13.3,3.1 \mathrm{~Hz}, 1 \mathrm{H}, \mathrm{H}-3^{\prime}\right), 2.44$ (dt, $\left.J=13.2,5.2 \mathrm{~Hz}, 1 \mathrm{H}, \mathrm{H}-3^{\prime}\right) ;{ }^{13} \mathrm{C}$ NMR $(126$ $\mathrm{MHz}, \mathrm{CDCl}_{3}$ ) $\delta 172.2(\mathrm{PhCO}), 165.4(\mathrm{PhCO}), 153.1$ (C-4), 152.0 (C-2), 152.0 (C-6), 142.8 (C-8), 136.8, 134.1, 133.5, 132.9, 129.8, 129.4, 128.7, 128.6, 128.5, 128.1, 127.9(Ph), 127.4 (C-5), 95.1 (C-1'), 69.5 $\left(\mathrm{CH}_{2} \mathrm{Ph}\right), 68.9\left(\mathrm{C}-2^{\prime}\right), 61.5\left(\mathrm{C}^{-} 5^{\prime}\right), 47.8\left(\mathrm{C}-4^{\prime}\right), 29.0\left(\mathrm{C}-3^{\prime}\right)$; HRMS (ESI-TOF) m/z: $[\mathrm{M}+\mathrm{H}]^{+}$calcd for $\mathrm{C}_{38} \mathrm{H}_{32} \mathrm{~N}_{5} \mathrm{O}_{6} 654.2346$; Found 654.2358.

2-O-Benzoyl-4-( $N^{6}$-benzoyladenine-9-yl)-3,4-dideoxy- $\alpha$-D-threo-pentopyranose (35). To a stirred solution of $34(140 \mathrm{mg}, 0.25 \mathrm{mmol})$ in anhydrous $\mathrm{CH}_{2} \mathrm{Cl}_{2}(4 \mathrm{~mL})$ was added $1 \mathrm{M} \mathrm{BCl}_{3}(0.76 \mathrm{~mL}, 0.76$ mmol) at $-78{ }^{\circ} \mathrm{C}$. Then, the reaction mixture was slowly warmed to $0{ }^{\circ} \mathrm{C}$ over $2.5 \mathrm{~h}$ and stirred at this temperature for $30 \mathrm{~min}$. After completion of the reaction, the mixture was cooled to $-20{ }^{\circ} \mathrm{C}$ and quenched by dropwise addition of saturated aq. $\mathrm{NaHCO}_{3}(10 \mathrm{~mL})$. The aqueous layer was extracted with $\mathrm{CH}_{2} \mathrm{Cl}_{2}(3$ $\times 5 \mathrm{~mL})$. The combined organic layers were washed with brine $(10 \mathrm{~mL})$ and dried over $\mathrm{Na}_{2} \mathrm{SO}_{4}$, filtered, and concentrated in vacuo. The resulting residue was filtered through a pad of silica gel to give crude $\mathbf{3 5}$ as a colorless oil, which was used as such in the following step. HRMS (ESI-TOF) m/z: $[\mathrm{M}+\mathrm{H}]^{+}$calcd for $\mathrm{C}_{24} \mathrm{H}_{22} \mathrm{~N}_{5} \mathrm{O}_{5} 460.1615$; Found 460.1617.

\section{Acetyl 2-O-benzoyl-4-( $N^{6}$-benzoyladenine-9-yl)-3,4-dideoxy- $\alpha$-D-threo-pentopyranoside}

(36).

Compound 36 was prepared using a similar procedure as that described for 26c starting from 35 (117 mg, $0.25 \mathrm{mmol})$, pyridine $(5 \mathrm{~mL})$, and acetic anhydride $(0.048 \mathrm{~mL}, 0.5 \mathrm{mmol})$, and obtained after silica gel column chromatography (gradient hexane/EtOAc, 8:1, v/v; 3:1, v/v;) as a colorless sticky oil (99 mg, 78\%). ${ }^{1} \mathrm{H}$ NMR (500 MHz, $\left.\mathrm{CDCl}_{3}\right) \delta 8.76$ (s, 1H, H-2), 8.19-8.05 (m, 3H, H-8, Ph), 8.02 (d, J= 7.4 Hz, 2H, Ph), 7.63-7.53 (m, 2H, Ph), 7.49 (td, $J=7.9,2.1 \mathrm{~Hz}, 4 \mathrm{H}, \mathrm{Ph}), 6.19$ (d, $\left.J=1.8 \mathrm{~Hz}, 1 \mathrm{H}, \mathrm{H}-1^{\prime}\right), 5.33$ (td, $J=5.3$, $1.8 \mathrm{~Hz}, 1 \mathrm{H}, \mathrm{H}-2^{\prime}$ ), 5.14 (tt, $J=11.0,4.3 \mathrm{~Hz}, 1 \mathrm{H}, \mathrm{H}-4^{\prime}$ ), 4.34 (appt, $J=10.8 \mathrm{~Hz}, 1 \mathrm{H}, \mathrm{H}-5^{\prime}$ ), 4.12 (ddd, $J=$ 11.1, 4.7, $\left.1.8 \mathrm{~Hz}, 1 \mathrm{H}, \mathrm{H}-5^{\prime \prime}\right), 3.04$ (ddd, $\left.J=14.3,12.1,3.2 \mathrm{~Hz}, 1 \mathrm{H}, \mathrm{H}-3^{\prime}\right), 2.51$ (dt, $J=14.2,4.7 \mathrm{~Hz}, 1 \mathrm{H}$, $\left.\mathrm{H}-3{ }^{\prime \prime}\right), 2.24\left(\mathrm{~s}, 3 \mathrm{H}, \mathrm{CH}_{3} \mathrm{CO}\right) ;{ }^{13} \mathrm{C} \mathrm{NMR}\left(126 \mathrm{MHz}, \mathrm{CDCl}_{3}\right) \delta 168.8\left(\mathrm{CH}_{3} \mathrm{CO}\right), 165.3(\mathrm{PhCO}), 152.6(\mathrm{C}-2)$, 152.2 (C-4), 150.0 (C-6), 141.3(C-8), 133.8, 133.6, 132.9, 123.0, 129.2, 128.9, 128.7, 128.1 (Ph), 123.5 (C5), $89.6\left(\mathrm{C}-1^{\prime}\right), 68.0\left(\mathrm{C}-2^{\prime}\right), 63.3\left(\mathrm{C}-5^{\prime}\right), 47.9\left(\mathrm{C}-4^{\prime}\right), 29.3$ (C-3'), $21.1\left(\mathrm{CH}_{3} \mathrm{CO}\right)$; HRMS (ESI-TOF) m/z: $[\mathrm{M}+\mathrm{H}]^{+}$calcd for $\mathrm{C}_{26} \mathrm{H}_{24} \mathrm{~N}_{5} \mathrm{O}_{6} 502.1721$; Found 502.1723.

Benzyl 3,4-dideoxy-4-trifluoroacetylamino- $\alpha$-D-threo-pentopyranoside (38). To a mixture of 31 ( $1 \mathrm{~g}$, $4.48 \mathrm{mmol})$ and triethylamine $(1.87 \mathrm{~mL}, 13.44 \mathrm{mmol})$ in methanol $(50 \mathrm{~mL})$, ethyl trifluoroacetate $(1.07 \mathrm{~mL}$, $8.96 \mathrm{mmol}$ ) was added dropwise. The mixture was stirred at room temperature for $2 \mathrm{~h}$. After removal of all the volatiles under reduced pressure, the resulting residue was purified by silica gel column chromatography (hexane/EtOAc, $3: 1)$ to give $\mathbf{3 8}(1.3 \mathrm{~g}, 91 \%)$ as a colorless oil. ${ }^{1} \mathrm{H}$ NMR $\left(300 \mathrm{MHz}, \mathrm{CDCl}_{3}\right) \delta 7.55-7.16(\mathrm{~m}$, $5 \mathrm{H}, \mathrm{Ph}), 6.91(\mathrm{~d}, J=7.9 \mathrm{~Hz}, 1 \mathrm{H}, \mathrm{NH}), 4.80$ (d, $\left.J=11.6 \mathrm{~Hz}, 1 \mathrm{H}, \mathrm{CH}_{2} \mathrm{Ph}\right), 4.53$ (d, $\left.J=11.6 \mathrm{~Hz}, 1 \mathrm{H}, \mathrm{CH}_{2} \mathrm{Ph}\right)$, 
4.45 (d, $J=4.8 \mathrm{~Hz}, 1 \mathrm{H}, \mathrm{H}-1), 4.27$ (m, 1H, H-2), 3.80-3.61 (m, 3H, H-5, H-5' and OH), 3.01 (d, $J=3.8$ $\mathrm{Hz}, 1 \mathrm{H}, \mathrm{H}-4), 2.17-1.98$ (ddd, $J=13.5,6.7,4.0 \mathrm{~Hz}, 1 \mathrm{H}, \mathrm{H}-3$ ), 1.88-1.69 (ddd, $J=13.5,7.4,4.1 \mathrm{~Hz}, 1 \mathrm{H}$, $\left.\mathrm{H}-3^{\prime}\right) ;{ }^{13} \mathrm{C}$ NMR $\left(75 \mathrm{MHz}, \mathrm{CDCl}_{3}\right) \delta 157.0\left(\mathrm{q},{ }^{2} J_{\mathrm{F}, \mathrm{C}}=37.8 \mathrm{~Hz}, \mathrm{COCF}_{3}\right), 137.0,128.64,128.20(\mathrm{Ph}), 115.8$ $\left(\mathrm{q},{ }^{1} J_{\mathrm{F}, \mathrm{C}}=288.9 \mathrm{~Hz}, \mathrm{CF}_{3}\right), 101.3(\mathrm{C}-1), 70.3(\mathrm{C}-2), 66.6\left(\mathrm{CH}_{2} \mathrm{Ph}\right), 64.6(\mathrm{C}-5), 44.4$ (C-4), $32.8(\mathrm{C}-3)$; HRMS (ESI-TOF) m/z: [M+Na] calcd for $\mathrm{C}_{14} \mathrm{H}_{16} \mathrm{~F}_{3} \mathrm{~N}_{1} \mathrm{O}_{4} \mathrm{Na}$ 342.0924; Found 342.0916.

3,4-dideoxy-4-trifluoroacetylamino- $\alpha / \beta$-D-threo-pentopyranose (39). To a solution of $\mathbf{3 8}(1.00 \mathrm{~g}, 3.13$ $\mathrm{mmol})$ in methanol $(50 \mathrm{~mL})$ was added $10 \% \mathrm{Pd} / \mathrm{C}(1 \mathrm{~g}, 0.94 \mathrm{mmol})$, and evacuation-replacement cycles were carried out using a hydrogen baloon $(3 \times)$. The reaction mixture was stirred at room temperature for $20 \mathrm{~h}$ under an atmospheric pressure of hydrogen. After completion of the reaction, the catalyst was removed by filtration through a pad of Celite and washed with methanol. The filtrate was concentrated under reduced pressure to afford $39(590 \mathrm{mg}, 82 \%)$ as a colorless foam without further purification. ${ }^{1} \mathrm{H}$ NMR $(600 \mathrm{MHz}$, DMSO-d6) $\delta 9.32(\mathrm{~d}, J=6.7 \mathrm{~Hz}, 0.16 \mathrm{H}, \mathrm{NH} \beta), 9.26(\mathrm{~d}, J=7.9 \mathrm{~Hz}, 1 \mathrm{H}, \mathrm{NH} \alpha), 6.34(\mathrm{~d}, J=4.0 \mathrm{~Hz}, 1 \mathrm{H}$, OH-1 $\alpha$ ), 6.29 (d, $J=4.3 \mathrm{~Hz}, 0.16 \mathrm{H}, \mathrm{OH}-1 \beta), 4.94$ (bs, $1 \mathrm{H}, \mathrm{OH}-2 \alpha), 4.85-4.77$ (m, 0.22H, OH-2 $\beta$ ), 4.69 $(\mathrm{dd}, J=4.8,2.0 \mathrm{~Hz}, 0.18 \mathrm{H}, \mathrm{H}-1 \beta), 4.68(\mathrm{dd}, J=3.3,2.2 \mathrm{~Hz}, 1 \mathrm{H}, \mathrm{H}-1 \alpha), 4.17-4.08$ (m, $1 \mathrm{H}, \mathrm{H}-4 \alpha), 4.07-$ $4.00(\mathrm{~m}, 0.2 \mathrm{H}, \mathrm{H}-4 \beta), 3.80$ (ddd, $J=11.5,3.6,0.9 \mathrm{~Hz}, 0.18 \mathrm{H}, \mathrm{H}-5 \beta), 3.66$ (t, $J=10.2 \mathrm{~Hz}, 1 \mathrm{H}, \mathrm{H}-5 \alpha), 3.56$ (bs, $1.14 \mathrm{H}, \mathrm{H}-2 \alpha$ ), 3.43 (ddd, $J=10.6,4.6,1.6 \mathrm{~Hz}, 1 \mathrm{H}, \mathrm{H}-5^{\prime} \alpha$ and $\left.\mathrm{H}-2 \beta\right), 3.30$ (dd, $J=11.1,6.6 \mathrm{~Hz}, 0.3$ H, H-5' $\beta$ ), 1.96 (ddd, $J=13.1,10.9,3.2 \mathrm{~Hz}, 1 \mathrm{H}, \mathrm{H}-3 \alpha$ ), 1.88 (dddd, $J=13.3,7.3,4.3,0.9 \mathrm{~Hz}, 0.2 \mathrm{H}, \mathrm{H}-3 \beta$ ), $1.65\left(\mathrm{dtd}, J=13.1,4.8,1.4 \mathrm{~Hz}, 1 \mathrm{H}, \mathrm{H}-3^{\prime} \alpha\right), 1.42\left(\mathrm{ddd}, J=13.3,7.8,3.7 \mathrm{~Hz}, 0.14 \mathrm{H}, \mathrm{H}-3{ }^{\prime} \beta\right) ;{ }^{13} \mathrm{C}$ NMR $(151$ MHz, DMSO-d6) $\delta 156.2\left(\mathrm{q},{ }^{2} J_{\mathrm{F}, \mathrm{C}}=38 \mathrm{~Hz}, C \mathrm{COCF}_{3}\right), 115.9\left(\mathrm{q},{ }^{1} J_{\mathrm{F}, \mathrm{C}}=289 \mathrm{~Hz}, C \mathrm{~F}_{3}\right), 93.7(\mathrm{C}-1 \beta), 93.4(\mathrm{C}-$

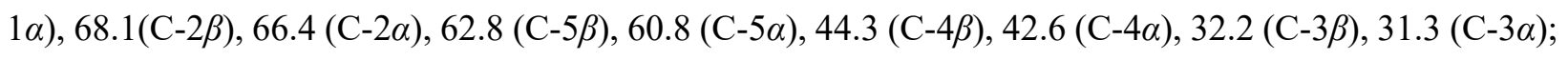
HRMS (ESI-TOF) m/z: [M+Na] $]^{+}$calcd for $\mathrm{C}_{7} \mathrm{H}_{10} \mathrm{~F}_{3} \mathrm{~N}_{1} \mathrm{O}_{4} \mathrm{Na} 252.0454$; Found 252.0448.

\section{1,2-Di- $O$-acetyl-3,4-dideoxy-4-trifluoroacetylamino- $\alpha$-D-threo-pentopyranoside $\quad \mathbf{( 4 0 )} \quad 1 O, 2 O$ -}

Diacetylated compound $\mathbf{4 0}$ was prepared using a similar procedure as that described for $\mathbf{2 6 c}$ starting from 39 (500 mg, $2.18 \mathrm{mmol}), \mathrm{Ac}_{2} \mathrm{O}(0.62 \mathrm{~mL}, 6.55 \mathrm{mmol})$, and pyridine $(25 \mathrm{~mL})$, and obtained after silica gel column chromatography (gradient hexane/EtOAc, 6:1, v/v; 2:1, v/v) as a colorless sticky oil (550 mg, 80\%), ${ }^{1} \mathrm{H}$ NMR (600 MHz, $\left.\mathrm{CDCl}_{3}\right) \delta 6.78(\mathrm{~d}, J=7.9 \mathrm{~Hz}, 1 \mathrm{H}, \mathrm{NH}), 5.88$ (d, $\left.J=2.8 \mathrm{~Hz}, 1 \mathrm{H}, \mathrm{H}-1\right), 4.93$ (td, $J=6.1$, $3.8 \mathrm{~Hz}, 1 \mathrm{H}, \mathrm{H}-2$ ), 4.37 (dtt, $J=17.6,7.9,4.6 \mathrm{~Hz}, 1 \mathrm{H}, \mathrm{H}-4$ ), 3.88 (ddd, $J=11.4,4.2,1.5 \mathrm{~Hz}, 1 \mathrm{H}, \mathrm{H}-5$ ), 3.66 (dd, $\left.J=11.0,9.7 \mathrm{~Hz}, 1 \mathrm{H}, \mathrm{H}-5^{\prime}\right), 2.17-2.09$ (m, 8H, $\left.\mathrm{CH}_{3} \mathrm{CO}, \mathrm{CH}_{3} \mathrm{CO}, \mathrm{H}-3, \mathrm{H}-3\right) ;{ }^{13} \mathrm{C}$ NMR $(151 \mathrm{MHz}$, $\left.\mathrm{CDCl}_{3}\right) \delta 170.0\left(\mathrm{CH}_{3} \mathrm{CO}\right), 168.9\left(\mathrm{CH}_{3} \mathrm{CO}\right), 157.0\left(\mathrm{q},{ }^{2} J_{\mathrm{F}, \mathrm{C}}=38 \mathrm{~Hz}, C \mathrm{COCF}_{3}\right), 115.5\left(\mathrm{q},{ }^{1} J_{\mathrm{F}, \mathrm{C}}=289 \mathrm{~Hz}, \mathrm{CF}_{3}\right)$, 89.8 (C-1), 67.1 (C-2), 63.4 (C-5), 42.5 (C-4), 29.5 (C-3), 21.0 ( $\left.\mathrm{CH}_{3} \mathrm{CO}\right), 20.9\left(\mathrm{CH}_{3} \mathrm{CO}\right)$; HRMS (ESI-TOF) $\mathrm{m} / \mathrm{z}:[\mathrm{M}+\mathrm{Na}]^{+}$calcd for $\mathrm{C}_{11} \mathrm{H}_{14} \mathrm{~F}_{3} \mathrm{~N}_{1} \mathrm{O}_{6} \mathrm{Na} 336.0666$; Found 336.0660.

Diisopropylphosphonomethyl

2-O-acetyl-3,4-dideoxy-4-trifluoroacetylamino- $\alpha$-D-threopentopyranoside (41). Phosphonomethylated compound 41 was prepared using a similar procedure as that described for 27 starting from 40 (300 mg, 0.96 mmol), TMSOTf (0.35 mL, $1.92 \mathrm{mmol}$ ), diisopropylphosphonomethanol $(564 \mathrm{mg}, 2.87 \mathrm{mmol})$ in dry DCM $(15 \mathrm{~mL})$. Purification by silica gel column chromatography (gradient $\mathrm{CH}_{2} \mathrm{Cl}_{2} / \mathrm{MeOH}, 99: 1, \mathrm{v} / \mathrm{v} ; 49: 1, \mathrm{v} / \mathrm{v} ; 24: 1, \mathrm{v} / \mathrm{v}$ ) afforded 41 as a colorless sticky oil, which was still contaminated with diisopropylphosphonomethanol. ${ }^{1} \mathrm{H}$ NMR $\left(600 \mathrm{MHz}, \mathrm{CDCl}_{3}\right)$ $\delta 7.45$ (d, $J=8.3 \mathrm{~Hz}, 1 \mathrm{H}, \mathrm{NH}), 4.91$ (td, $J=4.7,2.2 \mathrm{~Hz}, 1 \mathrm{H}, \mathrm{H}-2), 4.83-4.69$ (m, 2H, [CH(CH$\left.\left.)_{2}\right]\right), 4.69$ (d, $J=1.8 \mathrm{~Hz}, 1 \mathrm{H}, \mathrm{H}-1), 4.45-4.34$ (m, $1 \mathrm{H}, \mathrm{H}-4), 3.92$ (dd, $J=13.2,10.0 \mathrm{~Hz}, 1 \mathrm{H}, \mathrm{PCH}_{2}$ ), 3.79-3.72 (ddd, 
$J=10.9,5.1,1.7 \mathrm{~Hz}, 1 \mathrm{H}, \mathrm{H}-5), 3.72-3.66$ (m, 1H, PCH $H_{2}, 3.64$ (appt, $\left.J=10.7 \mathrm{~Hz}, 1 \mathrm{H}, \mathrm{H}-5^{\prime}\right), 2.12$ (s, 3H, $\mathrm{CH}_{3} \mathrm{CO}$ ), 2.11-2.08 (m, 1H, H-3), 2.07-1.99 (dt, $\left.J=13.7,4.2 \mathrm{~Hz}, 1 \mathrm{H}, \mathrm{H}-3{ }^{\prime}\right), 1.38-1.30$ (m, 12H, $\left.\left[\mathrm{CH}\left(\mathrm{CH}_{3}\right)_{2}\right]\right) ;{ }^{13} \mathrm{C} \mathrm{NMR}\left(151 \mathrm{MHz}, \mathrm{CDCl}_{3}\right) \delta 170.2\left(\mathrm{CH}_{3} \mathrm{CO}\right), 157.1\left(\mathrm{q},{ }^{2} J_{\mathrm{F}, \mathrm{C}}=37.0 \mathrm{~Hz}, \mathrm{COCF}_{3}\right), 115.8(\mathrm{q}$, $\left.{ }^{1} J_{\mathrm{F}, \mathrm{C}}=288.9 \mathrm{~Hz}, C \mathrm{~F}_{3}\right), 96.4\left(\mathrm{~d},{ }^{3} J_{\mathrm{P}, \mathrm{C}}=11.1 \mathrm{~Hz}, \mathrm{C}-1\right), 71.8,71.7\left(\mathrm{~d},{ }^{2} J_{\mathrm{P}, \mathrm{C}}=6.2 \mathrm{~Hz},\left[\mathrm{CH}\left(\mathrm{CH}_{3}\right)_{2}\right]\right), 68.0(\mathrm{C}-2)$, $60.9\left(\mathrm{~d},{ }^{1} J_{\mathrm{P}, \mathrm{C}}=171.7 \mathrm{~Hz}, \mathrm{PCH}\right), 61.4(\mathrm{C}-5), 41.8(\mathrm{C}-4), 29.0(\mathrm{C}-3), 24.0\left[\mathrm{CH}\left(\mathrm{CH}_{3}\right)_{2}\right]$; ${ }^{31} \mathrm{P} \mathrm{NMR}(121 \mathrm{MHz}$, $\mathrm{CDCl}_{3}$ ) $\delta$ 19.0; HRMS (ESI-TOF) m/z: $[\mathrm{M}+\mathrm{H}]^{+}$calcd for $\mathrm{C}_{16} \mathrm{H}_{28} \mathrm{~F}_{3} \mathrm{~N}_{1} \mathrm{O}_{8} \mathrm{P}_{1} 450.1499$; Found 450.1497.

Diisopropylphosphonomethyl 4-amino-3,4-dideoxy- $\alpha$-D-threo-pentopyranoside (42). Compound 42 was prepared using a similar procedure as that described for 28 starting from crude 41 and $7 \mathrm{M} \mathrm{NH}_{3}$ in $\mathrm{MeOH}\left(15 \mathrm{~mL}\right.$ ), and obtained after silica gel column chromatography (gradient $\mathrm{CH}_{2} \mathrm{Cl}_{2} / \mathrm{MeOH}, 50: 1, \mathrm{v} / \mathrm{v}$; $25: 1, \mathrm{v} / \mathrm{v} ; 6: 1, \mathrm{v} / \mathrm{v})$ as a colorless sticky oil (121 mg, $40 \%$ over two steps), ${ }^{1} \mathrm{H}$ NMR (600 $\left.\mathrm{MHz}, \mathrm{CDCl}_{3}\right) \delta$ 4.81-4.67 (m, 2H, [CH(CH$\left.\left.)_{2}\right]\right), 4.54(\mathrm{~d}, J=3.0 \mathrm{~Hz}, 1 \mathrm{H}, \mathrm{H}-1), 3.99$ (dd, $\left.J=13.6,9.1 \mathrm{~Hz}, 1 \mathrm{H}, \mathrm{PCH}_{2}\right), 3.91$ (m, 1H, H-2), 3.76-3.68 (m, 2H, H-5 and $\mathrm{PCH}_{2}$ ), 3.65 (appt, $J=9.5 \mathrm{~Hz}, 1 \mathrm{H}, \mathrm{H}-5$ '), 3.49-3.42 (m, 1H, H4), 2.06-2.01 (m, 1H, H-3), $1.96\left(\mathrm{td}, J=11.2,3.2 \mathrm{~Hz}, 1 \mathrm{H}, \mathrm{H}-3{ }^{\prime}\right), 1.37-1.29\left(\mathrm{~m}, 12 \mathrm{H},\left[\mathrm{CH}\left(\mathrm{CH}_{3}\right)_{2}\right]\right) ;{ }^{13} \mathrm{C}$ $\operatorname{NMR}\left(151 \mathrm{MHz}, \mathrm{CDCl}_{3}\right) \delta 101.2\left(\mathrm{~d},{ }^{3} J_{\mathrm{P}, \mathrm{C}}=10.4 \mathrm{~Hz}, \mathrm{C}-1^{\prime}\right), 71.7,71.5\left(\mathrm{~d},{ }^{2} J_{\mathrm{P}, \mathrm{C}}=5.6 \mathrm{~Hz},\left[\mathrm{CH}\left(\mathrm{CH}_{3}\right)_{2}\right]\right), 65.7$ $(\mathrm{C}-2), 64.7(\mathrm{C}-5), 61.6\left(\mathrm{~d},{ }^{1} \mathrm{~J}_{\mathrm{P}, \mathrm{C}}=170.9 \mathrm{~Hz}, \mathrm{PCH}\right), 43.6(\mathrm{C}-4), 33.6(\mathrm{C}-3), 24.0\left[\mathrm{CH}\left(\mathrm{CH}_{3}\right)_{2}\right]$; ${ }^{31} \mathrm{P} \mathrm{NMR}(121$ $\mathrm{MHz}, \mathrm{CDCl}_{3}$ ) $\delta$ 19.3; HRMS (ESI-TOF) m/z: $[\mathrm{M}+\mathrm{H}]^{+}$calcd for $\mathrm{C}_{12} \mathrm{H}_{27} \mathrm{~N}_{1} \mathrm{O}_{6} \mathrm{P}_{1} 312.1570$; Found 312.1570

Diisopropylphosphonomethyl 4-(6-chloropurine-9-yl)-3,4-dideoxy- $\alpha$-D-threo-pentopyranoside (43). Compound $\mathbf{4 3}$ was prepared using a similar procedure as that described for $\mathbf{3 2}$ starting from $\mathbf{4 2}$ (120 mg, $0.39 \mathrm{mmol}$ ), 4,6-dichloro-5-formamidopyrimidine ( $96 \mathrm{mg}, 0.5 \mathrm{mmol}$ ), and DIPEA (0.2 mL, $1.16 \mathrm{mmol}$ ) in n-butanol ( $5 \mathrm{~mL}$ ), and obtained after silica gel column chromatography (gradient $\mathrm{CH}_{2} \mathrm{Cl}_{2} / \mathrm{MeOH}, 99: 1, \mathrm{v} / \mathrm{v}$; 49:1, v/v; 24:1, v/v) as a colorless sticky oil (130 mg, 75\%). ${ }^{1} \mathrm{H}$ NMR (600 MHz, $\left.\mathrm{CDCl}_{3}\right) \delta 8.75(\mathrm{~s}, 1 \mathrm{H}, \mathrm{H}-$ 2), 8.37 (s, 1H, H-8), 5.14 (tt, $\left.J=12.6,4.1 \mathrm{~Hz}, 1 \mathrm{H}, \mathrm{H}-4^{\prime}\right), 4.80$ (tt, $\left.J=12.4,6.2 \mathrm{~Hz}, 2 \mathrm{H},\left[\mathrm{CH}\left(\mathrm{CH}_{3}\right)_{2}\right]\right), 4.74$ (d, $\left.J=3.8 \mathrm{~Hz}, 1 \mathrm{H}, \mathrm{H}-1^{\prime}\right), 4.29$ (dd, $\left.J=11.5,7.7 \mathrm{~Hz}, 1 \mathrm{H}, \mathrm{H}-5^{\prime}\right), 4.09$ (dd, $J=13.8,9.4 \mathrm{~Hz}, 1 \mathrm{H}, \mathrm{PCH}$ ), 3.98 (dd, $\left.J=11.7,3.8 \mathrm{~Hz}, 1 \mathrm{H}, \mathrm{H}-5^{\prime}\right), 3.98\left(\mathrm{td}, J=7.0,3.8 \mathrm{~Hz}, 1 \mathrm{H}, \mathrm{H}-2^{\prime}\right), 3.84$ (dd, $J=13.8,8.3 \mathrm{~Hz}, 1 \mathrm{H}, \mathrm{PCH} H_{2}$, 2.71 (ddd, $\left.J=13.0,9.1,3.6 \mathrm{~Hz}, 1 \mathrm{H}, \mathrm{H}-3^{\prime}\right), 2.20$ (dt, $\left.J=13.2,4.8 \mathrm{~Hz}, 1 \mathrm{H}, \mathrm{H}-3^{\prime}\right), 1.40-1.32$ (m, 12H, $\left.\left[\mathrm{CH}\left(\mathrm{CH}_{3}\right)_{2}\right]\right) ;{ }^{13} \mathrm{C}$ NMR $\left(151 \mathrm{MHz}, \mathrm{CDCl}_{3}\right) \delta 152.0(\mathrm{C}-2), 151.9(\mathrm{C}-4), 151.4(\mathrm{C}-6), 144.0(\mathrm{C}-8), 131.8(\mathrm{C}-$ 5), $102.2\left(\mathrm{~d},{ }^{3} J_{\mathrm{P}, \mathrm{C}}=11.1 \mathrm{~Hz}, \mathrm{C}-1^{\prime}\right), 71.9,71.7\left(\mathrm{~d},{ }^{2} J_{\mathrm{P}, \mathrm{C}}=6.2 \mathrm{~Hz},\left[\mathrm{CH}\left(\mathrm{CH}_{3}\right)_{2}\right]\right), 66.0\left(\mathrm{C}-2^{\prime}\right), 63.8\left(\mathrm{C}-5^{\prime}\right), 62.1$ $\left(\mathrm{d},{ }^{1} J_{\mathrm{P}, \mathrm{C}}=171.1 \mathrm{~Hz}, \mathrm{PCH}\right), 48.8\left(\mathrm{C}-4^{\prime}\right), 32.7\left(\mathrm{C}-3^{\prime}\right), 24.2\left[\mathrm{CH}\left(\mathrm{CH}_{3}\right)_{2}\right] ;{ }^{31} \mathrm{P} \mathrm{NMR}\left(121 \mathrm{MHz}, \mathrm{CDCl}_{3}\right) \delta 19.6$; HRMS (ESI-TOF) m/z: [M+H] $]^{+}$calcd for $\mathrm{C}_{17} \mathrm{H}_{27} \mathrm{Cl}_{1} \mathrm{~N}_{4} \mathrm{O}_{6} \mathrm{P}_{1}$ 449.1351; Found 449.1349.

Diisopropylphosphonomethyl 4-(adenine-9-yl)-3,4-dideoxy- $\alpha$-D-threo-pentopyranoside

(44).

Compound 44 was prepared using a similar procedure as that described for 37 starting from $\mathbf{4 3}$ (100 mg, $0.22 \mathrm{mmol})$ in a mixture of aq. $\mathrm{NH}_{3}(25 \%) / 1,4$-dioxane $=1: 1(10 \mathrm{~mL})$, and obtained after silica gel column chromatography (gradient $\mathrm{CH}_{2} \mathrm{Cl}_{2} / \mathrm{MeOH}, 50: 1$, v/v; 25:1, v/v; 15:1, v/v) as a colorless sticky oil (88 mg, 92\%). ${ }^{1} \mathrm{H}$ NMR (600 MHz, methanol-d4) $\delta 8.23$ (s, 1H, H-8), 8.19 (s, 1H, H-2), 5.08-4.97 (tt, $J=10.7,3.7$ $\left.\mathrm{Hz}, 1 \mathrm{H}, \mathrm{H}-4^{\prime}\right), 4.82-4.75$ (m, 2H, [CH( $\left.\left.\left(\mathrm{CH}_{3}\right)_{2}\right]\right), 4.74$ (d, $\left.J=2.3 \mathrm{~Hz}, 1 \mathrm{H}, \mathrm{H}-1^{\prime}\right), 4.14$ (appt, $J=10.5 \mathrm{~Hz}, 1 \mathrm{H}$, H-5') $4.10-4.05$ (dd, $J=14.0,9.2 \mathrm{~Hz}, 1 \mathrm{H}, \mathrm{PCH}_{2}$ ), 3.95-3.89 (m, 2H, H-2' and H-5"), 3.88 (dd, $J=14.0$, $9.2 \mathrm{~Hz}, 1 \mathrm{H}, \mathrm{PCH}$ ), 2.70 (ddd, $\left.J=14.6,11.1,3.0 \mathrm{~Hz}, 1 \mathrm{H}, \mathrm{H}-3^{\prime}\right), 2.19-2.14$ (m, 1H, H-3'), 1.40-1.34 (dd, $J$ $\left.=6.2,1.9 \mathrm{~Hz}, 12 \mathrm{H},\left[\mathrm{CH}\left(\mathrm{CH}_{3}\right)_{2}\right]\right) ;{ }^{13} \mathrm{C}$ NMR $(151 \mathrm{MHz}$, methanol-d4) $\delta 157.3(\mathrm{C}-6), 153.7(\mathrm{C}-2), 150.8(\mathrm{C}-$ 4), $140.9(\mathrm{C}-8), 120.1(\mathrm{C}-5), 101.7\left(\mathrm{~d},{ }^{3} J_{\mathrm{P}, \mathrm{C}}=11.6 \mathrm{~Hz}, \mathrm{C}-1^{\prime}\right), 73.4,73.3\left[\mathrm{CH}\left(\mathrm{CH}_{3}\right)_{2}\right], 67.2\left(\mathrm{C}-2^{\prime}\right), 63.6(\mathrm{C}-$ 
$\left.5^{\prime}\right), 62.2\left(\mathrm{~d},{ }^{1} J_{\mathrm{P}, \mathrm{C}}=170.9 \mathrm{~Hz}, \mathrm{PC} \mathrm{H}_{2}\right), 48.5\left(\mathrm{C}-4^{\prime}\right), 32.9\left(\mathrm{C}-3^{\prime}\right), 24.3\left[\mathrm{CH}\left(\mathrm{CH}_{3}\right)_{2}\right] ;{ }^{31} \mathrm{P}$ NMR $(121 \mathrm{MHz}$, methanol-d4) $\delta$ 20.0; HRMS (ESI-TOF) m/z: $[\mathrm{M}+\mathrm{H}]^{+}$calcd for $\mathrm{C}_{17} \mathrm{H}_{29} \mathrm{~N}_{5} \mathrm{O}_{6} \mathrm{P}_{1} 430.1850$; Found 430.1848 .

Phosphonomethyl 4-(adenine-9-yl)-3,4-dideoxy- $\alpha$-D-threo-pentopyranoside (2b). Compound $2 \mathrm{~b}$ was prepared using a similar procedure as that described for 2a starting from 44 (70 $\mathrm{mg}, 0.16 \mathrm{mmol}), 2,6-$ lutidine $(0.15 \mathrm{~mL}, 1.3 \mathrm{mmol})$, and $\operatorname{TMSBr}(0.17 \mathrm{~mL}, 0.16 \mathrm{mmol})$ in dry acetonitrile $(2 \mathrm{~mL})$ and obtained as a colorless sticky oil $\left(\mathbf{2 b} \cdot 1 \mathrm{Et}_{3} \mathrm{~N}\right.$ salt, $\left.22 \mathrm{mg}, 40 \%\right) . \varepsilon_{259}=16.9 \times 10^{3}\left(\mathrm{M}^{-1} \mathrm{~cm}^{-1}\right)$ in water; ${ }^{1} \mathrm{H} \mathrm{NMR}(600$ $\left.\mathrm{MHz}, \mathrm{D}_{2} \mathrm{O}\right) \delta 8.22$ (s, 1H, H-8), 8.05 (s, 1H, H-2), 4.72 (m, 1H, H-4'), 4.71 (d, J=3.3 Hz, 1H, H-1'), 4.09 (dd, $\left.J=11.4,8.7 \mathrm{~Hz}, 1 \mathrm{H}, \mathrm{H}-5^{\prime}\right), 3.97$ (td, $\left.J=4.8,3.3 \mathrm{~Hz}, 1 \mathrm{H}, \mathrm{H}-2^{\prime}\right), 3.92$ (dd, $J=11.4,4.0 \mathrm{~Hz}, 1 \mathrm{H}, \mathrm{H}-5^{\prime}$ ), $3.90\left(\mathrm{dd}, J=13.2,9.3 \mathrm{~Hz}, 1 \mathrm{H}, \mathrm{PCH}_{2}\right), 3.64(\mathrm{dd}, J=13.0,9.5 \mathrm{~Hz}, 1 \mathrm{H}, \mathrm{PCH}), 3.16(\mathrm{q}, J=7.4 \mathrm{~Hz}, 6 \mathrm{H}$, $\mathrm{CH}_{2} \mathrm{CH}_{3}$ ), 2.56 (ddd, $\left.J=13.4,10.1,3.4 \mathrm{~Hz}, 1 \mathrm{H}, \mathrm{H}-3^{\prime}\right), 2.15$ (dt, $\left.J=13.3,4.3 \mathrm{~Hz}, 1 \mathrm{H}, \mathrm{H}-3^{\prime \prime}\right), 1.23$ (t, $J=7.3$ $\left.\mathrm{Hz}, 9 \mathrm{H}, \mathrm{CH}_{2} \mathrm{CH}_{3}\right) ;{ }^{13} \mathrm{C}$ NMR (151 MHz, $\left.\mathrm{D}_{2} \mathrm{O}\right) \delta 156.5(\mathrm{C}-6), 153.3(\mathrm{C}-2), 149.8(\mathrm{C}-4), 141.7$ (C-8), 119.4 $(\mathrm{C}-5), 102.4\left(\mathrm{~d},{ }^{3} J_{\mathrm{P}, \mathrm{C}}=11.8 \mathrm{~Hz}, \mathrm{C}-1^{\prime}\right), 67.1\left(\mathrm{C}-2^{\prime}\right), 65.3\left(\mathrm{~d},{ }^{1} J_{\mathrm{P}, \mathrm{C}}=158.5 \mathrm{~Hz}, \mathrm{PCH} \mathrm{H}_{2}\right), 64.1\left(\mathrm{C}-5^{\prime}\right), 48.7(\mathrm{C}-$ 4'), 32.6 (C-3'); ${ }^{31} \mathrm{P}$ NMR (121 MHz, $\left.\mathrm{D}_{2} \mathrm{O}\right) \delta 15.2$; HRMS (ESI-TOF) $\mathrm{m} / \mathrm{z}$ : [M-H] ${ }^{+}$calcd for $\mathrm{C}_{11} \mathrm{H}_{15} \mathrm{~N}_{5} \mathrm{O}_{6} \mathrm{P}_{1}$ 344.0765; Found 344.0760.

\section{Diphosphorylphosphonomethyl 4-(adenine-9-yl)-3,4-dideoxy- $\alpha$-D-threo-pentopyranoside}

(45).

Adenine $\alpha$-D-threo-pentopyranoside nucleoside phosphonic acid $\mathbf{2 b}(30 \mathrm{mg}, 0.087 \mathrm{mmol})$ was dissolved in anhydrous DMF $(1 \mathrm{~mL})$ and carbonyldiimidazole $(70.4 \mathrm{mg}, 0.434 \mathrm{mmol})$ was added. The mixture was stirred for $30 \mathrm{~min}$ at room temperature, and then a solution of pyrophosphate ( $333 \mathrm{mg}, 0.608 \mathrm{mmol})$ in dry DMF ( $2 \mathrm{ml}$ ) was added and the stirring was continued overnight. An excess of $25 \%$ aq. ammonia ( $1 \mathrm{~mL})$ was added and the mixture was concentrated in vacuo. The resulting residue was purified by chromatography on a DEAE-cellulose column (gradient: 0.1 to 1 M TEAB (v/v); 1/0, 1/0.2, 1/0.5, 1/1). Further purification was performed by RP-HPLC to afford diphosphate(phosphonomethyl) 3-deoxy-4deoxy-4-(adenine-9-yl)- $\alpha$-D-threo-pentopyranoside triethylammonium salt $\mathbf{4 5}$ as a white solid (30\% yield). 1H NMR (600 MHz, D2O): $\delta 8.38$ (s, 1H, H-2), 8.23 (s, 1H, H-8), 4.91 (tt, J = 9.3, $4.1 \mathrm{~Hz}, 1 \mathrm{H}, \mathrm{H}-4$ '), 4.82 $\left(\mathrm{d}, \mathrm{J}=3.2 \mathrm{~Hz}, 1 \mathrm{H}, \mathrm{H}-1^{\prime}\right), 4.19$ (dd, J = 12.0, 8.6 Hz, 1H, H-5'), 4.08-4.03 (m, 2H, PCH2 and H-2'), 3.99 (dd, J = 12.0, 4.1 Hz, 1H, H-5"), 4.19 (dd, J = 13.2, 9.8 Hz, 1H, PCH2), 2.63 (ddd, J = 13.5, 9.9, 3.1 Hz, 1H, H-3'), 2.15 (dt, J = 13.2, 5.1 Hz, 1H, H-3"); 13C NMR (150 MHz, D2O): $\delta 157.0$ (C-6), 153.7 (C-2), 150.3 (C-4), 142.1 (C-8), 119.8 (C-5), 102.6 (d, 3JP, C = 9.8 Hz, C-1'), 67.0 (C-2'), 65.2 (d, 1JP, C = 167.1 Hz, PCH2), 60.3 (C-5'), 48.7 (C-4'), 32.6 (C-3'); 31P NMR (121 MHz, D2O): $\delta 7.6$ (d, J = 23.1 Hz, P $\alpha$ ), $6.4(\mathrm{~d}, \mathrm{~J}=18.9 \mathrm{~Hz}, \mathrm{P} \gamma),-22.7\left(\mathrm{t}, \mathrm{J}=21.4 \mathrm{~Hz}, \mathrm{P}_{\beta}\right.$ ); HRMS (ESI-TOF) $\mathrm{m} / \mathrm{z}$ : [M-H]- calcd for $\mathrm{C}_{11} \mathrm{H}_{17} \mathrm{~N}_{5} \mathrm{O}_{12} \mathrm{P}_{3}$, 504.0092; found 504.0096.

\section{ASSOCIATED CONTENT}

\section{Supporting Information}

NMR spectra, supplementary NMR data, procedures, scheme, and figures.

\section{AUTHOR INFORMATION}

Corresponding author

*piet.herdewijn@kuleuven.be 


\section{ORCID}

Piet Herdewijn: 0000-0003-3589-8503

Elisabetta Groaz: 0000-0002-8866-2265

Eveline Lescrinier: 0000-0001-7066-4329

Shrinivas Dumbre: 0000-0002-1237-9586

\section{AKNOWLEDGEMENTS}

X.L. acknowledges the China Scholarship Council (CSC) for funding (No. 201307040022). We express our gratitude to Hoai Nguyen and Luc Baudemprez for excellent technical assistance. We wish to thank Prof. Graciela Andrei for carrying out the antiviral screening, Prof. Jef Rozenski for conducting mass spectrometry measurements, and Dr. Mikhail Abramov for diphosphate synthesis.

\section{REFERENCES}

1. Jordheim, L. P.; Durantel, D.; Zoulim, F.; Dumontet, C., Advances in the Development of Nucleoside and Nucleotide Analogues for Cancer and Viral Diseases. Nat. Rev. Drug Discov. 2013, 12 (6), 447-464.

2. Khvorova, A.; Watts, J. K., The Chemical Evolution of Oligonucleotide Therapies of Clinical Utility. Nature Biotechnol. 2017, 35 (3), 238-248.

3. Wan, W. B.; Seth, P. P., The Medicinal Chemistry of Therapeutic Oligonucleotides. J. Med. Chem. 2016, 59 (21), 9645-9667.

4. $\quad$ Ryan, D. E.; Taussig, D.; Steinfeld, I.; Phadnis, S. M.; Lunstad, B. D.; Singh, M.; Vuong, X.; Okochi, K. D.; McCaffrey, R.; Olesiak, M.; Roy, S.; Yung, C. W.; Curry, B.; Sampson, J. R.; Bruhn, L.; Dellinger, D. J., Improving CRISPR-Cas Specificity with Chemical Modifications in Single-Guide RNAs. Nucleic Acids Res. 2018, 46 (2), 792-803.

5. Verheggen, I.; Van Aerschot, A.; Toppet, S.; Snoeck, R.; Janssen, G.; Balzarini, J.; Declercq, E.; Herdewijn, P., Synthesis and Antiherpes Virus Activity of 1,5-Anhydrohexitol Nucleosides. J. Med. Chem. 1993, 36 (14), 2033-2040.

6. Declercq, R.; Herdewijn, P.; VanMeervelt, L., 1,5-Anhydro-2,3-Dideoxy-2-(Guanin-9-yl)-D-Arabino-Hexitol. Acta Crystallogr. C 1996, 52, 1213-1215.

7. Van Aerschot, A.; Verheggen, I.; Hendrix, C.; Herdewijn, P., 1,5-Anhydrohexitol Nucleic-Acids, a New Promising Antisense Construct. Angew. Chem. Int. Ed. Eng. 1995, 34 (12), 1338-1339.

8. Hendrix, C.; Rosemeyer, H.; Verheggen, I.; Seela, F.; VanAerschot, A.; Herdewijn, P., 1',5'-Anhydrohexitol Oligonucleotides: Synthesis, Base Pairing and Recognition by Regular Oligodeoxyribonucleotides and Oligoribonucleotides. Chem. Eur. J. 1997, 3 (1), 110-120.

9. Lescrinier, E.; Esnouf, R.; Schraml, J.; Busson, R.; Heus, H. A.; Hilbers, C. W.; Herdewijn, P., Solution Structure of a HNA-RNA Hybrid. Chem. Biol. 2000, 7 (9), 719-731.

10. Pinheiro, V. B.; Taylor, A. I.; Cozens, C.; Abramov, M.; Renders, M.; Zhang, S.; Chaput, J. C.; Wengel, J.; Peak-Chew, S. Y.; McLaughlin, S. H.; Herdewijn, P.; Holliger, P., Synthetic Genetic Polymers Capable of Heredity and Evolution. Science (Washington, DC, US) 2012, 336 (6079), 341-344. 
11. Taylor, A. I.; Pinheiro, V. B.; Smola, M. J.; Morgunov, A. S.; Peak-Chew, S.; Cozens, C.; Weeks, K. M.; Herdewijn, P.; Holliger, P., Catalysts from Synthetic Genetic Polymers. Nature 2015, 518 (7539), 427-430.

12. Pezo, V.; Liu, F. W.; Abramov, M.; Froeyen, M.; Herdewijn, P.; Marliere, P., Binary Genetic Cassettes for Selecting XNA-Templated DNA Synthesis In Vivo. Angew. Chem. Int. Ed. 2013, 52 (31), 8139-8143.

13. Piperno, A.; Chiacchio, M. A.; Iannazzo, D.; Romeo, R., Synthesis and Biological Activity of Phosphonated Nucleosides: Part 1. Furanose, Carbocyclic and Heterocyclic Analogues. Curr. Med. Chem. 2006, 13 (30), 3675-3695.

14. De Clercq, E.; Holy, A., Acyclic Nucleoside Phosphonates: A Key Class of Antiviral Drugs. Nat. Rev. Drug Discov. 2005, 4 (11), 928-940.

15. Pradere, U.; Garnier-Amblard, E. C.; Coats, S. J.; Amblard, F.; Schinazi, R. F., Synthesis of Nucleoside Phosphate and Phosphonate Prodrugs. Chem. Rev. 2014, 114 (18), 9154-9218.

16. Perezperez, M. J.; Rozenski, J.; Herdewijn, P., Stereospecific Synthesis of a Pentopyranosyl Analog of D4t Monophosphate. Bioorg. Med.Chem. Lett. 1994, 4 (10), 1199-1202.

17. Perezperez, M. J.; Balzarini, J.; Rozenski, J.; Declercq, E.; Herdewijn, P., Synthesis and Antiviral Activity of Phosphonate Derivatives of Enantiomeric Dihydro-2h-Pyranyl Nucleosides. Bioorg. Med. Chem. Lett. 1995, 5 (11), 1115-1118.

18. Perezperez, M. J.; Doboszewski, B.; Declercq, E.; Herdewijn, P., Phosphonates Derivatives of 2',3'-Dideoxy2',3'-Didehydro-Pentopyranosyl Nucleosides. Nucleosides Nucleotides 1995, 14 (3-5), 707-710.

19. Perezperez, M. J.; Doboszewski, B.; Rozenski, J.; Herdewijn, P., Stereocontrolled Synthesis of Phosphonate Derivatives of Tetrahydro-2h-Pyranyl and Dihydro-2h-Pyranyl Nucleosides - the Selectivity of the Ferrier Rearrangement. Tetrahedron: Asymmetry 1995, 6 (4), 973-984.

20. Perezperez, M. J.; Rozenski, J.; Busson, R.; Herdewijn, P., Application of the Mitsunobu-Type Condensation Reaction to the Synthesis of Phosphonate Derivatives of Cyclohexenyl and Cyclohexanyl Nucleosides. J. Org. Chem. 1995, 60 (6), 1531-1537.

21. Du, J. F.; Choi, Y.; Lee, K.; Chun, B. K.; Hong, J. H.; Chu, C. K., A Practical Synthesis of L-FMAU from LArabinose. Nucleosides Nucleotides 1999, 18 (2), 187-195.

22. Pav, O.; Zbornikova, E.; Budesinsky, M.; Rosenberg, I., A New Class of Phosphanucleosides Containing a 3Hydroxy-1-Hydroxymethylphospholane 1-Oxide Ring. Tetrahedron 2013, 69 (43), 9120-9129.

23. The formation of the $\beta$ isomer was also observed, however isolation by column chromatography provided only trace amounts of material insufficiently pure for complete characterization.

24. Ostrowski, T.; Wroblowski, B.; Busson, R.; Rozenski, J.; De Clercq, E.; Bennett, M. S.; Champness, J. N.; Summers, W. C.; Sanderson, M. R.; Herdewijn, P., 5-Substituted Pyrimidines with a 1,5-Anhydro-2,3Dideoxy-D-Arabino-Hexitol Moiety at N-1: Synthesis, Antiviral Activity, Conformational Analysis, and Interaction with Viral Thymidine Kinase. J. Med. Chem. 1998, 41 (22), 4343-4353.

25. Robeyns, K. H., P.; Van Meervelt, L., Direct Observation of Two Cyclohexenyl (CeNA) Ring Conformations in Duplex DNA. Artif DNA: PNA XNA 2010, 1, 2-8.

26. Kim, C. U.; Luh, B. Y.; Martin, J. C., Regiospecific and Highly Stereoselective Electrophilic Addition to Furanoid Glycals - Synthesis of Phosphonate Nucleotide Analogs with Potent Activity against HIV. J. Org. Chem. 1991, 56 (8), 2642-2647.

27. Koh, Y. H.; Shim, J. H.; Wu, J. Z.; Zhong, W. D.; Hong, Z.; Girardet, J. L., Design, Synthesis, and Antiviral Activity of Adenosine 5 '-Phosphonate Analogues as Chain Terminators against Hepatitis C Virus. J. Med. Chem. 2005, 48 (8), 2867-2875. 